\title{
A tropospheric chemistry reanalysis for the years 2005-2012 based on an assimilation of OMI, MLS, TES, and MOPITT satellite data
}

\author{
K. Miyazaki ${ }^{1}$, H. J. Eskes ${ }^{2}$, and K. Sudo ${ }^{3}$ \\ ${ }^{1}$ Japan Agency for Marine-Earth Science and Technology, Yokohama 236-0001, Japan \\ ${ }^{2}$ Royal Netherlands Meteorological Institute (KNMI), Wilhelminalaan 10, 3732 GK, De Bilt, the Netherlands \\ ${ }^{3}$ Graduate School of Environmental Studies, Nagoya University, Nagoya, Japan \\ Correspondence to: K. Miyazaki (kmiyazaki@jamstec.go.jp)
}

Received: 19 February 2015 - Published in Atmos. Chem. Phys. Discuss.: 24 March 2015

Revised: 23 June 2015 - Accepted: 9 July 2015 - Published: 27 July 2015

\begin{abstract}
We present the results from an 8-year tropospheric chemistry reanalysis for the period 2005-2012 obtained by assimilating multiple data sets from the OMI, MLS, TES, and MOPITT satellite instruments. The reanalysis calculation was conducted using a global chemical transport model and an ensemble Kalman filter technique that simultaneously optimises the chemical concentrations of various species and emissions of several precursors. The optimisation of both the concentration and the emission fields is an efficient method to correct the entire tropospheric profile and its year-to-year variations, and to adjust various tracers chemically linked to the species assimilated. Comparisons against independent aircraft, satellite, and ozonesonde observations demonstrate the quality of the analysed $\mathrm{O}_{3}, \mathrm{NO}_{2}$, and $\mathrm{CO}$ concentrations on regional and global scales and for both seasonal and yearto-year variations from the lower troposphere to the lower stratosphere. The data assimilation statistics imply persistent reduction of model error and improved representation of emission variability, but they also show that discontinuities in the availability of the measurements lead to a degradation of the reanalysis. The decrease in the number of assimilated measurements increased the ozonesonde-minus-analysis difference after 2010 and caused spurious variations in the estimated emissions. The Northern/Southern Hemisphere $\mathrm{OH}$ ratio was modified considerably due to the multiple-species assimilation and became closer to an observational estimate, which played an important role in propagating observational information among various chemical fields and affected the emission estimates. The consistent concentration and emission products provide unique information on year-to-year variations in the atmospheric environment.
\end{abstract}

\section{Introduction}

Long-term records of the tropospheric composition of gases such as ozone $\left(\mathrm{O}_{3}\right)$, carbon monoxide $(\mathrm{CO})$, and nitrogen oxides $\left(\mathrm{NO}_{x}\right)$ are important for understanding the changes in tropospheric chemistry and human activity and consequences for the atmospheric environment and climate change (HTAP, 2010; IPCC, 2013). Satellite instruments provide observations of the global distributions of tropospheric composition. For example, measurements of tropospheric $\mathrm{O}_{3}$ have been retrieved using the Tropospheric Emission Spectrometer (TES) since 2004 (Beer, 2006) and by the Infrared Atmospheric Sounding Interferometer (IASI) since 2007 (Coman et al., 2012). Tropospheric $\mathrm{NO}_{2}$ column concentrations have been retrieved by the Ozone Monitoring Instrument (OMI) since 2004 (Levelt et al., 2006), the Scanning Imaging Absorption Spectrometer for Atmospheric Cartography (SCIAMACHY) from 2002 to 2012 (Bovensmann et al., 1999), the Global Ozone Monitoring Experiment (GOME) from 1996 to 2003, and GOME-2 since 2007 (Callies et al., 2000). The availability of satellite-derived measurements of various chemical species has prompted increasing interest in developing methods for combining these sources of satellite observational information for studies of long-term variations within the atmospheric environment and for improving estimates of emissions sources (Inness et al., 2013; Streets et al., 2013).

Combining measurements of $\mathrm{O}_{3}, \mathrm{CO}$ and $\mathrm{NO}_{x}$ in the atmosphere puts constraints on the concentration of $\mathrm{OH}$, the main radical responsible for the removal of pollution from the atmosphere and determining the lifetime of many chemicals (Levy, 1971; Logan et al., 1981; Thompson, 1992). At the same time the combined use provides constraints on dif- 
ferent sources of surface emissions and production of $\mathrm{NO}_{x}$ by lightning $\left(\mathrm{LNO}_{x}\right)$ (e.g. Martin et al., 2007; Miyazaki et al., 2014). The information that may be obtained from a combined use of multiple satellite data sets without involving a model is limited, related to differing vertical sensitivity profiles, different overpass times, and mismatches in spatial and temporal coverage between the instruments, as well as missing information on the chemical regime and origin of the air masses.

Data assimilation is the technique for combining different observational data sets with a model by considering the characteristics of each measurement (e.g. Kalnay, 2003; Lahoz and Schneider, 2014). Advanced data assimilation schemes like the Kalman filter or the related 4D-Var technique use the information provided by satellite-derived measurements and propagate it, in time and space, from a limited number of observed species to a wide range of chemical components to provide global fields that are physically and chemically consistent and in agreement with the observations. Various studies have demonstrated the capability of data assimilation techniques regarding the analysis of chemical species in the troposphere and stratosphere.

Assimilation of satellite limb measurements for $\mathrm{O}_{3}$ profiles and nadir measurements for $\mathrm{O}_{3}$ columns has been used to study $\mathrm{O}_{3}$ variations in the stratosphere and the upper troposphere (e.g. Stajner and Wargan, 2004; Jackson, 2007; Stajner et al., 2008; Wargan et al., 2010; Flemming et al., 2011; Barré et al., 2013; Emili et al., 2014). Long-term integrated data sets of stratospheric $\mathrm{O}_{3}$ have been produced by several studies by combining multiple satellite retrieval data sets (e.g. Kiesewetter et al., 2010; van der A et al., 2010). The assimilation of satellite observations has been also applied to investigate global variations in the tropospheric composition of gases such as $\mathrm{O}_{3}$ and $\mathrm{CO}$ (e.g. Parrington et al., 2009; Coman et al., 2012; Miyazaki et al., 2012b). For providing long-term integrated data of tropospheric composition, as a pioneer study, Inness et al. (2013) performed an 8-year reanalysis of tropospheric chemistry for 2003-2010 using an advanced data assimilation system. They included atmospheric concentrations of $\mathrm{O}_{3}, \mathrm{CO}, \mathrm{NO}_{x}$, and formaldehyde $\left(\mathrm{CH}_{2} \mathrm{O}\right)$ as the forecast model variables in the integrated forecasting system with modules for atmospheric composition (C-IFS), and they demonstrated improved $\mathrm{O}_{3}$ and $\mathrm{CO}$ profiles for the free troposphere. They also highlighted biases remaining in the lower troposphere associated with fixed surface emissions, which are not adjusted in the 4D-Var assimilation scheme presented by Inness et al. (2013).

Currently available bottom-up inventories of emissions, produced based on statistical data such as emission-related activities and emissions factors, contain large uncertainties, mainly because of inaccurate activity rates and emission factors for each category and poor representation of their seasonal and interannual variations (e.g. Jaeglé et al., 2005; Xiao et al., 2010; Reuter et al., 2014). Top-down inverse approaches using satellite retrievals have been applied to ob- tain optimised emissions of CO (e.g. Kopacz et al., 2010; Hooghiemstra et al., 2011) and $\mathrm{NO}_{x}$ (e.g. Lamsal et al., 2010; Miyazaki et al., 2012a; Mijling et al., 2013) by minimising the differences between observed and simulated concentrations, as summarised by Streets et al. (2013). In addition to surface emissions, the improved representations of $\mathrm{LNO}_{x}$ sources are important for a realistic representation of $\mathrm{O}_{3}$ formation and chemical processes in the upper troposphere (Schumann and Huntrieser, 2007; Miyazaki et al., 2014).

The simultaneous adjustment of emissions and concentrations of various species is a new development in tropospheric chemical reanalysis and long-term emissions analysis. Miyazaki et al. (2012b) developed a data assimilation system, called CHASER-DAS, for the simultaneous optimisation of the atmospheric concentration of various trace gases, together with an optimisation of the surface emissions of $\mathrm{NO}_{x}$ and $\mathrm{CO}$, and the $\mathrm{LNO}_{x}$ sources, while taking their complex chemical interactions into account, as represented by the CHASER chemistry-transport model. Within the simultaneous optimisation framework, the analysis adjustment of atmospheric concentrations of chemically related species has the potential to improve the emission inversion (Miyazaki and Eskes, 2013; Miyazaki et al., 2014). This was compared with an emission inversion based on measurements from one species alone, where uncertainties in the model chemistry affect the quality of the emission source estimates. In addition, the improved estimates of emissions benefit the atmospheric concentration analysis through a reduction in model forecast error. The simultaneous adjustment of the emissions and the concentrations is therefore a powerful approach to optimise all aspects of the chemical system influencing tropospheric $\mathrm{O}_{3}$ (Miyazaki et al., 2012b).

In this study, we present a tropospheric chemistry reanalysis data set for the 8-year period from 2005 to 2012 using CHASER-DAS. This reanalysis is produced with the CHASER-DAS system introduced in Miyazaki et al. (2012b). The system uses the ensemble Kalman filter (EnKF) assimilation technique and assimilates Microwave Limb Sounder (MLS), OMI, TES, and Measurement of Pollution in the Troposphere (MOPITT) retrieved observations. The chemical concentrations and emission sources are simultaneously optimised during the reanalysis, and are expected to provide useful information for various research topics related to the interannual variability of the atmospheric environment and short-term trends.

The remainder of this paper is structured as follows. Section 2 describes the observations used for the assimilation and validation. Section 3 introduces the data assimilation system and Sect. 4 evaluates the reanalysis performance based on analyses of data assimilation statistics. Section 5 presents comparisons against independent observations. Section 6 describes the emission source estimation results. Section 7, which discusses possible errors in the reanalysis data and offers thoughts on future developments, is followed by the conclusions in Sect. 8. 


\section{Data assimilation system}

The CHASER-DAS system (Miyazaki et al., 2012a, b, 2014; Miyazaki and Eskes, 2013) has been developed based on an EnKF approach and a global chemical transport model called CHASER. The data assimilation settings used for the reanalysis calculation are mostly the same as in Miyazaki et al. (2014), but the calculation was extended to cover the eight years from 2005 to 2012, and several updates were applied to the a priori and state vector settings. Brief descriptions of the forecast model, data assimilation approach, and experimental settings are presented below.

\subsection{Forecast model}

The CHASER model (Sudo et al., 2002; Sudo and Akimoto, 2007) was used as a forecast model. It has so-called T42 horizontal resolution $\left(2.8^{\circ}\right.$ for longitude and the T42 Gaussian grid for latitude) and 32 vertical levels from the surface to $4 \mathrm{hPa}$. It is coupled to the atmospheric general circulation model (AGCM) version 5.7b of the Center for Climate System Research and Japanese National Institute for Environmental Studies (CCSR/NIES). Meteorological fields are provided by the AGCM at every time step of CHASER (i.e. every $20 \mathrm{~min}$ ). The AGCM fields were nudged toward the National Centers for Environmental Prediction/Department of Energy Atmospheric Model Intercomparison Project II (NCEP-DOE/AMIP-II) reanalysis (Kanamitsu et al., 2002) at every time step of the AGCM to reproduce past meteorological fields. The nudged AGCM enabled us to perform CHASER calculations that included short-term atmospheric variations and parameterised transport processes by sub-gridscale convection and boundary layer mixing.

The a priori value for surface emissions of $\mathrm{NO}_{x}$ and $\mathrm{CO}$ were obtained from bottom-up emission inventories. Anthropogenic $\mathrm{NO}_{x}$ and $\mathrm{CO}$ emissions were obtained from the Emission Database for Global Atmospheric Research (EDGAR) version 4.2. Emissions from biomass burning are based on the monthly Global Fire Emissions Database (GFED) version 3.1 (van der Werf et al., 2010). Emissions from soils are based on monthly mean Global Emissions Inventory Activity (GEIA) (Graedel et al., 1993). EDGAR version 4.2 was not available after 2008 at the time the reanalysis was started; therefore, the emissions for 2008 were used in the calculations for 2009-2012. GFED 3.1 was not available for 2012, and thus the emissions averaged over 2005-2011 were used in the calculation for 2012. For surface $\mathrm{NO}_{x}$ emissions, a diurnal variability scheme developed by Miyazaki et al. (2012a, b) was applied depending on the dominant category for each area: anthropogenic, biogenic, and soil emissions.

For the calculation of a priori $\mathrm{LNO}_{x}$ emissions, the global distribution of the flash rate was parameterised in CHASER for convective clouds based on the relation between lightning activity and cloud top height (Price and Rind, 1992).
To obtain a realistic estimate of the global annual total flash occurrence, a tuning factor was applied for the global total frequency, which is independent of the lightning adjustment in the assimilation. The global distribution of the total flash rate is generally reproduced well by the model in comparison with the observations, except for overestimations over northern South America and underestimations over both Central Africa and most of the oceanic Intertropical Convergence Zone (Miyazaki et al., 2014).

\subsection{Data assimilation technique}

The data assimilation technique employed is an EnKF approach, i.e. a local ensemble transform Kalman filter (LETKF; Hunt et al., 2007) based on the ensemble square root filter (SRF) method, which uses an ensemble forecast to estimate the background error covariance matrix. The covariance matrices of the observation error and background error determine the relative weights given to the observation and the background in the analysis. The LETKF has conceptual and computational advantages over the original EnKF. First, the analysis is performed locally in space and time, which reduces sampling errors caused by limited ensemble size. Second, performing the analysis independently for different grid points allow parallel computations to be performed that reduce the computational cost. These advantages are important in the chemical reanalysis calculation because of the many analysis steps included in the 8-year reanalysis run and the large state vector size used for the multiple-states optimisation (cf. Sect. 2.3 and 2.7)

The assimilation step transforms a background ensemble $\left(\boldsymbol{x}_{i}^{\mathrm{b}} ; i=1, \ldots, k\right)$ into an analysis ensemble $\left(\boldsymbol{x}_{i}^{\mathrm{a}} ; i=1, \ldots, k\right)$ and updates the analysis mean, where $\boldsymbol{x}$ represents the model variable, $\mathrm{b}$ the background state, a the analysis state, and $k$ the ensemble size. The forecast and analysis steps are described briefly below.

\subsubsection{The forecast step}

In the forecast step, the background ensemble mean $\overline{\boldsymbol{x}^{\mathrm{b}}}$ and its perturbation $\mathbf{X}^{\mathrm{b}}$ are obtained from the evolution of each ensemble member using the forecast model at every model grid,

$\overline{\boldsymbol{x}^{\mathrm{b}}}=\frac{1}{k} \sum_{i=1}^{k} \boldsymbol{x}_{i}^{\mathrm{b}} ; \quad \mathbf{X}_{i}^{\mathrm{b}}=\boldsymbol{x}_{i}^{\mathrm{b}}-\overline{\boldsymbol{x}^{\mathrm{b}}}$

$\mathbf{X}_{i}^{\mathrm{b}}$ is the $i$ th column of an $N \times k$ matrix $\mathbf{X}^{\mathrm{b}}$, where $N$ indicates the system dimension (the state vector size times the physical system dimension). Based on the assumption that background ensemble perturbations $\mathbf{X}^{\mathrm{b}}$ sample the forecast errors, the background error covariance is estimated as follows:

$\mathbf{P}^{\mathrm{b}}=\mathbf{X}^{\mathrm{b}}\left(\mathbf{X}^{\mathrm{b}}\right)^{T}$ 
where the background error covariance $\mathbf{P}^{\mathrm{b}}$ varies with time and space, reflecting dominant atmospheric processes and locations of the observations.

An ensemble of background vectors $\boldsymbol{y}_{i}^{\mathrm{b}}$ and an ensemble of background perturbations in the observation space $\mathbf{Y}^{\mathrm{b}}$ are estimated using the observation operator $H$ (cf. Sect. 2.5):

$\boldsymbol{y}_{i}^{\mathrm{b}}=H\left(\boldsymbol{x}_{i}^{\mathrm{b}}\right) ; \mathbf{Y}_{i}^{\mathrm{b}}=\boldsymbol{y}_{i}^{\mathrm{b}}-\overline{\boldsymbol{y}^{\mathrm{b}}}$.

\subsubsection{The analysis step}

The analysis ensemble mean is obtained by updating the background ensemble mean:

$\overline{\boldsymbol{x}^{a}}=\overline{\boldsymbol{x}^{\mathrm{b}}}+\mathbf{X}^{\mathrm{b}} \widetilde{\mathbf{P}}^{a}\left(\mathbf{Y}^{\mathrm{b}}\right)^{T} \mathbf{R}^{-1}\left(\boldsymbol{y}^{\mathrm{o}}-\overline{\boldsymbol{y}^{\mathrm{b}}}\right)$,

where $\boldsymbol{y}^{\mathrm{o}}$ represents the observation vector, $\mathbf{R}$ is the $p \times p$ observation error covariance, and $p$ indicates the number of observations. The observation error information is obtained for each retrieval (cf. Sect. 2.6), where $\widetilde{\mathbf{P}}^{\mathrm{a}}$ is the $k \times k$ local analysis error covariance in the ensemble space:

$\widetilde{\mathbf{P}}^{\mathrm{a}}=\left[\frac{(k-1) I}{1+\Delta}+\left(\mathbf{Y}^{\mathrm{b}}\right)^{\mathrm{T}} \mathbf{R}^{-1} \mathbf{Y}^{\mathrm{b}}\right]^{-1}$.

A covariance inflation factor $(\Delta=6 \%)$ was applied to inflate the forecast error covariance at each analysis step. The inflation is used to prevent an underestimation of background error covariance and resultant filter divergence caused by model errors and sampling errors. The estimation of the $\widetilde{\mathbf{P}}^{\mathrm{a}}$ matrix does not require any calculation of large vectors or matrices with $N$ dimensions in the LETKF algorithm.

The new analysis ensemble perturbation matrix in the model space $\left(\mathbf{X}^{\mathbf{a}}\right)$ is obtained by transforming the background ensemble $\mathbf{X}^{\mathrm{b}}$ with $\widetilde{\mathbf{P}}^{\mathrm{a}}$ :

$\mathbf{X}^{\mathrm{a}}=\mathbf{X}^{\mathrm{b}}\left[(k-1) \widetilde{\mathbf{P}}^{\mathrm{a}}\right]^{1 / 2}$.

The new ensemble members $\boldsymbol{x}_{i}^{\mathrm{b}}$ after the next forecast step are then obtained from model simulations starting from the analysis ensemble $\boldsymbol{x}_{i}^{\mathrm{a}}$.

\subsection{State vector}

The state vector for the reanalysis calculation is chosen to optimise the tropospheric chemical system and to improve the reanalysis performance. The state vector used in the reanalysis includes several emission sources (surface emissions of $\mathrm{NO}_{x}$ and $\mathrm{CO}$, and $\mathrm{LNO}_{x}$ sources) as well as the predicted concentrations of 35 chemical species. The chemical concentrations in the state vector are expressed in the form of volume mixing ratio, while the emissions are represented by scaling factors for each surface grid cell for the total $\mathrm{NO}_{x}$ and $\mathrm{CO}$ emissions at the surface (not for individual sectors), and for each production rate profile of the $\mathrm{LNO}_{x}$ sources. Perturbations obtained by adding these model parameters into the state vector introduced an ensemble spread of chemical concentrations and emissions in the forecast step. The background error correlations, estimated from the ensemble model simulations at each analysis step, determine the relationship between the concentrations and emissions of related species, which can reflect daily, seasonal, interannual, and geographical variations in transport and chemical reactions. The emission sources were optimised at every analysis step throughout the reanalysis period, which reduced the initial bias in the a priori emissions during the data assimilation cycle.

\subsection{Covariance localisation}

The EnKF approach always has the problem of introducing unrealistic long-distance error correlations because of the limited number of ensemble members. During the reanalysis calculation, such spurious correlations lead to errors in the fields that may accumulate and will influence the reanalysis quality in a negative way. In order to improve the filter performance, the covariance among non- or weakly related variables in the state vector is set to zero based on sensitivity calculation results, as in Miyazaki et al. (2012b). The analysis of surface emissions of $\mathrm{NO}_{x}$ and $\mathrm{CO}$ allowed for error correlations with $\mathrm{OMI} \mathrm{NO}_{2}$ and MOPITT $\mathrm{CO}$ data, while those with other data were neglected. For the $\mathrm{LNO}_{x}$ sources, covariances with MOPITT CO data were neglected. Concentrations of $\mathrm{NO}_{y}$ species and $\mathrm{O}_{3}$ were optimised from TES $\mathrm{O}_{3}$, OMI $\mathrm{NO}_{2}$, and $\mathrm{MLS} \mathrm{O}_{3}$ and $\mathrm{HNO}_{3}$ observations. One difference to the study of Miyazaki et al. (2012b) is that concentrations of non-methane hydrocarbons (NMHCs) were not optimised in the reanalysis. The assimilation of MOPITT CO data led to concentrations of NMHCs that increased to unrealistic values during the reanalysis, likely associated with too much chemical destruction of $\mathrm{CO}$ (cf. Sect. 7.4.2).

Covariance localisation was also applied to avoid the influence of remote observations, which is described in Sect. 2.7.

\subsection{Observation operator}

The observation operator $(H)$ includes the spatial interpolation operator $(S)$, a priori profile $\left(\boldsymbol{x}_{\mathrm{a}}\right.$ priori $)$, and averaging kernel $(\boldsymbol{A})$, which maps the model fields $\left(\boldsymbol{x}_{i}^{\mathrm{b}}\right)$ into retrieval space $\left(y_{i}^{\mathrm{b}}\right)$, thereby accounting for the vertical averaging implicit in the observations, as follows:

$\boldsymbol{y}_{i}^{\mathrm{b}}=H\left(\boldsymbol{x}_{i}^{\mathrm{b}}\right)=\boldsymbol{x}_{\text {a priori }}+\boldsymbol{A}\left(S\left(\boldsymbol{x}_{i}^{\mathrm{b}}\right)-\boldsymbol{x}_{\mathrm{a} \text { priori }}\right)$,

where $\boldsymbol{x}_{i}^{\mathrm{b}}$ is the $N$-dimensional state vector and $\boldsymbol{y}_{i}^{\mathrm{b}}$ is the $p$-dimensional model equivalent of the observational vector. The averaging kernel $\boldsymbol{A}$ defines the vertical sensitivity profile of the satellite observation. Even though the retrieval $\boldsymbol{y}^{\mathrm{o}}$ and the model equivalent $\boldsymbol{y}_{i}^{\mathrm{b}}$ both depend on the a priori, the use of the kernel removes the dependence of the analysis or the relative model-retrieval comparison $\left(\boldsymbol{y}_{i}^{\mathrm{b}}-\boldsymbol{y}^{\mathrm{o}}\right) / \boldsymbol{y}_{i}^{\mathrm{b}}$ on the re- 
trieval a priori profile (Eskes and Boersma, 2003; Migliorini, 2012).

\subsection{Observation error}

The observation error provided in the retrieval data products includes contributions from the smoothing errors, model parameter errors, forward model errors, geophysical noise, and instrument errors. In addition, a representativeness error was added for the OMI $\mathrm{NO}_{2}$ and MOPITT CO observations to account for the spatial resolution differences between the model and the observation using a super-observation approach following Miyazaki et al. (2012a). The superobservation error was estimated by considering an error correlation of $15 \%$ among the individual satellite observations within a model grid cell.

\subsection{Reanalysis settings}

Because a single continuous data assimilation calculation for 8 years requires a long computational time, we parallelised the reanalysis calculation. Eight series of 1-year calculations from 1 January of each year in 2005-2012 with a 2-month spin-up starting from 1 November of the previous year were conducted to produce the 8-year reanalysis data set. Each 1 -year run was parallelised on 16 processors. The 2-month spin-up removed the differences in the analysis between the different time series, providing a continuous 8-year data set. Because of distinct diurnal variations in the tropospheric chemical system, the data assimilation cycle was set to be short (i.e. $120 \mathrm{~min}$ ) to reduce sampling errors. The emission and concentration fields were analysed and updated at every analysis step.

In the reanalysis calculation the ensemble size was set to 30 , which is somewhat smaller than the 48 members used in our previous studies. A smaller ensemble size reduces computational cost but slightly degrades analysis performance, as quantified in Miyazaki et al. (2012b). The horizontal localisation scale $L$ was set to $450 \mathrm{~km}$ for $\mathrm{NO}_{x}$ emissions and to $600 \mathrm{~km}$ for $\mathrm{CO}$ emissions, $\mathrm{LNO}_{x}$, and for the concentrations. The physical vertical localisation length was set to $\ln (P 1 / P 2)[\mathrm{hPa}]=0.2$. These choices are based on sensitivity experiments (Miyazaki et al., 2012b), for which the influence of an observation was set to zero when the horizontal distance between the observation and analysis point was larger than $2 L \times \sqrt{10 / 3}$ (the cut-off radius is set to $2191 \mathrm{~km}$ for $L=600 \mathrm{~km}$ ). We also account for the influence of the averaging kernels of the instruments, which captures the vertical sensitivity profiles of the retrievals. The ensemble members and ensemble spread (error covariance) do vary from one location to the next, and from one species to the next, thereby representing the large number of degrees of freedom contained in the model and the way these are constrained by the observations.
The a priori error was set to $40 \%$ for surface emissions of $\mathrm{NO}_{x}$ and $\mathrm{CO}$ and $60 \%$ for $\mathrm{LNO}_{x}$ sources, but a model error term was not implemented for emissions during the forecast. To prevent covariance underestimation and maintain emission variability during the long-term reanalysis calculation, we applied covariance inflation to the emission source factors in the analysis step - i.e. model error is implemented through a covariance inflation term. The standard deviation was artificially inflated to a minimum predefined value $(30 \%$ of the initial standard deviation) at each analysis step. This was found to be important for representing realistic seasonal and interannual variability in the emission estimates, as confirmed by the improved agreements between the predicted concentrations and independent observations when this emission covariance inflation setting is used.

In addition to the standard reanalysis run, we conducted a control run for the 8-year period from 2005 to 2012 and several sensitivity calculations for 2005 and 2010 by changing the data assimilation settings. The control run was performed without any data assimilation, but using the same model settings as used in the reanalysis run. The settings and results of sensitivity calculations are presented in Sect. 7.

\section{Observations}

\subsection{Assimilated data sets}

The assimilated observations were obtained from the OMI, TES, and MLS on the Aura satellite, launched in July 2004 and from MOPITT on Earth Observing System (EOS) Terra, which was launched in December 1999.

\subsubsection{OMI tropospheric $\mathrm{NO}_{2}$ column}

The OMI provides measurements of both direct and atmosphere-backscattered sunlight in the ultraviolet-visible range (Levelt et al., 2006). The reanalysis used tropospheric $\mathrm{NO}_{2}$ column retrievals obtained from the version-2 DOMINO data product (Boersma et al., 2011). The analysis increments in the assimilation of $\mathrm{OMI} \mathrm{NO}$ were limited to adjust only the surface emissions of $\mathrm{NO}_{x}, \mathrm{LNO}_{x}$ sources, and concentrations of $\mathrm{NO}_{y}$ species. Low-quality data were excluded before assimilation following the recommendations of the product's specification document (Boersma et al., 2011). Since December 2009, approximately half of the pixels have been compromised by the so-called row anomaly, which reduced the daily coverage of the instrument.

\subsection{2 $\mathrm{TES} \mathrm{O}_{3}$}

The TES $\mathrm{O}_{3}$ data used are the version 5 level 2 nadir data obtained from the global survey mode (Herman and $\mathrm{Ku}$ lawik, 2013). This data set consists of 16 daily orbits with spatial resolution of $5-8 \mathrm{~km}$ along the orbit track. The vertical resolution of TES $\mathrm{O}_{3}$ profile retrievals is typically $6 \mathrm{~km}$ 
in the tropics and in the summer hemisphere for cloud-free conditions (Worden et al., 2004). The standard quality flags were used to exclude low-quality data (Herman and Kulawik, 2013). We also excluded data poleward of $72^{\circ}$, because of the small retrieval sensitivity. The data assimilation was performed based on the logarithm of the mixing ratio following the retrieval product specification.

\subsubsection{MLS $\mathrm{O}_{3}$ and $\mathrm{HNO}_{3}$}

The MLS data used are the version $3.3 \mathrm{O}_{3}$ and $\mathrm{HNO}_{3}$ level 2 products (Livesey et al., 2011). We excluded tropical-cloudinduced outliers, following the recommendations in Livesey et al. (2011). We used data for pressures lower than $215 \mathrm{hPa}$ for $\mathrm{O}_{3}$ and $150 \mathrm{hPa}$ for $\mathrm{HNO}_{3}$ to constrain the $\mathrm{LNO}_{x}$ sources and concentration of $\mathrm{O}_{3}$ and $\mathrm{NO}_{y}$ species. The accuracy and precision of the measurement error, described in Livesey et al. (2011), were included as the diagonal element of the observation error covariance matrix.

\subsubsection{MOPITT CO}

The MOPITT CO data used are the version 6 level 2 TIR products (Deeter et al., 2013). The MOPITT instrument is mainly sensitive to free-tropospheric $\mathrm{CO}$, especially in the middle troposphere, with degrees of freedom for signal (DOFs) typically much larger than 0.5 . We excluded data poleward of $65^{\circ}$ and during night-time because of data quality problems (Heald et al., 2004). The data at $700 \mathrm{hPa}$ were used for constraining the surface $\mathrm{CO}$ emissions.

\subsection{Validation data sets}

For the comparisons with satellite observations, the model concentrations were interpolated to the retrieval pixels at the overpass time of the satellite while applying the averaging kernel of each retrieval, and then both the retrieved and simulated concentrations are mapped on a horizontal grid with a resolution of $2.5^{\circ} \times 2.5^{\circ}$. For comparisons with aircraft and ozonesonde observations, the data were binned on a pressure grid with an interval of $30 \mathrm{hPa}$ and mapped with a horizontal resolution of $5.0^{\circ} \times 5.0^{\circ}$, while the model output was interpolated to the time and space of each sample.

\subsubsection{GOME-2 and SCIAMACHY $\mathrm{NO}_{2}$}

Tropospheric $\mathrm{NO}_{2}$ retrievals were obtained from the TEMIS website (www.temis.nl) and consist of the version 2.3 GOME-2 and SCIAMACHY products (Boersma et al., 2011). The ground pixel size of the GOME-2 retrievals is $80 \mathrm{~km} \times 40 \mathrm{~km}$ with a global coverage within 1.5 days, whereas that of the SCIAMACHY retrievals is $60 \mathrm{~km} \times 30 \mathrm{~km}$ with global coverage provided approximately once every 6 days. The equatorial overpass times of GOME2 and SCIAMACHY are at 09:30 and 10:00 LT, respec- tively. Observations with radiance reflectance of $<50 \%$ from clouds with quality flag $=0$ were used for validation.

\subsubsection{MOZAIC/IAGOS aircraft data}

Aircraft $\mathrm{O}_{3}$ and $\mathrm{CO}$ measurements obtained from the MOZAIC/IAGOS (Measurement of OZone, water vapour, carbon monoxide and nitrogen oxide by AIrbus in-service airCraft/In-service Aircraft for Global Observing System) programmes (Petzold et al., 2013; Zbinden et al., 2013) were used to validate the tropospheric profiles near airports and the upper-tropospheric spatial distributions at flight altitude of about $12 \mathrm{~km}$ in the Northern Hemisphere $(\mathrm{NH})$ and some parts of the tropics. The data are available at www.iagos.fr. The measurements of $\mathrm{O}_{3}$ and $\mathrm{CO}$ have an estimated accuracy of $\pm(2 \mathrm{ppb}+2 \%)$ and $\pm 5 \mathrm{ppb}( \pm 5 \%)$, respectively (Zbinden et al., 2013).

\subsubsection{HIPPO aircraft data}

HIAPER Pole-to-Pole Observation (HIPPO) aircraft measurements provide global information on vertical profiles of various species over the Pacific (Wofsy et al., 2012). Latitudinal and vertical variations in $\mathrm{O}_{3}$ and $\mathrm{CO}$ obtained from the five HIPPO campaigns (HIPPO I, 8-30 January 2009; HIPPO II, 31 October to 22 November 2009; HIPPO III, 24 March to 16 April 2010; HIPPO IV, 14 June to 11 July 2011; and HIPPO V, 9 August to 9 September 2011) were used to validate the assimilated profiles.

\subsubsection{NASA aircraft campaign data}

Vertical profiles of seven key gases $\left(\mathrm{O}_{3}, \mathrm{CO}, \mathrm{NO}_{2}, \mathrm{OH}\right.$, $\mathrm{HO}_{2}, \mathrm{HNO}_{3}$, and $\mathrm{CH}_{2} \mathrm{O}$ ) obtained from six aircraft campaigns - Intercontinental Chemical Transport Experiment Phase B (INTEX-B), Arctic Research of the Composition of the Troposphere from Aircraft and Satellites (ARCTAS)A, ARCTAS-B, Deriving Information on Surface Conditions from Column and Vertically Resolved Observations Relevant to Air Quality (DISCOVER-AQ), Deep Convection Clouds and Chemistry (DC3)-DC8, and DC3-GV - were used.

The DC-8 measurements obtained during the INTEX-B campaign over the Gulf of Mexico (Singh et al., 2009) were used for the comparison for March 2006. Data collected over highly polluted areas (over Mexico City and Houston) were removed from the comparison, because they can cause serious errors in representativeness (Hains et al., 2010).

The NASA ARCTAS mission (Jacob et al., 2010) was conducted in two 3-week deployments based in Alaska (April 2008, ARCTAS-A) and western Canada (JuneJuly 2008, ARCTAS-B). During ARCTAS-A, most of the measurements were collected between 60 and $90^{\circ} \mathrm{N}$, whereas during ARCTAS-B, the measurements were mainly recorded in the sub-Arctic between 50 and $70^{\circ} \mathrm{N}$.

During the NASA DISCOVER-AQ campaign over Baltimore (US) in July 2011, the NASA P-3B aircraft performed 
extensive profiling of the optical, chemical, and microphysical properties of aerosols (Crumeyrolle et al., 2014).

The Deep Convective Clouds and Chemistry (DC3) experiment field campaign investigated the impact of deep, mid-latitude continental convective clouds, including their dynamical, physical, and lightning processes, on uppertropospheric composition and chemistry during May and June 2012 (Barth et al., 2015). The observations were conducted in three locations: northeastern Colorado, western Texas to central Oklahoma, and northern Alabama. The observations obtained from the DC-8 (DC3-DC8) and G-V (DC3-GV) aircraft were used.

\subsubsection{Ozonesonde data}

Ozonesonde observations taken from the World Ozone and Ultraviolet Radiation Data Center (WOUDC) database (available at http://www.woudc.org) were used to validate the vertical $\mathrm{O}_{3}$ profiles. All available data from the WOUDC database are used for the validation (totally 19273 profiles for 149 stations during 2005-2012). The observation error is $5-10 \%$ between 0 and $30 \mathrm{~km}$ (Smit et al., 2007).

\subsubsection{WDCGG CO}

The CO concentration observations were obtained from the World Data Centre for Greenhouse Gases (WDCGG) operated by the World Meteorological Organization (WMO) Global Atmospheric Watch programme (http://ds.data.jma. go.jp/gmd/wdcgg/). Hourly and event observations from 59 stations were used to validate the surface $\mathrm{CO}$ concentrations.

\section{Data assimilation statistics}

\section{$4.1 \quad \chi^{2}$ diagnosis}

The long-term stability of the data assimilation performance is important in evaluating the reanalysis. The $\chi^{2}$ test can be used to evaluate the data assimilation balance (e.g. Ménard and Chang, 2000), which is estimated from the ratio of the actual observation minus forecast (OmF: $\left.\boldsymbol{y}^{\mathrm{o}}-H\left(\boldsymbol{x}^{\mathrm{b}}\right)\right)$ to the sum of the estimated model and observation error covariances in the observational space $\left(\mathbf{H P}^{\mathrm{b}} \mathbf{H}^{T}+\mathbf{R}\right)$, as follows:

$\mathbf{Y}=\frac{1}{\sqrt{m}}\left(\mathbf{H P}^{\mathrm{b}} \mathbf{H}^{T}+\mathbf{R}\right)^{-1 / 2}\left(\boldsymbol{y}^{\mathrm{o}}-H\left(\boldsymbol{x}^{\mathrm{b}}\right)\right)$,

$\chi^{2}=\operatorname{trace} \mathbf{Y} \mathbf{Y}^{T}$,

where $m$ is the number of observations. $\chi^{2}$ becomes 1 if the background error covariances $\left(\mathbf{P}^{\mathrm{b}}\right)$ are properly determined to match with the observed $\mathrm{OmF}\left(\boldsymbol{y}^{\mathrm{o}}-H\left(\boldsymbol{x}^{\mathrm{b}}\right)\right)$ under the presence of the prescribed observation error $(\mathbf{R})$.

Figure 1 shows the temporal evolution of the number of assimilated observations $(m)$ and $\chi^{2}$ for each assimilated measurement type. The number of super-observations is shown for the OMI $\mathrm{NO}_{2}$ and MOPITT CO. For most cases, the mean values of $\chi^{2}$ are generally within $50 \%$ difference from the ideal value of 1 , which suggests that the forecast error covariance is reasonably well specified in the data assimilation throughout the reanalysis. Note that the covariance inflation factors for the concentrations and emissions were optimised to approach to the ideal value based on sensitivity experiments (Miyazaki et al., 2012b). For the $\mathrm{OMI} \mathrm{NO}_{2}$ assimilation, the $\chi^{2}$ is $>1$, which indicates overconfidence in the model or underestimation of the super-observation error (computed as a combination of the measurement error and the representativeness error). The $\chi^{2}$ for the $\mathrm{OMI} \mathrm{NO}_{2}$ was less sensitive to the choice of the inflation factor compared to that for other assimilated measurements. Lower tropospheric $\mathrm{NO}_{2}$ is controlled by fast chemical reactions restricted by biased chemical equilibrium states, leading to an underestimation of the background error covariance during the forecast. Although the emission analysis introduces spread to the concentration ensemble, the perturbations are present primarily near the surface and tend to be removed in the free troposphere because of the short chemical lifetime of $\mathrm{NO}_{x}$.

Before 2010, the annual mean $\chi^{2}$ is roughly constant, which confirms the good stability of the performance. Seasonal and interannual variations, especially after 2010, in $\chi^{2}$ can be attributed to variations in the coverage and quality of satellite retrievals as well as changes in atmospheric conditions (e.g. chemical lifetime and dominant transport type). The increased $\chi^{2}$ for $\mathrm{OMI} \mathrm{NO}_{2}$ after 2010 is associated with a decrease in the number of the assimilated measurements and changes in the super-observation error. Both the mean measurement error and the representativeness error (a function of the number of OMI observations) are typically larger in 2010-2012 than in 2005-2009; the mean measurement error and the total super-observation error (a sum of the measurement error and the representativeness error) averaged over $30-55^{\circ} \mathrm{N}$ in January are about 7 and $9 \%$ larger in 2010 2012 than in 2005-2009, respectively. After 2010, the excessive $\chi^{2}$ indicates underestimations in the analysis spread, while the increased $\mathrm{OmF}$ indicates smaller corrections by the assimilation (cf. Sect. 4.2). To correct the concentrations and emission from OMI super-observations that have larger super-observation errors, the forecast error needs to be further inflated. A technique to adaptively inflate the forecast error covariance for the concentrations and emissions of NO and $\mathrm{NO}_{2}$ is required to better represent the data assimilation balance throughout the reanalysis.

\subsection{OmF}

OmF statistics are computed in observation space to investigate the structure of model-observation differences and to measure improvements in the reanalysis (Fig. 2). Model biases, as measured from the OmF in the control run, are persistent throughout the reanalysis period and vary considerably with season. The figure shows an underestimation (i.e. 

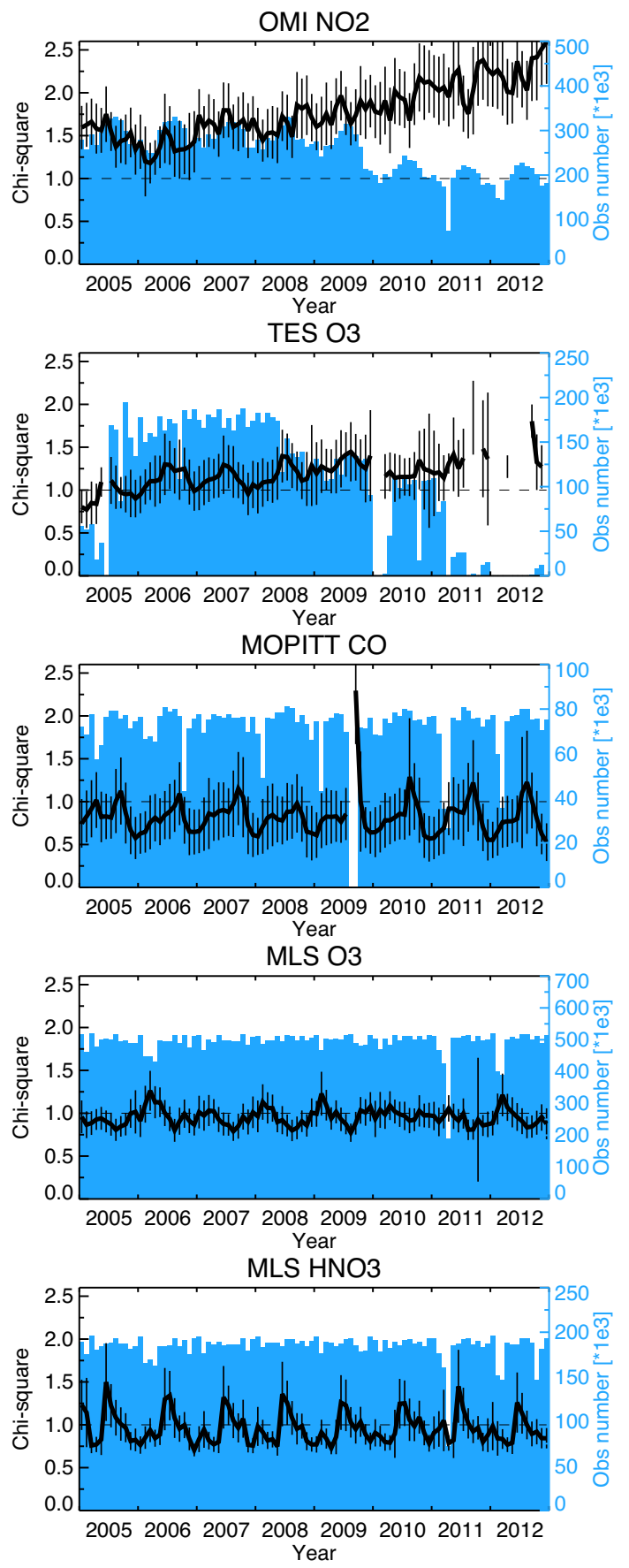

Figure 1. Time series of the monthly mean chi-square value and its standard deviation (black lines) and the number of assimilated observations per month (blue bars) for $\mathrm{OMI} \mathrm{NO}_{2}$, TES $\mathrm{O}_{3}$, MOPITT $\mathrm{CO}, \mathrm{MLS} \mathrm{O}_{3}$, and MLS $\mathrm{HNO}_{3}$. A super-observation approach is employed to the OMI and MOPITT measurements (the number of super-observations is shown), whereas individual observations are used in the analysis of the others. positive $\mathrm{OmF}$ ) of tropospheric $\mathrm{NO}_{2}$ columns compared with the $\mathrm{OMI} \mathrm{NO}$ 2 data from the Southern Hemisphere (SH) subtropics to $\mathrm{NH}$ mid-latitudes, an underestimation of tropospheric CO compared with MOPITT CO data in the NH, an overestimation (i.e. negative $\mathrm{OmF}$ ) of middle and uppertropospheric $\mathrm{O}_{3}$ in the extratropics compared with TES and $\mathrm{MLS}_{3}$ data, and underestimation of middle-tropospheric $\mathrm{O}_{3}$ in the tropics compared with TES. The underestimation of tropospheric CO by CHASER was found to be very similar to that in most of the other chemistry-transport models (CTMs) (Shindell et al., 2006).

After 2010, the positive OmF for MOPITT CO in the control run decreases in the $\mathrm{NH}$, and the positive OmF for OMI $\mathrm{NO}_{2}$ increases in the $\mathrm{NH}$ mid-latitudes. As the quality of these retrievals is considered constant in the reanalysis period (e.g. Worden et al., 2013), the interannual variations in OmF are probably attributed to long-term changes in the model bias. The anthropogenic emission inventories for 2008 were used in the model simulation for 2009-2012, which could be partly responsible for the absence of a concentration trend in the model.

In the reanalysis run, the $\mathrm{OmF}$ bias and root-mean-square error (RMSE) for $\mathrm{MLS} \mathrm{O}_{3}$ becomes nearly zero globally because of the assimilation. The systematic reductions of the OmF confirm the continuous corrections for model errors by the assimilation. The remaining error is almost equal to the mean observational error. The OmF reduction is relatively smaller for MLS $\mathrm{HNO}_{3}$ than for MLS $\mathrm{O}_{3}$ because of the larger observational errors.

The mean $\mathrm{OmF}$ bias against TES $\mathrm{O}_{3}$ data in the middle troposphere is almost completely removed because of the assimilation, and the mean OmF RMSE is reduced by about $40 \%$ in the SH extratropics and by up to $15 \%$ from the tropics to the NH. The error reduction is weaker in the lower troposphere (figure not shown) because of the reduced sensitivity of the TES retrievals to lower-tropospheric $\mathrm{O}_{3}$. The analysed $\mathrm{OmF}$ becomes larger after 2010 corresponding to the decreased number of assimilated measurements.

Data assimilation removes most of the OmF bias against MOPITT CO data with a mean bias (RMSE) reduction of about $85 \%(60 \%)$ in the $\mathrm{NH}$ extratropics and about $80 \%$ $(30 \%)$ in the tropics, respectively. The annual mean $\mathrm{OmF}$ becomes almost constant through the reanalysis, suggesting that the a posteriori emissions realistically represent the interannual variations.

The mean $\mathrm{OmF}$ bias against $\mathrm{OMI} \mathrm{NO}_{2}$ is reduced with a mean reduction of about $30-60 \%$ at the $\mathrm{NH}$ mid-latitudes and about $50-60 \%$ in the tropics. The remaining errors could be associated with the short chemical lifetime of $\mathrm{NO}_{x}$ in the boundary layer as compared to the OMI revisit time of roughly 1 day, biases in the simulated chemical equilibrium state, and the underestimation of the emission spread. The OmF is relatively larger in 2010-2012 than in other years, corresponding to about half the reduction in the OMI $\mathrm{NO}_{2}$ observation. The number of assimilated measurements 

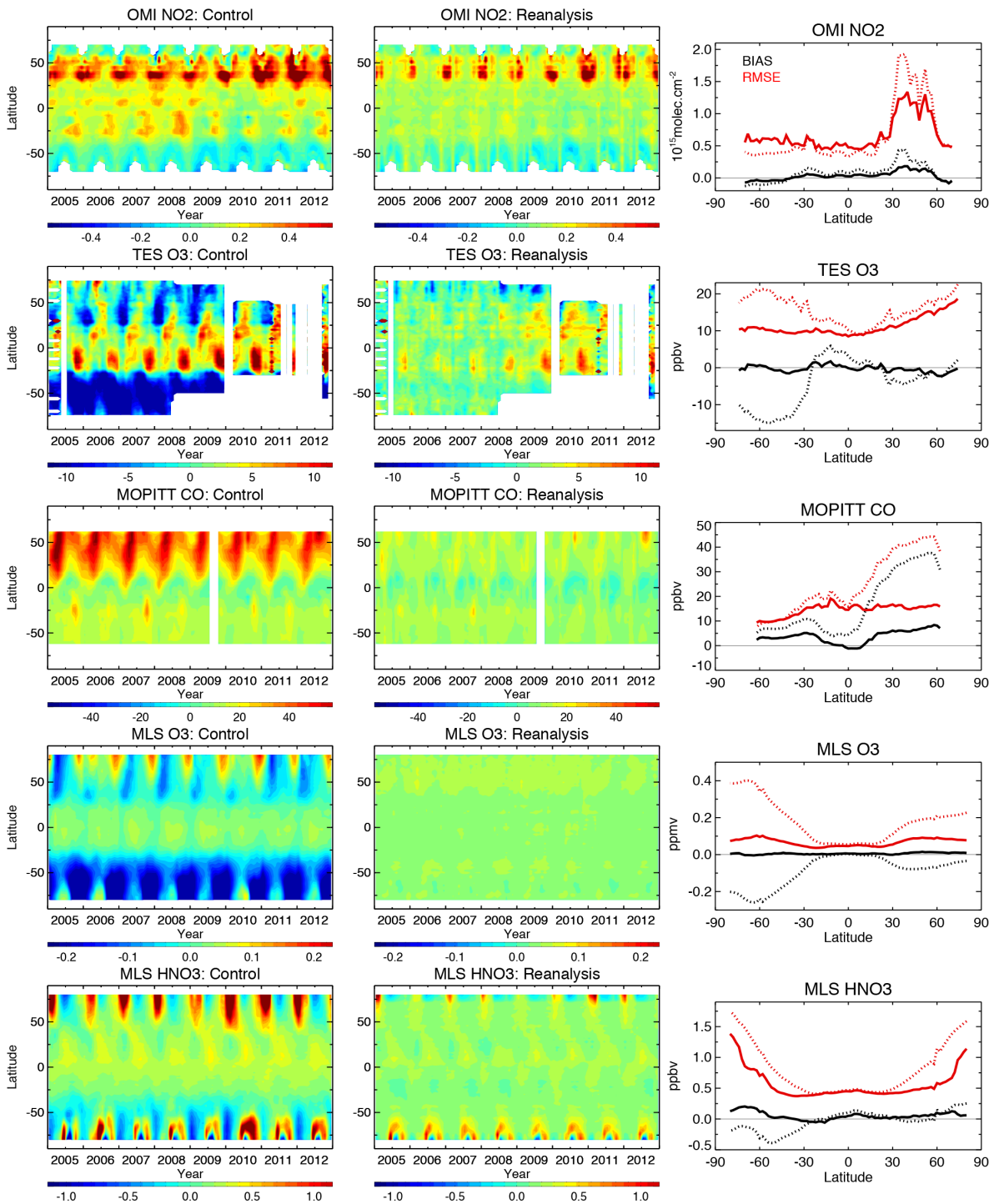

Figure 2. Time-latitude cross section of the monthly and zonal mean OmF obtained without assimilation (left panels) and with assimilation (centre panels). The positive and negative OmF values are shown in red and blue, respectively. Positive OmF represents negative model bias compared with observations. Right panels show latitudinal distributions of the 8-year mean OmF bias (black line) and RMSE (red line) obtained with assimilation (solid line) and without assimilation (dotted line). The first row is the OmF for $\mathrm{OMI} \mathrm{NO}_{2}$ data (in $10^{15} \mathrm{molec}^{-2}$ ), second row is for TES $\mathrm{O}_{3}$ data between 500 and $300 \mathrm{hPa}$ (in ppb), third row is for MOPITT CO data between 700 and $500 \mathrm{hPa}$ (in ppb), fourth row is for MLS O 3 data between 216 and $100 \mathrm{hPa}$ (in ppm), and fifth row is for MLS $\mathrm{HNO}_{3}$ data between $150 \mathrm{and} 80 \mathrm{hPa}$ (in ppb). A super-observation approach is employed to the OMI and MOPITT measurements, whereas individual observations are used in the analysis of the others.

is important for reducing model errors, even when global coverage is provided. The mean observation-minus-analysis $(\mathrm{OmA})$ bias is about $10-15 \%$; it is smaller in the NH midlatitudes and almost the same in the tropics and SH compared with the mean $\mathrm{OmF}$ in the reanalysis (figure not shown).

\subsection{Analysis increment}

The analysis increment information, estimated from the differences between the forecast and the analysis both in the re- analysis run, is a measure of the adjustment made in the analysis step. The analysis increment for $\mathrm{O}_{3}$ is mostly positive at $700 \mathrm{hPa}$ and negative at $400 \mathrm{hPa}$ at mid-latitudes (Fig. 3). The positive (negative) increments imply that the short-term model forecast underestimates (overestimates) the $\mathrm{O}_{3}$ concentrations. As the increments are introduced by the TES assimilation, these vertical structures suggest that the tropospheric TES $\mathrm{O}_{3}$ data have independent information for the lower- and upper-tropospheric $\mathrm{O}_{3}$. Jourdain et al. (2007) showed that the TES retrievals have 1-2 DOFs in the tropo- 

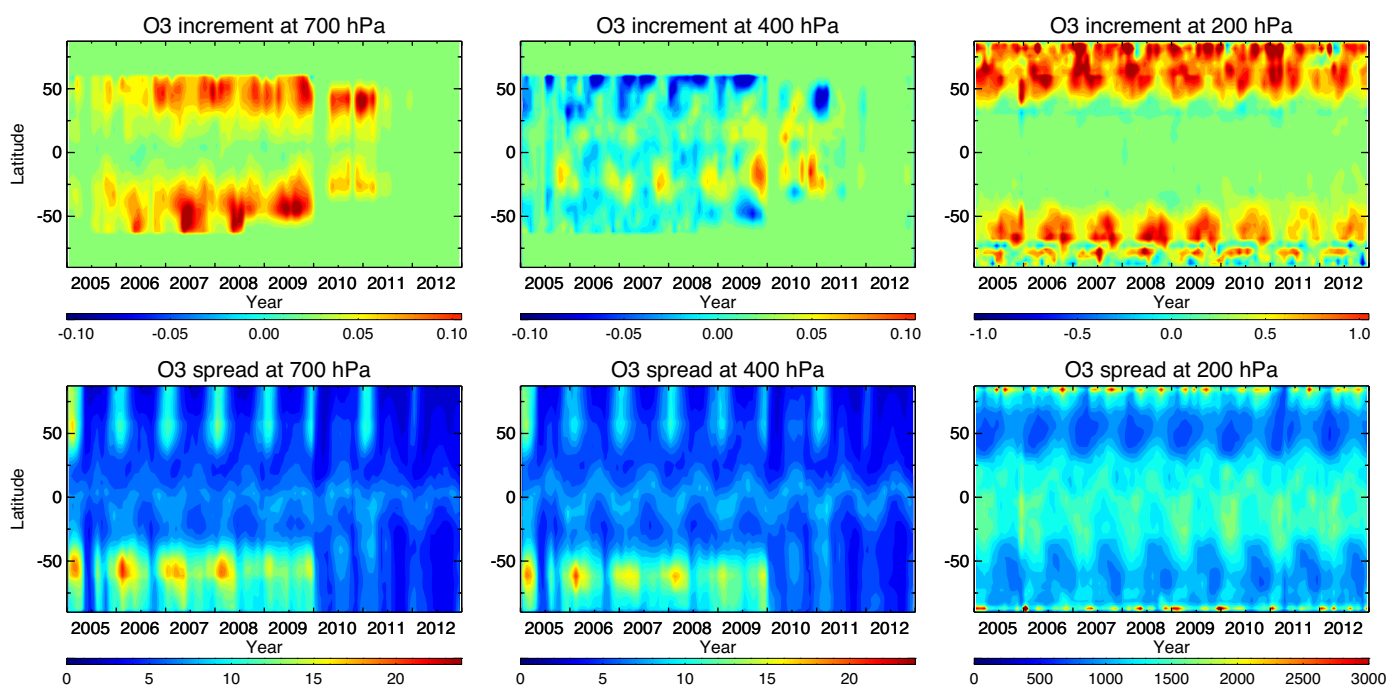

Figure 3. Time-latitude cross section of the analysis increment (upper panels, in ppb per analysis step) and the analysis spread (lower panels, in ppb/analysis step) obtained for $\mathrm{O}_{3}$ at $700 \mathrm{hPa}$ (left), $400 \mathrm{hPa}$ (centre), and $200 \mathrm{hPa}$ (right).

sphere, with the largest DOFs for clear-sky scenes occurring at low latitudes where TES can distinguish between lowerand upper-tropospheric $\mathrm{O}_{3}$. The obtained analysis increments correspond well to the $\mathrm{OmF}$ in the control run at the same altitude (figure not shown), confirming that the data assimilation effectively reduced the model errors through the analysis steps. Assimilation of other measurement generally provides much smaller increments on the tropospheric $\mathrm{O}_{3}$. The analysis increment varies largely with season and year, reflecting variations in short-term systematic model errors and observational constraints. After 2010 the availability of TES observations is strongly reduced, which explains the small increments in the later years.

The mean analysis increment for $\mathrm{NO}_{2}$ varies largely with space and time in the troposphere (not shown). For some regions with strong surface emissions, especially at $\mathrm{NH}$ midlatitudes, the $\mathrm{NO}_{2}$ increment becomes negative in the free troposphere because of the assimilation of non- $\mathrm{NO}_{2}$ measurements, compensating for the tropospheric $\mathrm{NO}_{2}$ column changes caused by the (positive) surface emissions adjustment. This demonstrates that simultaneous data assimilation provides independent constraints on the surface emissions and free-tropospheric $\mathrm{NO}_{2}$ concentration, because of the use of observations from multiple species with different measurement sensitivities. Large adjustments are introduced to the $\mathrm{NO}_{2}$ concentration in the upper troposphere-lower stratosphere (UTLS), because the $\mathrm{MLS} \mathrm{O}_{3}$ and $\mathrm{HNO}_{3}$ assimilation effectively corrects the model $\mathrm{NO}_{2}$ bias as a result of the correlations between species in the error covariance matrix.

\section{Evaluation using independent observations}

\section{$5.1 \quad \mathrm{O}_{3}$}

\subsubsection{Ozonesonde}

The validation of the reanalysis and control run with global ozonesonde observations is summarised in Table 1. As depicted in Figs. 4 and 5, the CHASER simulation reproduced the observed main features of global $\mathrm{O}_{3}$ distributions in the troposphere and lower stratosphere. However, there are systematic differences such as a negative bias in the NH highlatitude troposphere and a positive bias from the middle troposphere to the lower stratosphere in the $\mathrm{SH}$.

The reanalysis shows improved agreements with the ozonesonde observations. The mean negative bias in the $\mathrm{NH}$ high latitudes is reduced in the troposphere. In the NH midlatitudes, the model's positive bias in the UTLS and negative bias in the lower troposphere is mostly removed. The large reduction of the mean lower-tropospheric bias in the $\mathrm{NH}$ mid-latitudes is attributed primarily to increased $\mathrm{O}_{3}$ concentrations in boreal spring-summer (Fig. 5). The RMSEs compared with the ozonesonde observations are also reduced throughout the troposphere. The remaining errors, especially near the surface, are associated with low retrieval sensitivities in the lower troposphere and gaps in the spatial representation between the model and observations.

In the tropics, the data assimilation generally increases the $\mathrm{O}_{3}$ concentration, reducing the negative bias in the upper troposphere but increasing the positive bias in the lower troposphere. The increased positive bias could be attributed to the positive bias in the TES measurements (Sect. 7.2).

In the $\mathrm{SH}$, the model's positive bias from the middle troposphere to the lower stratosphere is attributed largely to a posi- 
Table 1. Model minus observation comparisons of the mean $\mathrm{O}_{3}$ concentrations between the analysis or control run (in brackets) and the observations. The units of the root-mean-square error (RMSE) and bias are ppb. Results are provided for WOUDC ozonesonde observations during 2005-2012, MOZAIC/IAGOS aircraft measurements during 2005-2012, and HIPPO aircraft measurements during 2009-2011.

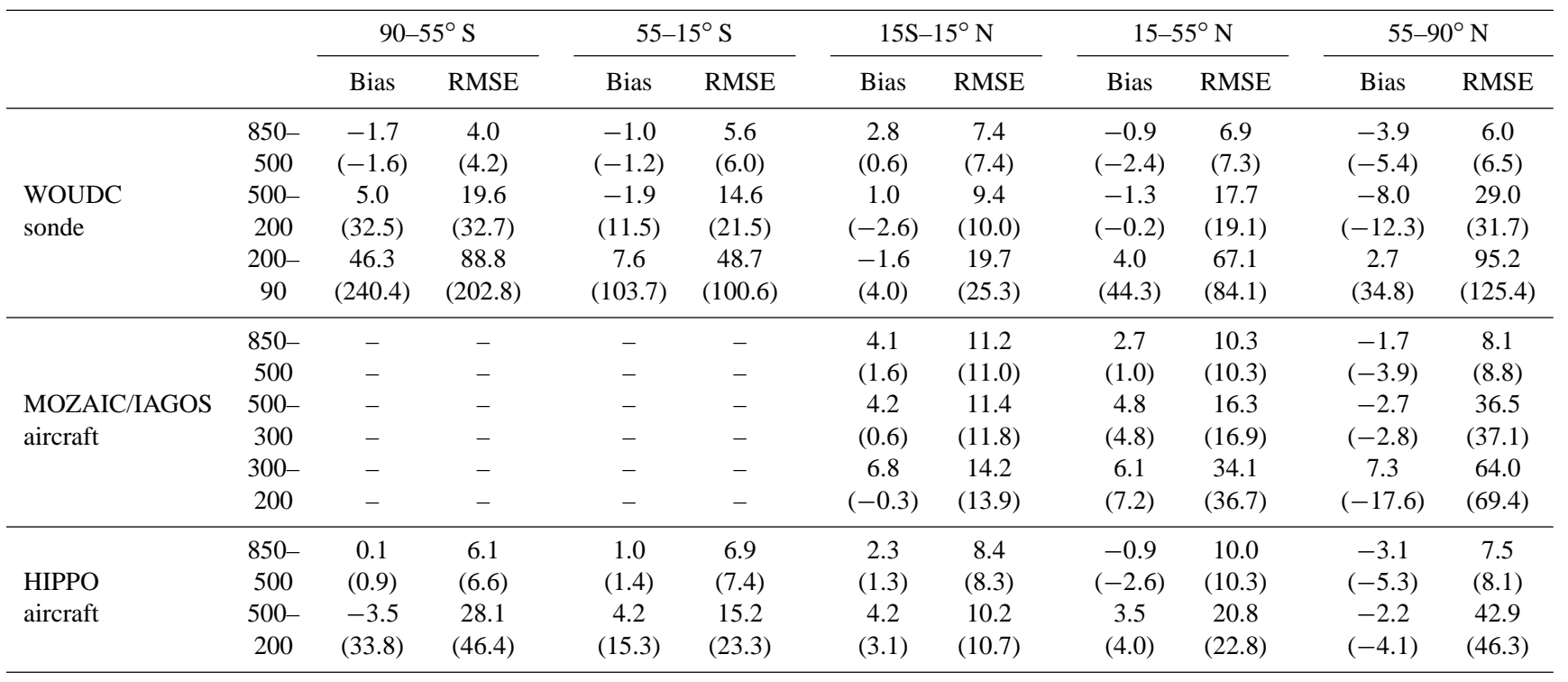

tive bias in the prescribed $\mathrm{O}_{3}$ concentrations above $70 \mathrm{hPa}$ in CHASER, which is mostly removed in the reanalysis. The observed seasonal and interannual variations are captured well in the reanalysis.

The observed tropospheric $\mathrm{O}_{3}$ concentration shows variations from year to year during the reanalysis period (Fig. 5). As summarised in Table 2, the reanalysis reveals better agreements with the observed linear slope in most cases. The observed linear slope during the reanalysis period is positive $\left(+2.9 \pm 2.8 \mathrm{ppb}(8 \text { years })^{-1}\right)$ at the NH mid-latitudes between 850 and $500 \mathrm{hPa}$, but the significance of this trend is not very high. The slope over the 8 -year period at the same region is also positive in the reanalysis data $(+1.2 \pm$ $\left.2.1 \mathrm{ppb}(8 \text { years })^{-1}\right)$, whereas it is negative in the control run $\left(-1.2 \pm 2.1 \mathrm{ppb}(8 \text { years })^{-1}\right)$. At the $\mathrm{NH}$ mid-latitudes in the lower stratosphere $(200-90 \mathrm{hPa})$, the observed slope is negative $\left(-17.7 \pm 41.9 \mathrm{ppb}(8 \text { years })^{-1}\right)$, whereas the reanalysis $\left(-25.7 \pm 38.8 \mathrm{ppb}(8 \text { years })^{-1}\right)$ shows better agreement with the observed slope than the control run $(-35.8 \pm$ $\left.46.3 \mathrm{ppb}(8 \text { years })^{-1}\right)$. The seasonal and year-to-year variations are generally well reproduced in the control run in the $\mathrm{NH}$ troposphere $(r=0.73-0.93)$, whereas the reanalysis further improves the temporal correlation by 0.07 between 850 and $500 \mathrm{hPa}$ and by 0.04 between 500 and $200 \mathrm{hPa}$ at the $\mathrm{NH}$ mid-latitudes.

The observed time series show obvious year-to-year variations in the tropics associated with variations such as in the El Niño-Southern Oscillation (ENSO), including their influences on the biomass-burning activity. The tropical $\mathrm{O}_{3}$ variations are better represented in the reanalysis $(r=0.80$ between 850 and $500 \mathrm{hPa}$ and $r=0.72$ between 500 and
$200 \mathrm{hPa}$ ) than in the control run $(r=0.74$ and $r=0.59)$. In the tropics and $\mathrm{SH}$, annual and zonal mean $\mathrm{O}_{3}$ concentration does not show clear linear trends during the reanalysis period either in the observations or reanalysis. However, local $\mathrm{O}_{3}$ concentrations might have significant trends. For instance, Thompson et al. (2014) showed wintertime free-tropospheric $\mathrm{O}_{3}$ increases over Irene and Réunion probably due to longrange transport of growing pollution in the SH. Further analyses will be required to investigate the detailed characteristics of $\mathrm{O}_{3}$ variation.

The ozonesonde-analysis difference is slightly larger in 2010-2012 than in 2005-2009 (Table 3 and Fig. 6). The large positive bias throughout the troposphere in winter and negative bias below $500 \mathrm{hPa}$ in spring-autumn remain in 20102012 (Fig. 6). This is associated with the decreased number of assimilation measurements (TES and OMI); this is discussed further in Sect. 7.3. In contrast, during 2005-2009 the mean $\mathrm{O}_{3}$ bias does not change significantly with year in the reanalysis, which confirms the stable performance of the $\mathrm{O}_{3}$ reanalysis field. Verstraeten et al. (2013) highlighted that the time series of the TES-sonde $\mathrm{O}_{3}$ biases do not change over time, which suggests that TES is an appropriate instrument for long-term analysis of free-tropospheric $\mathrm{O}_{3}$.

\subsubsection{Aircraft}

Both the model and the reanalysis generally capture well the observed horizontal, vertical, and seasonal variations in $\mathrm{O}_{3}$ concentration compared with the MOZAIC/IAGOS aircraft measurements (Figs. 7 and 8). However, the model mostly overestimates $\mathrm{O}_{3}$ concentration from the northern tropics to the mid-latitudes and underestimates it at the NH high lati- 

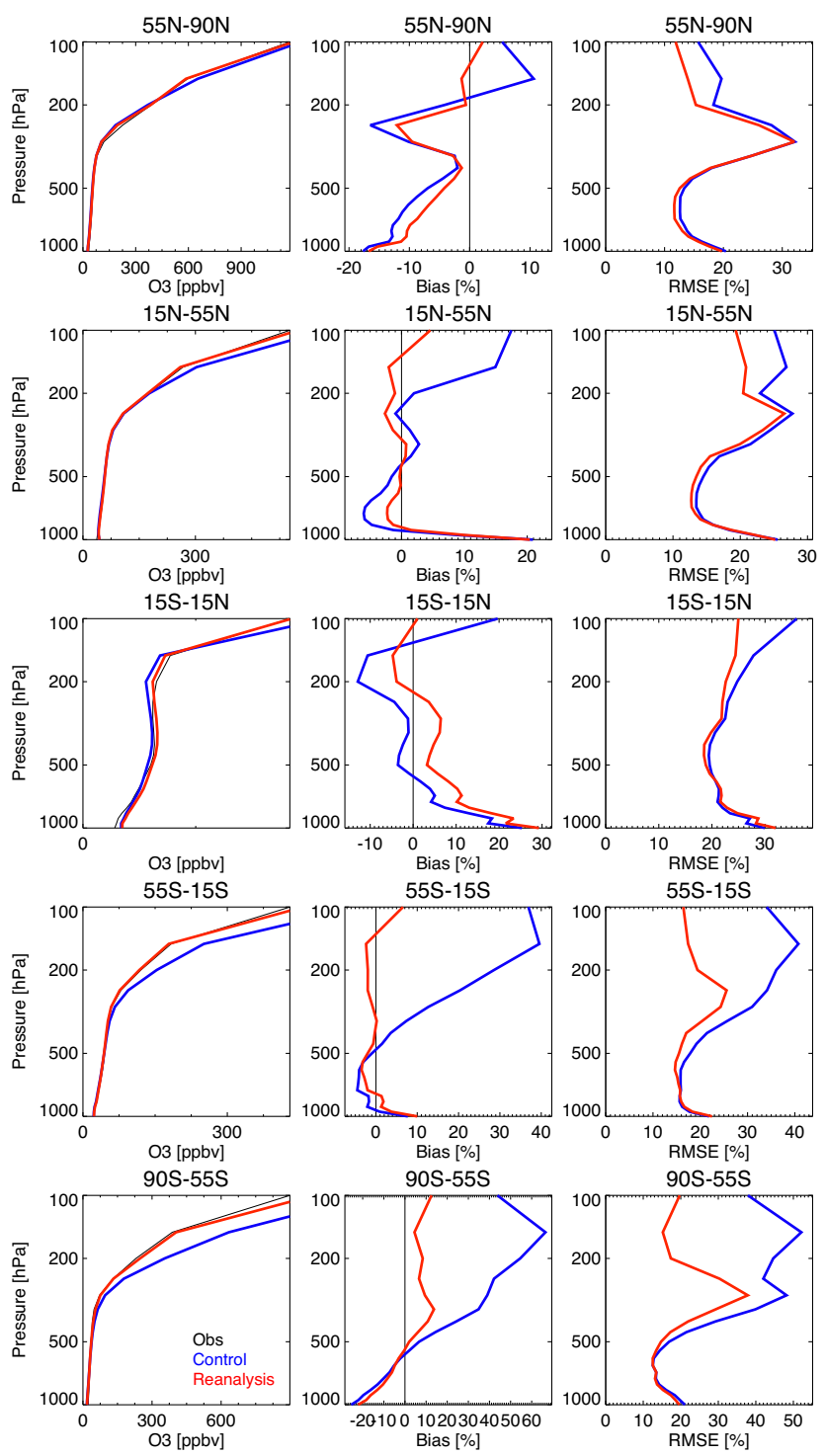

Figure 4. Comparison of the vertical $\mathrm{O}_{3}$ profiles between ozonesondes (black), control run (blue), and reanalysis (red) averaged for the period 2005-2012. The left column shows the mean profile; centre and right columns show the mean difference and the RMSE between the control run and the observations (blue) and between the reanalysis and the observations (red). From top to bottom, results are shown for the $\mathrm{NH}$ high latitudes $\left(55-90^{\circ} \mathrm{N}\right), \mathrm{NH}$ mid-latitudes $\left(15-55^{\circ} \mathrm{N}\right)$, tropics $\left(15^{\circ} \mathrm{S}-15^{\circ} \mathrm{N}\right)$, SH mid-latitudes $\left(15-55^{\circ} \mathrm{S}\right)$, and $\mathrm{SH}$ high latitudes $\left(55-90^{\circ} \mathrm{S}\right)$.

tudes in the middle and upper troposphere (between 850 and $300 \mathrm{hPa}$ in Table 1), as consistently revealed by comparison with ozonesonde observations.

Although the improvement is not large in the upper troposphere (500-300 hPa, Fig. 7), an improved agreement with the MOZAIC/IAGOS measurements is found in the reanalysis run in the middle troposphere $(850-500 \mathrm{hPa})$ and at the aircraft cruising altitude $(300-200 \mathrm{hPa})$, as summarised in
Table 1. Most of the negative bias of the model in the troposphere of the NH high latitudes is reduced throughout the reanalysis period. A substantial improvement is observed at the aircraft cruising altitude around the tropopause (between 300 and $200 \mathrm{hPa}$ ) at the $\mathrm{NH}$ high latitudes; the mean positive bias is reduced from $+8 \%$ in the control run to $+3 \%$ in the reanalysis. By separately assimilating individual measurements through the observing system experiments (OSEs), we confirmed that the improvement is mainly attributed to the MLS assimilation (not shown).

From the NH subtropics to the mid-latitudes, the mean positive bias of the model at the aircraft cruising altitude $(300-200 \mathrm{hPa})$ is reduced, whereas the positive bias of low concentration in autumn-winter in the middle troposphere $(850-500 \mathrm{hPa})$ is increased. In the tropics, the MOZAIC/IAGOS measurements were mostly collected near large biomass-burning areas (Fig. 7: e.g. Central Africa and Southeast Asia), where $\mathrm{O}_{3}$ concentration in the troposphere becomes too high in the reanalysis probably attributed to a positive bias in the TES $\mathrm{O}_{3}$ observations (cf. Sect. 7.2). Note that more substantial improvements in comparison with the aircraft measurements are found in 2005-2009 than in the later years.

HIPPO measurements provide information on the vertical $\mathrm{O}_{3}$ profiles over the Pacific. The observed tropospheric $\mathrm{O}_{3}$ concentration is higher in the extratropics than the tropics, with higher concentrations in the NH than the SH (Fig. 9). The observed tropospheric $\mathrm{O}_{3}$ concentration displays a maximum in the NH subtropics in March (HIPPO3) because of the strong influence of stratospheric inflows along the westerly jet stream. The observed latitudinal-vertical distributions are generally captured well by both the model and the reanalysis for all the HIPPO campaigns.

The model shows negative biases in the NH extratropics and positive biases from the tropics to the SH compared with the HIPPO measurements (Table 1). These characteristics of the bias are commonly found in comparisons with global ozonesonde observations in this study (cf. Sect. 5.1.1) and are reduced effectively in the reanalysis. A considerable bias reduction can be found in the lower- and middle-tropospheric $\mathrm{O}_{3}$ at the $\mathrm{NH}$ mid-latitudes where $\mathrm{O}_{3}$ variations could be influenced by long-range transport from the Eurasian continent. Direct concentration adjustment by TES measurements in the troposphere and by MLS measurements in the UTLS played important roles in correcting tropospheric $\mathrm{O}_{3}$ profiles. In addition, corrections made to the $\mathrm{O}_{3}$ precursors emissions over the Eurasian continent by OMI, especially over East Asia, were important in influencing tropospheric $\mathrm{O}_{3}$ concentration over the North Pacific around $35-60^{\circ} \mathrm{N}$, especially in boreal spring. This demonstrates that the assimilation of multiple-species data sets is a powerful means by which to correct the global tropospheric $\mathrm{O}_{3}$ profiles, including those over remote oceans. In contrast, the positive bias in the tropics is further increased in the reanalysis (from $+5 \%$ in the control run to $+8 \%$ in the reanalysis between 

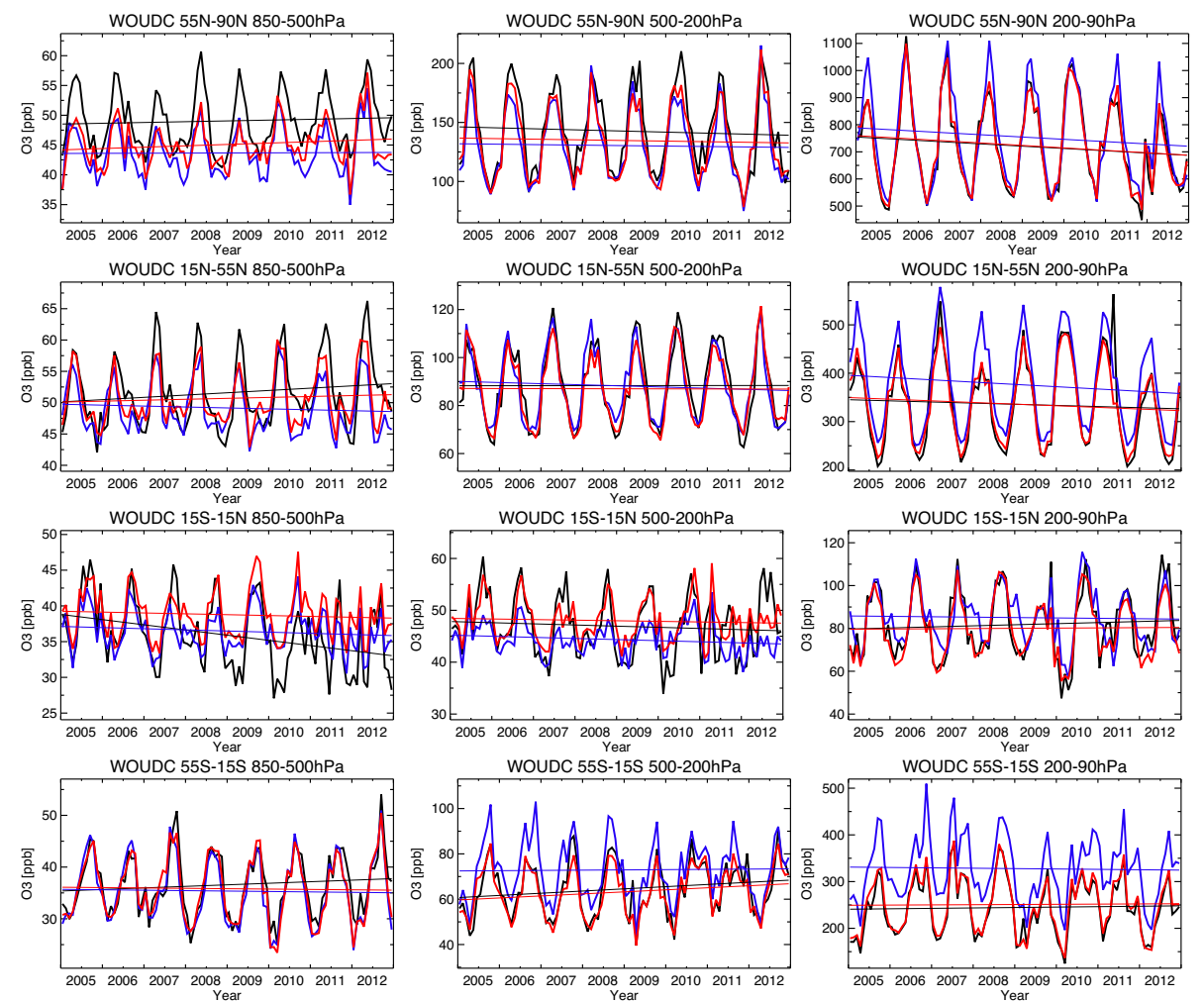

WOUDC 55S-15S 500-200hPa

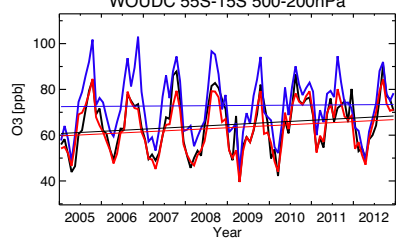

WOUDC 55S-15S 200-90hPa WOUDC 90S-55S 850-500hPa

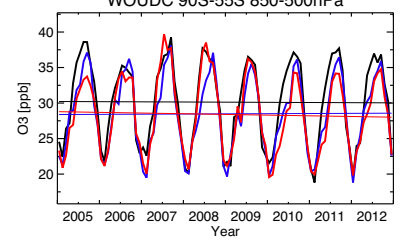

WOUDC 90S-55S 500-200hPa
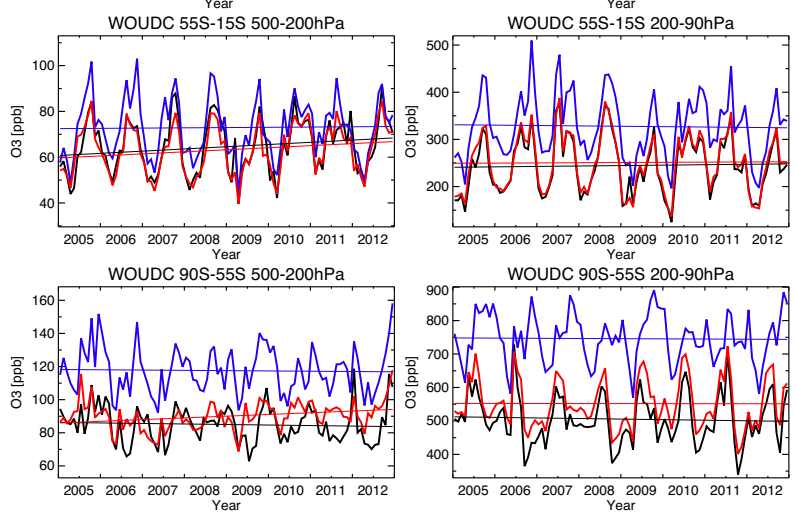

Figure 5. Time series of the monthly mean $\mathrm{O}_{3}$ concentration obtained from ozonesondes (black), control run (blue), and reanalysis (red) averaged between 850 and $500 \mathrm{hPa}$ (left column), 500 and $200 \mathrm{hPa}$ (centre column), and 200 and $90 \mathrm{hPa}$ (right column). From top to bottom the results are shown for the $\mathrm{NH}$ high latitudes $\left(55-90^{\circ} \mathrm{N}\right), \mathrm{NH}$ mid-latitudes $\left(15-55^{\circ} \mathrm{N}\right)$, tropics $\left(15^{\circ} \mathrm{S}-15^{\circ} \mathrm{N}\right)$, $\mathrm{SH}$ mid-latitudes $(15-$ $\left.55^{\circ} \mathrm{S}\right)$, and $\mathrm{SH}$ high latitudes $\left(55-90^{\circ} \mathrm{S}\right)$.

850 and $500 \mathrm{hPa}$ and from +10 to $+15 \%$ between 500 and $300 \mathrm{hPa}$ ), as mostly commonly found in comparisons against the MOZAIC/IAGOS and ozonesonde measurements (cf. Sect. 5.1.1 and 5.1.2).

Vertical profiles obtained during the NASA aircraft campaigns were also used to validate the $\mathrm{O}_{3}$ profile (Fig. 10). The comparisons show improved agreements in the reanalysis in the middle and upper troposphere during INTEX-B over Mexico and during the ARCTAS campaign over the Arctic, but the model's positive bias near the surface is further increased for the INTEX-B profile. For the DISCOVERAQ profile, the model's negative bias in the free troposphere is mostly removed in the reanalysis. For the DC3 profiles, the model captures the observed tropospheric $\mathrm{O}_{3}$ profiles well, whereas the assimilation leads to small overestimations.

\section{$5.2 \mathrm{CO}$}

\subsubsection{Surface}

Surface CO concentrations are compared with the WDCGG surface observations from 59 stations, as summarised in Table 4 and depicted for 12 selected stations in Fig. 11. The control run underestimates $\mathrm{CO}$ concentration by up to about $60 \mathrm{ppb}$ in the $\mathrm{NH}$ extratropics, with the largest negative bias in winter and smallest bias in summer. The model underestimation has been commonly found in most of the CTMs (Shindell et al., 2006; Kopacz et al., 2010; Fortems-Cheiney et al., 2011; Stein et al., 2014). The model's negative bias is also found in most tropical sites, but not in the SH.

Most of the negative bias in the NH extratropics and in the tropics is removed in the reanalysis run, due to the increased surface CO emissions in the analysis (cf. Sect. 6). The MOPITT assimilation dominates the negative bias reduction 
Table 2. Linear trend (slope in $\mathrm{ppb}(8 \text { years })^{-1}$ ) and standard deviation (in ppb) of $\mathrm{O}_{3}$ derived from the WMO ozonesonde observations, the control run, and the reanalysis during 2005-2012.

\begin{tabular}{|c|c|c|c|c|c|c|c|c|c|c|}
\hline & \multicolumn{2}{|c|}{$90-55^{\circ} \mathrm{S}$} & \multicolumn{2}{|c|}{$55-15^{\circ} \mathrm{S}$} & \multicolumn{2}{|c|}{$15 \mathrm{~S}-15^{\circ} \mathrm{N}$} & \multicolumn{2}{|c|}{$15-55^{\circ} \mathrm{N}$} & \multicolumn{2}{|c|}{$55-90^{\circ} \mathrm{N}$} \\
\hline & Obs. & $\begin{array}{l}\text { Reanalysis } \\
\text { (control) }\end{array}$ & Obs. & $\begin{array}{c}\text { Reanalysis } \\
\text { (control) }\end{array}$ & Obs. & $\begin{array}{l}\text { Reanalysis } \\
\text { (control) }\end{array}$ & Obs. & $\begin{array}{c}\text { Reanalysis } \\
\text { (control) }\end{array}$ & Obs. & $\begin{array}{l}\text { Reanalysis } \\
\text { (control) }\end{array}$ \\
\hline $\begin{array}{l}850- \\
500\end{array}$ & $-0.2 \pm 2.9$ & $\begin{array}{c}-0.8 \pm 2.7 \\
(+0.2 \pm 2.6)\end{array}$ & $+2.4 \pm 2.9$ & $\begin{array}{c}-0.5 \pm 3.0 \\
(-0.7 \pm 3.1)\end{array}$ & $-6.3 \pm 2.3$ & $\begin{array}{c}-1.6 \pm 1.7 \\
(-1.8 \pm 1.4)\end{array}$ & $+2.9 \pm 2.8$ & $\begin{array}{c}+1.2 \pm 2.1 \\
(-1.2 \pm 2.1)\end{array}$ & $+1.1 \pm 2.4$ & $\begin{array}{c}+1.8 \pm 1.8 \\
(+0.2 \pm 1.9)\end{array}$ \\
\hline $\begin{array}{l}500- \\
200\end{array}$ & $-2.5 \pm 5.5$ & $\begin{array}{c}+8.2 \pm 4.1 \\
(-1.4 \pm 6.9)\end{array}$ & $+7.7 \pm 5.7$ & $\begin{array}{c}+7.2 \pm 5.3 \\
(+0.9 \pm 6.4)\end{array}$ & $-1.8 \pm 3.0$ & $\begin{array}{c}-0.9 \pm 2.0 \\
(-1.7 \pm 1.5)\end{array}$ & $+1.1 \pm 7.9$ & $\begin{array}{c}-0.3 \pm 7.1 \\
(-3.8 \pm 7.1)\end{array}$ & $-7.1 \pm 17.1$ & $\begin{array}{c}-4.2 \pm 15.4 \\
(-3.1 \pm 14.9)\end{array}$ \\
\hline $\begin{array}{l}200- \\
90\end{array}$ & $-13.6 \pm 36.7$ & $\begin{array}{c}-1.2 \pm 36.7 \\
(-4.4 \pm 36.4)\end{array}$ & $+7.2 \pm 29.5$ & $\begin{array}{c}+3.3 \pm 29.7 \\
(-6.5 \pm 33.1)\end{array}$ & $+3.8 \pm 7.5$ & $\begin{array}{c}+0.7 \pm 6.9 \\
(-1.7 \pm 6.4)\end{array}$ & $-17.7 \pm 41.9$ & $\begin{array}{c}-25.7 \pm 38.8 \\
(-35.8 \pm 46.3)\end{array}$ & $-67.7 \pm 78.4$ & $\begin{array}{c}-72.7 \pm 74.9 \\
(-68.0 \pm 85.6)\end{array}$ \\
\hline
\end{tabular}

Table 3. Comparisons of the mean $\mathrm{O}_{3}$ concentrations between the reanalysis run and the WOUDC ozonesonde observations in the Southern Hemisphere $(\mathrm{SH})\left(90-30^{\circ} \mathrm{S}\right)$, troposphere $(\mathrm{TR})\left(30^{\circ} \mathrm{S}-30^{\circ} \mathrm{N}\right)$ and Northern Hemisphere $(\mathrm{NH})\left(30-90^{\circ} \mathrm{N}\right)$. The mean differences are shown for each year of the reanalysis period and for mean concentrations during 2005-2009 and during 2010-2012. The latter includes results for the control run given in brackets.

\begin{tabular}{|c|c|c|c|c|c|c|c|c|c|}
\hline & \multicolumn{3}{|c|}{$850-500 \mathrm{hPa}$} & \multicolumn{3}{|c|}{$500-200 \mathrm{hPa}$} & \multicolumn{3}{|c|}{$200-90 \mathrm{hPa}$} \\
\hline & SH & TR & $\mathrm{NH}$ & SH & TR & NH & SH & TR & $\mathrm{NH}$ \\
\hline 2005 & -2.3 & 0.9 & -2.3 & 3.0 & 0.4 & 0.9 & 27.3 & 4.6 & 13.3 \\
\hline 2006 & -0.2 & 1.1 & -2.6 & 0.2 & -0.3 & -4.9 & 27.3 & -2.7 & 3.9 \\
\hline 2007 & 0.2 & 0.8 & -2.5 & -2.1 & -0.6 & -5.4 & 23.8 & -1.9 & -1.3 \\
\hline 2008 & 1.4 & 1.9 & -1.8 & 0.7 & 1.2 & -5.2 & 30.9 & 1.2 & 10.8 \\
\hline 2009 & 0.2 & 2.3 & -2.0 & 2.7 & 0.3 & -8.4 & 33.6 & -3.1 & 3.2 \\
\hline 2010 & -2.5 & 3.5 & -2.8 & 7.1 & 0.7 & -6.6 & 42.8 & 1.4 & -5.3 \\
\hline 2011 & -2.3 & 1.8 & -2.7 & 7.1 & 0.3 & -3.7 & 30.8 & -6.4 & -2.5 \\
\hline 2012 & -1.9 & 2.0 & -3.6 & 6.8 & -1.6 & 2.9 & 31.5 & -5.1 & 10.1 \\
\hline 2005-2009 & $\begin{array}{c}-0.1 \\
(-0.3)\end{array}$ & $\begin{array}{c}1.4 \\
(-0.3)\end{array}$ & $\begin{array}{l}-2.2 \\
(-3.5)\end{array}$ & $\begin{array}{c}0.9 \\
(27.6)\end{array}$ & $\begin{array}{c}0.2 \\
(-2.2)\end{array}$ & $\begin{array}{c}-4.6 \\
(-3.0)\end{array}$ & $\begin{array}{c}28.6 \\
(193.8)\end{array}$ & $\begin{array}{c}-0.4 \\
(11.0)\end{array}$ & $\begin{array}{c}6.0 \\
(52.0)\end{array}$ \\
\hline 2010-2012 & $\begin{array}{c}-2.3 \\
(-1.2)\end{array}$ & $\begin{array}{c}2.4 \\
(-0.6)\end{array}$ & $\begin{array}{l}-3.0 \\
(-5.6)\end{array}$ & $\begin{array}{c}7.0 \\
(26.5)\end{array}$ & $\begin{array}{l}-0.2 \\
(-3.2)\end{array}$ & $\begin{array}{c}-2.5 \\
(-4.7)\end{array}$ & $\begin{array}{c}35.0 \\
(191.0)\end{array}$ & $\begin{array}{l}-3.4 \\
(6.5)\end{array}$ & $\begin{array}{c}0.8 \\
(45.9)\end{array}$ \\
\hline
\end{tabular}

through the surface $\mathrm{CO}$ emission optimisation, whereas the assimilation of other data has only a small influence on the $\mathrm{CO}$ concentration analysis through changes in the $\mathrm{OH}$ field. The annual and regional mean surface bias becomes positive after assimilation at NH mid- and high latitudes, which is illustrated at locations such as Midway and Bermuda $\left(32^{\circ} \mathrm{N}\right.$, $65^{\circ} \mathrm{W}$; figure not shown). The observed negative trends at most $\mathrm{NH}$ sites are captured well in the reanalysis.

Tropical CO concentrations show district interannual variations associated with variations in tropical biomass-burning activities and meteorological conditions. The temporal correlations with the observations are about $0.1-0.2$ higher in the reanalysis compared with the control run in the tropics at Christmas Island and Barbados.

In the $\mathrm{SH}$, the model generally shows good agreement with the surface observations. However, assimilation increases the $\mathrm{CO}$ concentration and leads to overestimations in some places (e.g. Showa). The mean negative bias at the SH midlatitudes changed from $-10 \%$ in the control run to $+7 \%$ in the reanalysis.

\subsubsection{Aircraft}

The model underestimates the $\mathrm{CO}$ concentration in the tropics and the NH compared with the MOZAIC/IAGOS aircraft measurements throughout the troposphere (below $300 \mathrm{hPa}$ ) and around the tropopause at the aircraft cruising altitude (between 300 and $200 \mathrm{hPa}$ ), as depicted in Fig. 12. The model's negative bias is mostly removed in the reanalysis, with a mean improvement of $50-90 \%$ throughout the troposphere, as summarised in Table 4 . This confirms that the constraints provided for the surface emissions are propagated well into the concentrations of the entire troposphere with a delay in the peak timing and decay in the amplitude. Note that the $\mathrm{CO}$ concentrations were not directly adjusted in the data assimilation. The spatial distribution in the upper troposphere is also captured well in the reanalysis (Fig. 7). Despite the overall improvement, the low concentrations in the $\mathrm{NH}$ lower and middle troposphere in summer and autumn remain underestimated, whereas the analysed concentration becomes too high in the NH high latitudes at the aircraft cruising altitude (Fig. 12). A decreasing trend is observed in both the lower and upper troposphere in the $\mathrm{NH}$, which is 

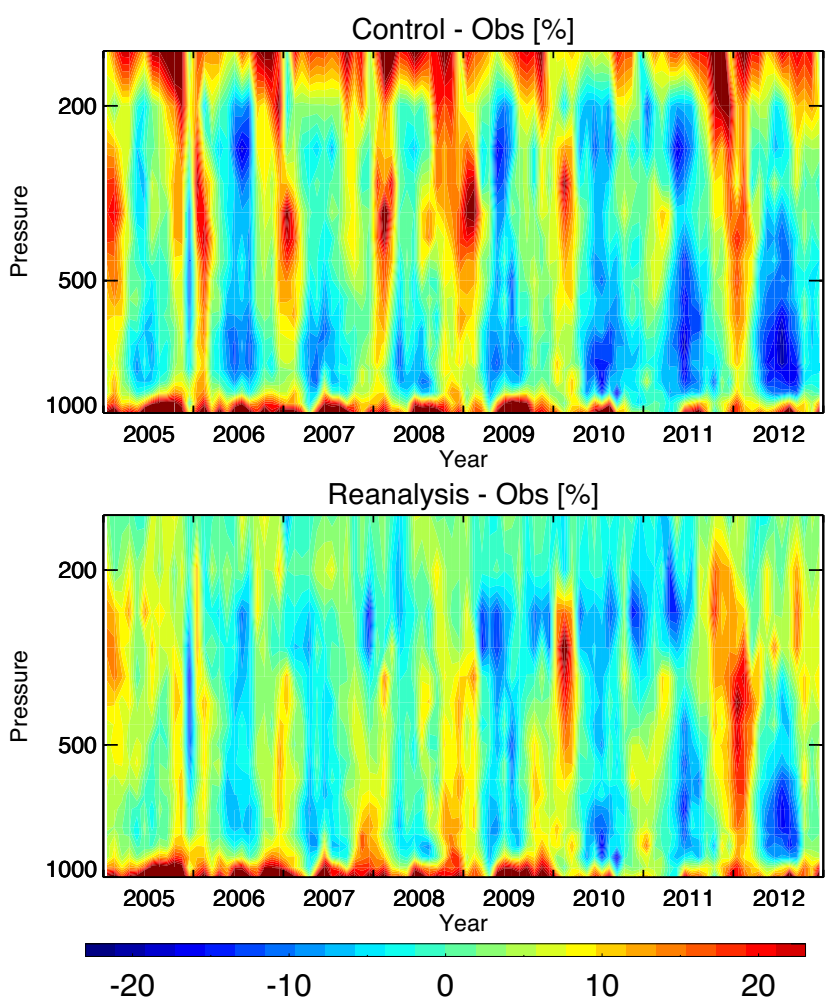

Figure 6. Vertical profiles of the time series of the monthly mean $\mathrm{O}_{3}$ concentration difference (in $\%$ ) between the control run and ozonesondes (top) and between the reanalysis and ozonesondes (bottom) averaged over the $\mathrm{NH}$ mid-latitudes $\left(15-55^{\circ} \mathrm{N}\right)$.

represented realistically in the reanalysis. The EDGAR 4.2 for 2008 was used for the model simulation for 2009-2012. The analysis and the comparison with the independent observations show that this caused unrealistic interannual $\mathrm{CO}$ variations and an underestimate of the decreasing trend in the control run.

The distinct interannual variations in the tropics (over Southeast Asia and around Central and North Africa) observed from the MOZAIC/IAGOS aircraft measurements mainly reflect variations in biomass-burning emissions. The temporal variations of $\mathrm{CO}$ are captured better by the reanalysis between 850 and $500 \mathrm{hPa}(r=0.67$ in the control run and 0.78 in the reanalysis).

The HIPPO observations exhibit large latitudinal CO gradients around $15-25^{\circ} \mathrm{N}$ over the Pacific for all campaigns (Fig. 13). Tropospheric air can be distinguished between the tropics and extratropics because of the transport barrier around the subtropical jet (Bowman and Carrie, 2002; Miyazaki et al., 2008). The transport barrier produces the large $\mathrm{CO}$ gradient in the subtropics and acts to accumulate high levels of $\mathrm{CO}$ in the $\mathrm{NH}$ extratropics. In the $\mathrm{SH}, \mathrm{CO}$ concentration increases with height in the free troposphere, because of the strong poleward transport in the upper troposphere from the tropics to the SH high latitudes.

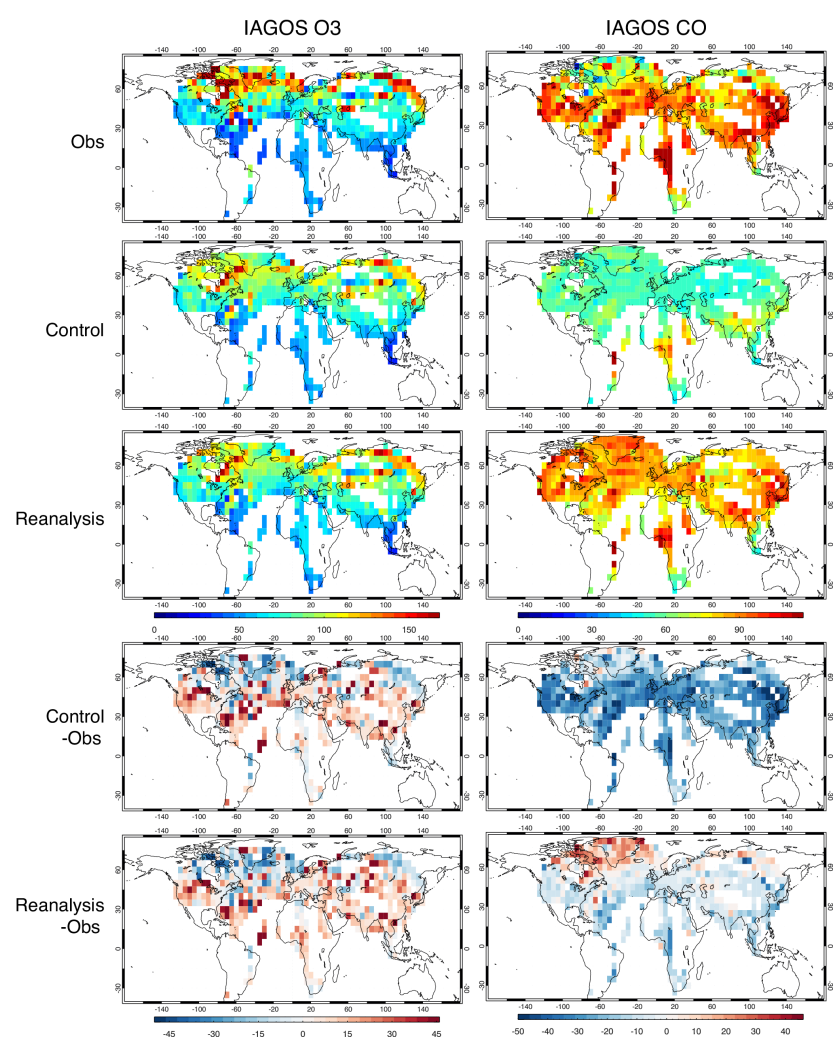

Figure 7. Spatial distributions of $\mathrm{O}_{3}$ (left column) and $\mathrm{CO}$ (right column) averaged between 500 and $300 \mathrm{hPa}$ and during 2005-2012 obtained from the MOZAIC/IAGOS aircraft measurements (first row), control run (second row), and reanalysis (third row). Differences between the control run and observations (fourth row) and between the reanalysis and observations (fifth row) are also plotted. Units are ppb.

The assimilation increases $\mathrm{CO}$ concentration and reduces the mean model negative bias by about $60-80 \%$ in the $\mathrm{NH}$ extratropics against the HIPPO measurements. The remaining negative bias could be attributed to overemphasised chemical destruction while air is transported from the Eurasian continent to the HIPPO locations over the central Pacific. For instance, the negative bias of the surface $\mathrm{CO}$ concentration is mostly removed in the reanalysis over Yonaguni at the ground surface, located near (downwind of) large sources of Chinese emissions (Fig. 11). This suggests that the emission sources are realistically represented in the reanalysis. Errors in stratospheric CO might also cause the negative bias through stratosphere-troposphere exchange (STE).

Reductions in the negative model bias of tropospheric $\mathrm{CO}$ can be found in comparisons against the NASA aircraft campaign profiles from INTEX-B, ARCTAS-A, and DC3 (Fig. 10), although the bias reduction is small for the ARCTAS-B profile. Bian et al. (2013) demonstrated that most of the enhanced $\mathrm{CO}$ concentrations observed during the ARCTAS-A originate from Asian anthropogenic emissions. This suggests that the reanalysis realistically repre- 
Table 4. Same as Table 1, but for mean CO concentrations. Units are ppb. Observations used are the WDCGG observations during 20052012, MOZAIC/IAGOS aircraft measurements during 2005-2012, and HIPPO aircraft measurements during $2009-2011$.

\begin{tabular}{|c|c|c|c|c|c|c|c|c|c|c|c|}
\hline & & \multicolumn{2}{|c|}{$90-55^{\circ} \mathrm{S}$} & \multicolumn{2}{|c|}{$55-15^{\circ} \mathrm{S}$} & \multicolumn{2}{|c|}{$15 \mathrm{~S}-15^{\circ} \mathrm{N}$} & \multicolumn{2}{|c|}{$15-55^{\circ} \mathrm{N}$} & \multicolumn{2}{|c|}{$55-90^{\circ} \mathrm{N}$} \\
\hline & & Bias & RMSE & Bias & RMSE & Bias & RMSE & Bias & RMSE & Bias & RMSE \\
\hline $\begin{array}{l}\text { WDCGG } \\
\text { surface }\end{array}$ & & $\begin{array}{l}-0.6 \\
(-4.6)\end{array}$ & $\begin{array}{l}7.3 \\
(8.0)\end{array}$ & $\begin{array}{c}4.3 \\
(-5.8)\end{array}$ & $\begin{array}{c}19.8 \\
(15.8)\end{array}$ & $\begin{array}{l}-13.6 \\
(-18.9)\end{array}$ & $\begin{array}{c}27.4 \\
(33.4)\end{array}$ & $\begin{array}{c}27.2 \\
(-41.7)\end{array}$ & $\begin{array}{c}62.8 \\
(60.4)\end{array}$ & $\begin{array}{c}11.1 \\
(-51.1)\end{array}$ & $\begin{array}{c}40.0 \\
(57.9)\end{array}$ \\
\hline $\begin{array}{l}\text { MOZAIC/IAGOS } \\
\text { aircraft }\end{array}$ & $\begin{array}{c}850- \\
500 \\
500- \\
300 \\
300- \\
200\end{array}$ & $\begin{array}{l}- \\
- \\
- \\
- \\
- \\
-\end{array}$ & $\begin{array}{l}- \\
- \\
- \\
- \\
- \\
-\end{array}$ & $\begin{array}{l}- \\
- \\
- \\
- \\
- \\
-\end{array}$ & $\begin{array}{l}- \\
- \\
- \\
- \\
- \\
-\end{array}$ & $\begin{array}{c}-19.8 \\
(-37.7) \\
-10.3 \\
(-21.3) \\
-9.9 \\
(-21.5)\end{array}$ & $\begin{array}{c}34.6 \\
(45.6) \\
18.1 \\
(25.4) \\
24.4 \\
(30.6)\end{array}$ & $\begin{array}{c}-15.1 \\
(-48.3) \\
-8.6 \\
(-30.0) \\
0.0 \\
(-16.8)\end{array}$ & $\begin{array}{c}29.3 \\
(53.1) \\
18.9 \\
(33.6) \\
18.2 \\
(24.7)\end{array}$ & $\begin{array}{c}-10.5 \\
(-51.1) \\
-3.4 \\
(-30.9) \\
10.2 \\
(-10.0)\end{array}$ & $\begin{array}{c}15.6 \\
(51.5) \\
19.7 \\
(35.3) \\
23.5 \\
(24.8)\end{array}$ \\
\hline $\begin{array}{l}\text { HIPPO } \\
\text { aircraft }\end{array}$ & $\begin{array}{c}850- \\
500 \\
500- \\
200\end{array}$ & $\begin{array}{c}2.1 \\
(-1.6) \\
6.2 \\
(2.6)\end{array}$ & $\begin{array}{c}2.8 \\
(2.4) \\
7.4 \\
(6.5)\end{array}$ & $\begin{array}{c}-0.6 \\
(-4.8) \\
-1.2 \\
(-5.0)\end{array}$ & $\begin{array}{c}5.1 \\
(5.9) \\
6.7 \\
(7.8)\end{array}$ & $\begin{array}{c}-3.6 \\
(-8.8) \\
-2.0 \\
(-7.0)\end{array}$ & $\begin{array}{c}6.9 \\
(10.6) \\
6.7 \\
(9.0)\end{array}$ & $\begin{array}{c}-11.8 \\
(-35.3) \\
-7.2 \\
(-23.9)\end{array}$ & $\begin{array}{c}17.1 \\
(37.0) \\
17.0 \\
(28.4)\end{array}$ & $\begin{array}{c}-11.5 \\
(-49.5) \\
-4.3 \\
(-27.9)\end{array}$ & $\begin{array}{c}16.4 \\
(50.0) \\
23.7 \\
(38.1)\end{array}$ \\
\hline
\end{tabular}
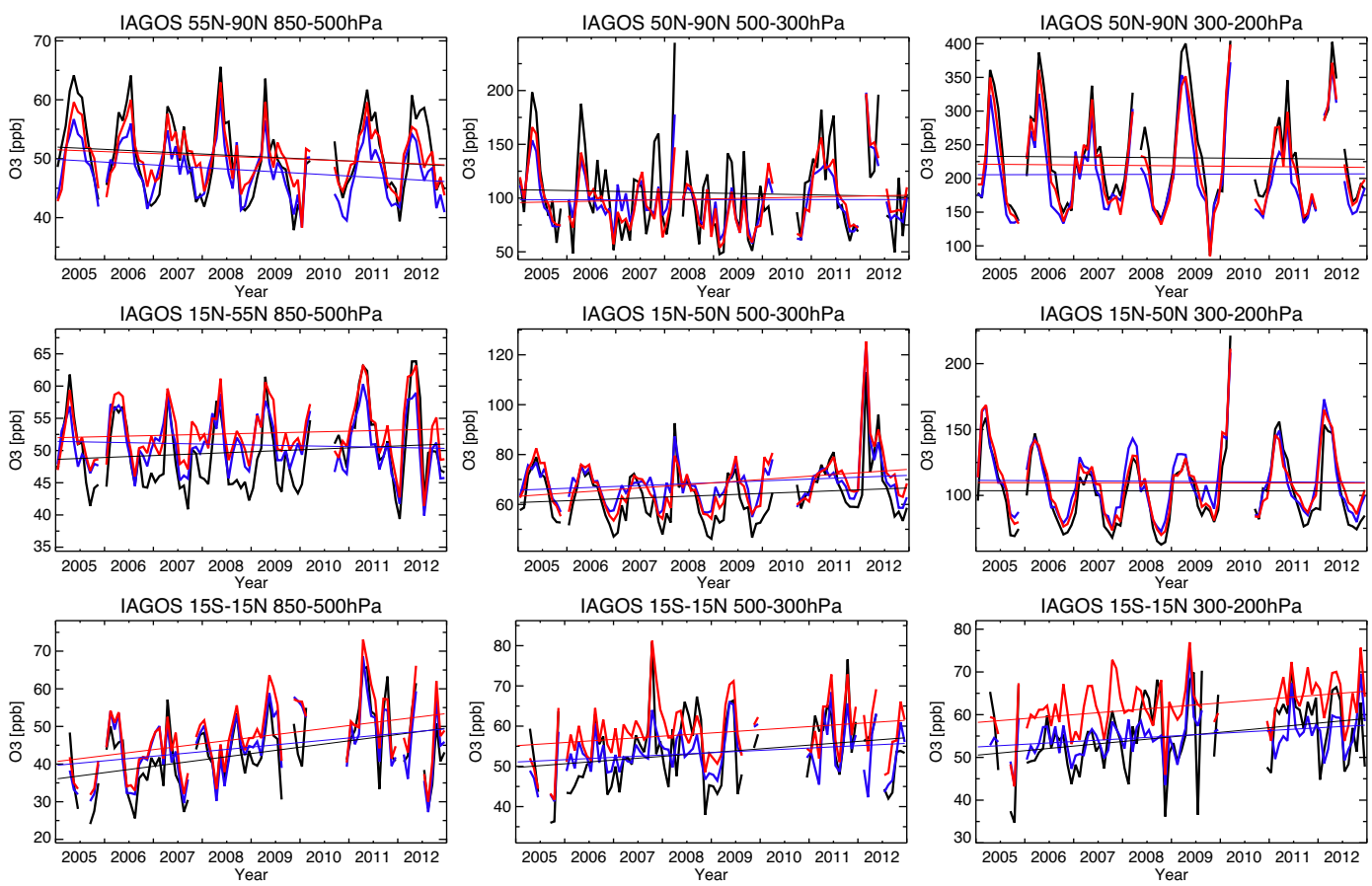

Figure 8. Time series of the monthly mean $\mathrm{O}_{3}$ concentration obtained from the MOZAIC/IAGOS aircraft measurements (black), control run (blue), and reanalysis (red) averaged between 850 and $500 \mathrm{hPa}$ (left column), 500 and $300 \mathrm{hPa}$ (centre column), and $300 \mathrm{and} 200 \mathrm{hPa}$ (right column). From top to bottom the results are shown for the $\mathrm{NH}$ high latitudes $\left(55-90^{\circ} \mathrm{N}\right), \mathrm{NH}$ mid-latitudes $\left(15-55^{\circ} \mathrm{N}\right)$, and tropics $\left(15^{\circ} \mathrm{S}-15^{\circ} \mathrm{N}\right)$.

sents the Asian anthropogenic emissions and their influences on the western Arctic CO level. Bian et al. (2013) also suggested a lower fraction of $\mathrm{CO}$ from Asian anthropogenic emissions during the ARCTAS-B than during the ARCTAS$A$ and showed that the along-track measurements are not representative of the concentrations within the large domain of the western Arctic during the ARCTAS-B, which may explain the small bias reduction for the ARCTAS-B profile in our comparison. MOPITT data are assimilated equatorward of $65^{\circ}$, and only the $\mathrm{CO}$ emissions are optimised in the reanalysis. Direct adjustment of CO concentration using highlatitude retrievals could be expected to improve the representation of $\mathrm{CO}$ in the ARCTAS profiles, as demonstrated by Klonecki et al. (2012) using IASI measurements. 

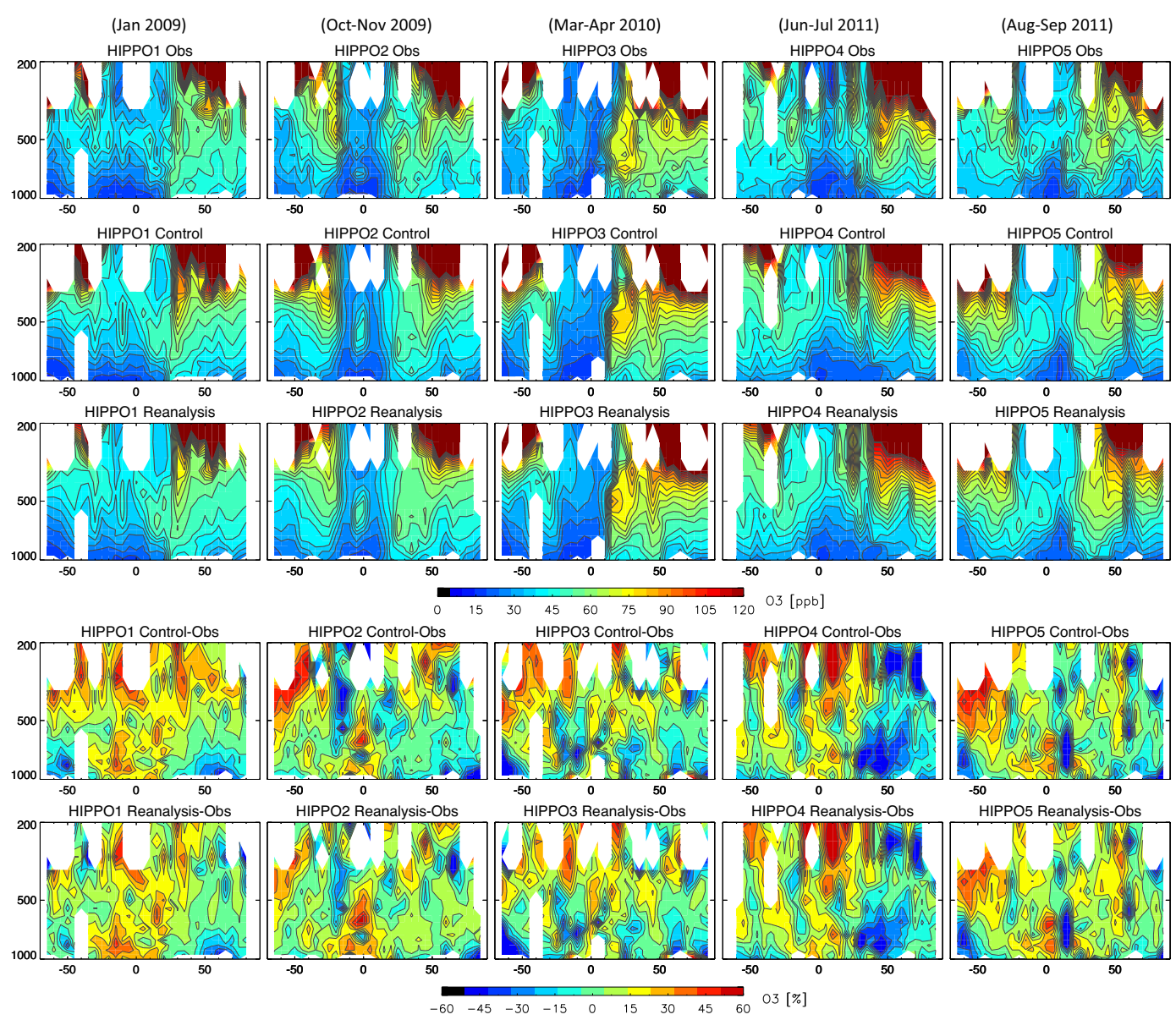

Figure 9. Latitude-pressure cross section of mean $\mathrm{O}_{3}$ concentration (in ppb) obtained from HIPPO aircraft measurements (first row), control run (second row), and reanalysis (third row). The relative difference (in \%) between the control run and the observation (fourth row) and between the reanalysis and the observation (fifth row) is also shown. Results are shown for all HIPPO campaigns (from left to right: HIPPO I, 8-30 January 2009; HIPPO II, 31 October to 22 November 2009; HIPPO III, 24 March to 16 April 2010; HIPPO IV, 14 June to 11 July 2011 ; and HIPPO V, 9 August to 9 September 2011).

\section{$5.3 \quad \mathrm{NO}_{2}$}

\subsubsection{Tropospheric column}

Compared with the satellite retrievals, the model generally underestimates the $\mathrm{NO}_{2}$ concentration over most industrial areas (e.g. East China, Europe, eastern USA, and South Africa) and over large biomass-burning areas (e.g. Central Africa), as shown by Fig. 14. The model underestimations are commonly found in comparisons against three different retrievals. The three products are produced using the same retrieval approach (Boersma et al., 2011). Therefore, the overpass time difference and diurnal variations in chemical processes and emissions dominate the differences between these retrievals. The negative bias over these regions is greatly reduced in the reanalysis, decreasing the 8-year global mean negative bias by about 65,45 , and $30 \%$ as compared with OMI, SCIAMACHY, and GOME-2, respectively (Table 5). The improvement can be also seen in the increased spatial correlation of $0.03-0.05$ and in the reduced RMSE of 15$30 \%$.

Over East China, the model's negative bias is large in winter, whereas the assimilation reduces the wintertime bias by about $40 \%$ compared with OMI retrievals. The observed low concentration in 2009 and high concentration in 2010-2012 are captured in the reanalysis, whereas the control run mostly failed to reproduce the interannual variability. The reanalysis shows larger positive trends than the control run, but the observed trend is even higher. The underestimation in the mean concentration and positive trend remain large in the reanalysis, especially when compared with the SCIAMACHY and GOME-2 retrievals. Note that over polluted areas, realistic concentration pathways of $\mathrm{NO}_{2}$ do not follow simple linear trends but reflect a combination of effects of environmental policies and economic activities. For instance, $\mathrm{NO}_{x}$ emissions in China have been increasing because of the rapid economic growth, although an economic slowdown affected the growth rate in 2009 (Gu et al., 2013). 


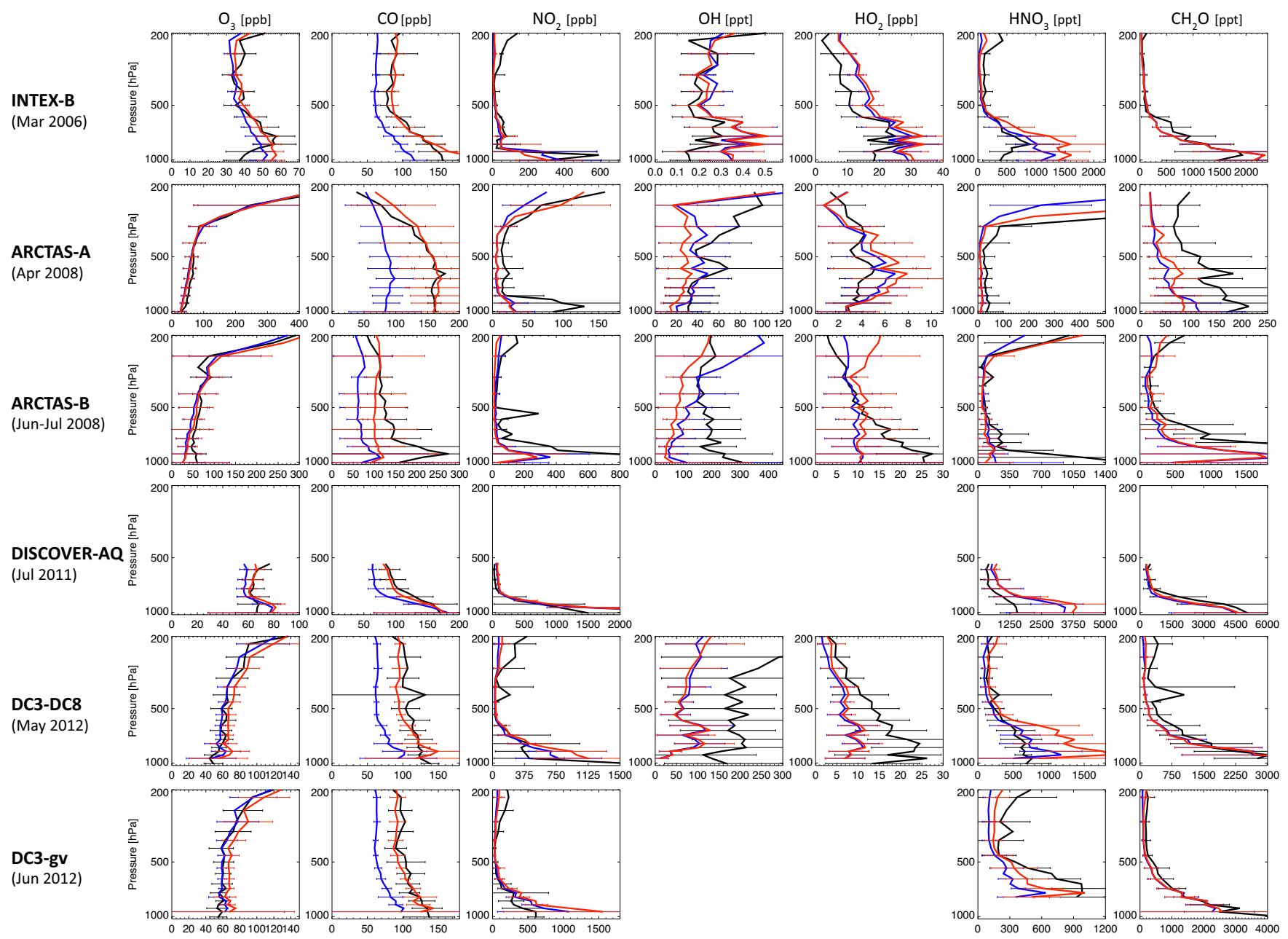

Figure 10. Mean vertical profiles of $\mathrm{O}_{3}(\mathrm{ppb}), \mathrm{CO}(\mathrm{ppb}), \mathrm{NO}_{2}$ (ppb), $\mathrm{OH}(\mathrm{ppt}), \mathrm{HO}_{2}$ (ppb), $\mathrm{HNO}_{3}$ (ppt), and $\mathrm{CH}_{2} \mathrm{O}$ (ppt) obtained from aircraft measurements (black), control run (blue), and reanalysis (red), for the INTEX-B profile (first row), ARCTAS-A profile (second row), ARCTAS-B profile (third row), DISCOVER-AQ profile (fourth row), DC3-DC8 profile (fifth row), and DC3-GV profile (sixth row). Error bars represent the standard deviation of all data within one bin (with an interval of $30 \mathrm{hPa}$ ).

Over Europe, the model's negative bias in summertime is reduced by about $10-30 \%$ in the reanalysis. The observed wintertime concentration is high in 2011-2012 and relatively low in 2010 because of the global economic recession and emission controls (Castellanos and Boersma, 2012). The assimilation increases the wintertime $\mathrm{NO}_{2}$ concentration in 2011-2012 and captures the observed interannual variations better.

Over the eastern USA, the observed $\mathrm{NO}_{2}$ concentration is high in 2005-2007 and low after 2008. The control run failed to reproduce these variations. In the reanalysis run, the model's negative bias is reduced in 2005-2007 compared with the OMI retrievals, showing a negative trend in the reanalysis period. The improvement is smaller for the SCIAMACHY and GOME-2 retrievals.

Despite the general improvement, the reanalysis still has large negative biases compared with the satellite retrievals over the polluted regions. There may be several reasons for the remaining underestimation of $\mathrm{NO}_{2}$ concentrations. The analysis increment can partly be lost after the forecast because of the short lifetime of $\mathrm{NO}_{x}$ (Miyazaki and Eskes, 2013), especially when concentrations are adjusted. Other model processes, such as the diurnal cycle, boundary layer mixing and venting, and the chemical equilibrium at overpass, may not be described well. Also, the averaging kernels show a relatively small sensitivity close to the surface, resulting in relatively smaller adjustments in the assimilation. The remaining bias varied considerably with season (e.g. the bias is mostly absent during summer over East China and the eastern USA), whereas the eight series of 1-year calculations were conducted separately. Therefore, the remaining underestimation of $\mathrm{NO}_{2}$ concentrations did not cause (spurious) gradual intra-annual and year-to-year increases in the estimated surface $\mathrm{NO}_{x}$ emissions during the reanalysis period 

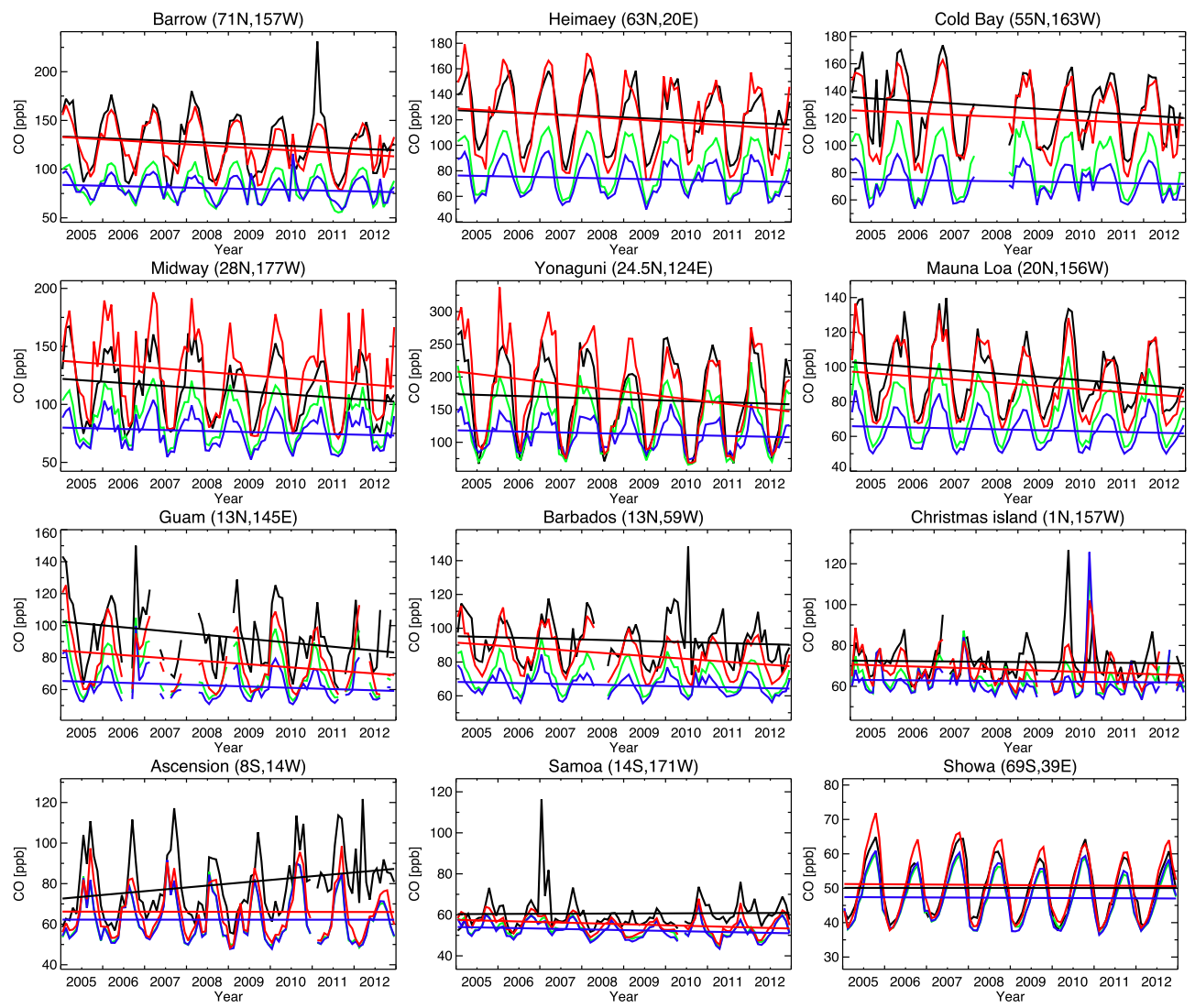

Figure 11. Time series of monthly mean CO concentration obtained from the WDCGG ground measurements (black), control run (blue), and reanalysis (red). Model simulation results with the HTAP emissions are also plotted (green).

Table 5. Comparisons of global tropospheric $\mathrm{NO}_{2}$ columns between the control run and the satellite retrievals in brackets, and between the reanalysis run and the satellite retrievals: OMI for 20052012, SCIAMACHY for 2005-2011, and GOME-2 for 2007-2012. $\mathrm{S}$-Corr is the global spatial correlation coefficient. The bias represents the control run or reanalysis minus the retrievals. The averaging kernel of each retrieval is applied to the control run and the reanalysis. The units for the RMSE and bias are $10^{15}$ molec $\mathrm{cm}^{-2}$.

\begin{tabular}{lccc}
\hline & OMI & SCIAMACHY & GOME-2 \\
\hline S-Corr & 0.970 & 0.916 & 0.924 \\
& $(0.931)$ & $(0.862)$ & $(0.881)$ \\
\hline Bias & -0.048 & -0.091 & -0.185 \\
& $(-0.122)$ & $(-0.162)$ & $(-0.256)$ \\
\hline RMSE & 0.383 & 0.946 & 0.847 \\
& $(0.533)$ & $(1.102)$ & $(0.990)$ \\
\hline
\end{tabular}

(cf. Sect. 6.1). The larger discrepancies with respect to the SCIAMACHY and GOME-2 retrievals may be attributed to the errors in the simulated diurnal $\mathrm{NO}_{2}$ variations and a bias between OMI and these retrievals. Both the emission factors and the tropospheric concentrations of $\mathrm{NO}_{x}$ are constrained primarily in the early afternoon by OMI, whereas no direct observational constraint on tropospheric $\mathrm{NO}_{x}$ is available in the morning (i.e. during the SCIAMACHY and GOME-2 overpass time).

Over North and Central Africa, the data assimilation removes most of the negative bias throughout the year because of the increased biomass-burning emissions. The remaining negative bias in the reanalysis is relatively large when compared with the GOME-2 over North Africa and with SCIAMACHY and GOME-2 over Central Africa. The observed concentration is relatively small in 2010-2012 over North Africa, and the reanalysis captures the observed interannual variations better compared with the control run.

The control run fails to reproduce the observed distinct seasonal and interannual variations over Southeast Asia $(r=$ $0.74-0.79$ in the control run and $r=0.89-0.98$ in the reanalysis compared with the three retrievals). The control run underestimates the concentration throughout the year with the largest biases in boreal spring in 2008-2009. The negative bias is greatly reduced in the reanalysis throughout the year, and the interannual variations are represented realistically. The remaining negative bias is large, especially when compared with the GOME-2 retrievals. 


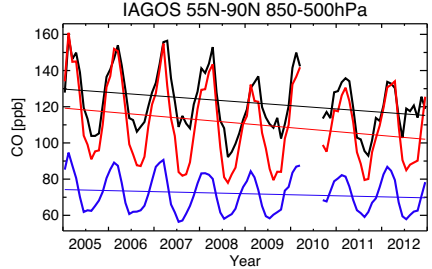
IAGOS $15 \mathrm{~N}-55 \mathrm{~N} 850-500 \mathrm{hPa}$
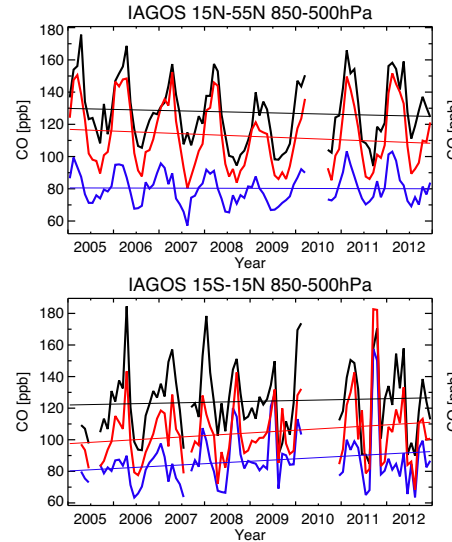
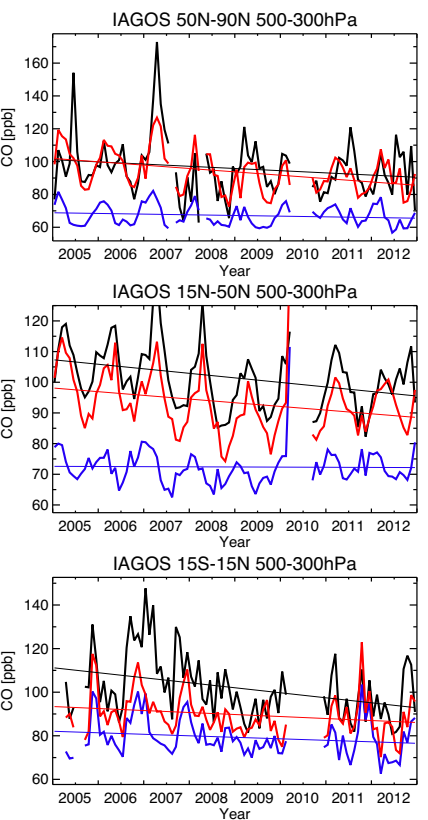

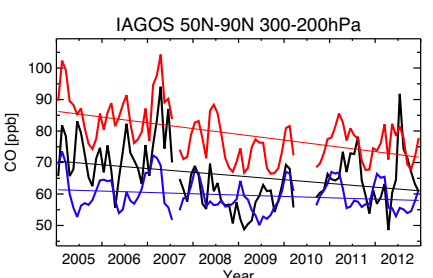

IAGOS 15N-50N 300-200hPa
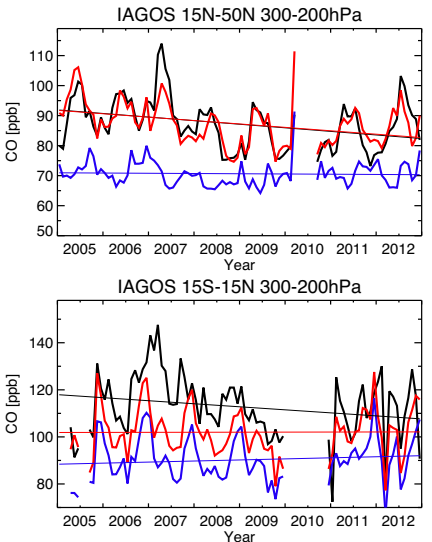

Figure 12. Same as in Fig. 8, but for CO concentration obtained from MOZAIC/IAGOS aircraft measurements.

\subsubsection{Aircraft}

Compared with the vertical $\mathrm{NO}_{2}$ profiles from the aircraft measurements, the simulated $\mathrm{NO}_{2}$ concentration in the troposphere is generally too low (Fig. 10). For the ARCTAS profiles, the data assimilation has less impact in the troposphere. At high latitudes, the surface $\mathrm{NO}_{x}$ emissions have only a small effect on the tropospheric $\mathrm{NO}_{2}$ profiles, and the observational error of the OMI measurements is large in comparison with the observed low concentration. Compared with the two DC3 profiles, the model is too high in the lower troposphere and too low in the middle/upper troposphere. Data assimilation further increases the positive bias in the lower troposphere. The relatively coarse resolution of the model could cause large differences near the surface for comparisons at urban sites such as the DC3 profiles. Compared with the DISCOVER-AQ profile, the rapid change in $\mathrm{NO}_{2}$ concentration in the lower troposphere is captured well by both the model and the reanalysis. The MLS $\mathrm{O}_{3}$ and $\mathrm{HNO}_{3}$ data assimilation effectively corrects the amount of $\mathrm{NO}_{2}$ in the lower stratosphere, especially for the ARCTAS-A profile, because of the use of the interspecies correlation in the analysis step and by influencing the $\mathrm{NO}_{x} / \mathrm{NO}_{y}$ species in the forecast step.

\subsection{Other reactive species}

The observed main features of the $\mathrm{HNO}_{3}$ profiles are captured by both the control and reanalysis runs. The increase in $\mathrm{HNO}_{3}$ toward the surface is driven mainly by oxidation of $\mathrm{NO}_{x}$ in polluted areas, which is visible in the INTEX-B, ARCTAS-B, DC3-DC8, DC3-GV, and DISCOVER-AQ pro- files. The positive corrections by assimilation, primarily attributable to the increased $\mathrm{NO}_{2}$ concentration and $\mathrm{NO}_{x}$ emissions, reduce the model's underestimation for the DC3-GV profile, but led to concentrations that are too high for the INTEX-B, DC3-DC8, DC3-GV, and DISCOVER-AQ profiles. The assimilation only slightly influences the tropospheric $\mathrm{HNO}_{3}$ concentration for the ARCTAS profiles because of the negligible impact of surface $\mathrm{NO}_{x}$ emissions at $\mathrm{NH}$ high latitudes and because of the absence of $\mathrm{HNO}_{3}$ measurements for the troposphere. To further improve the lower-tropospheric $\mathrm{HNO}_{3}$ concentrations, corrections for its removal processes including depositions might be important. In the middle and upper troposphere, both the control and reanalysis runs generally underestimate $\mathrm{HNO}_{3}$ concentration. The assimilation partly reduces the negative bias for the DC3 profiles. Additional positive increments of $\mathrm{NO}_{2}$ appear to be required in order to compensate for the negative bias in $\mathrm{HNO}_{3}$. In the UTLS, the model $\mathrm{HNO}_{3}$ negative bias is reduced globally in the reanalysis because of the MLS assimilation. For the ARCTAS profiles, Liang et al. (2011) and Wespes et al. (2012) found that an adequate representation of stratospheric $\mathrm{NO}_{y}$ inputs is important for the accurate simulation of tropospheric Arctic $\mathrm{O}_{3}$ and $\mathrm{NO}_{x}$ at pressures $<400 \mathrm{hPa}$.

The vertical $\mathrm{HO}_{2}$ profile mainly reflects variations in water vapour concentrations in the troposphere, which decrease with latitude. The control run overestimates the tropospheric $\mathrm{HO}_{2}$ concentration for the INTEX-B and ARCTAS-A profiles but underestimates it for the ARCTAS-B, DC3-DC8, and $\mathrm{DC} 3-\mathrm{GV}$ profiles. The reanalysis generally increases $\mathrm{HO}_{2}$ concentrations, while it decreases $\mathrm{OH}$ concentration. 

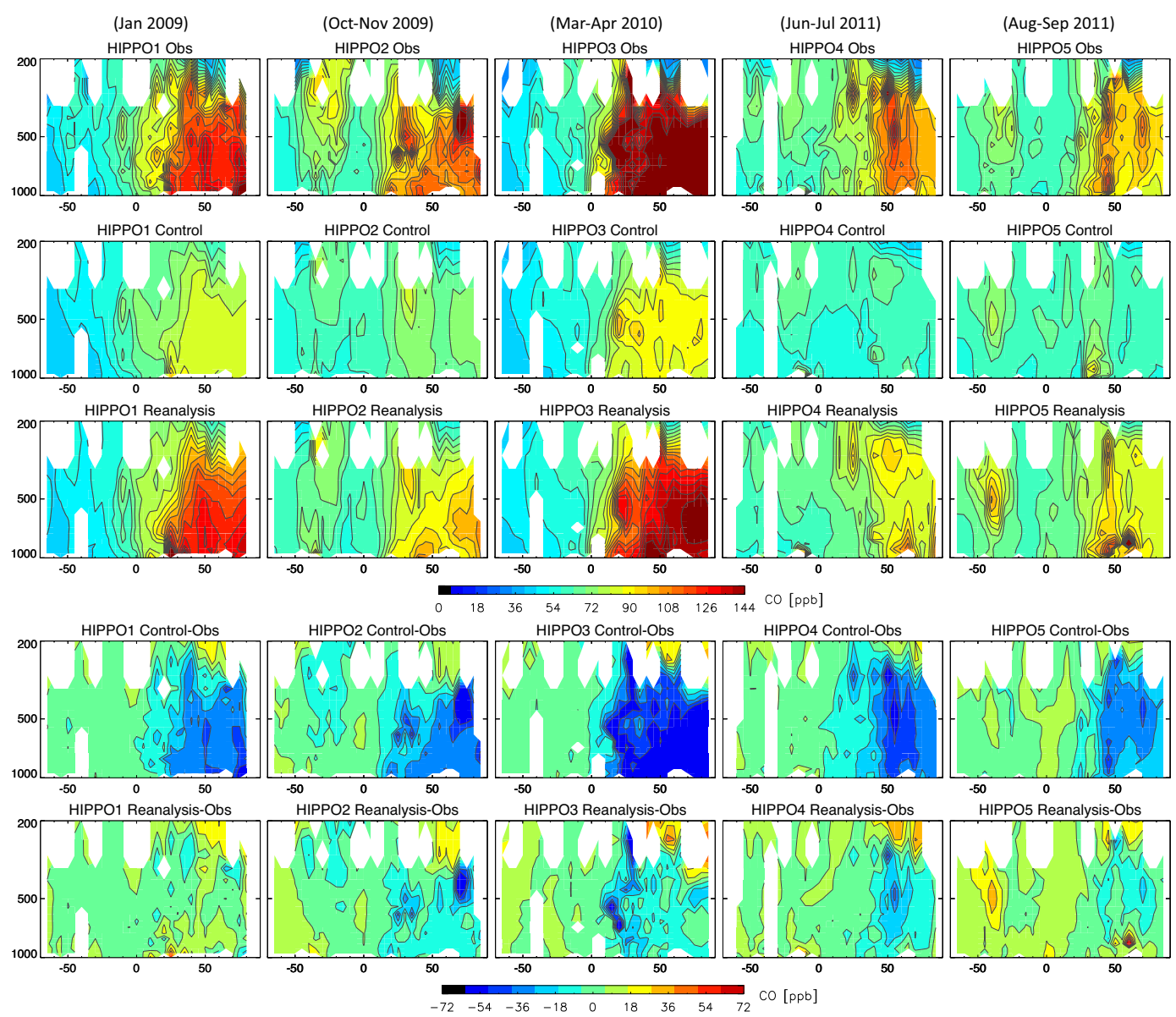

Figure 13. Same as in Fig. 9, but for $\mathrm{CO}$ concentration (in ppb, from first to third row) and its absolute difference (in ppb, from fourth to fifth row) obtained from HIPPO aircraft measurements.

The reaction of $\mathrm{OH}$ with $\mathrm{CO}$ converts $\mathrm{OH}$ into $\mathrm{HO}_{2}$. Because of the increased $\mathrm{CO}$ concentration, the assimilation increases the production of $\mathrm{HO}_{2}$ in the $\mathrm{NH}$. On the other hand, the $\mathrm{HO}_{2} / \mathrm{OH}$ ratio should decrease because of $\mathrm{NO}_{x}$ increases, which enhances the $\mathrm{NO}+\mathrm{HO}_{2}$ and $\mathrm{NO}_{2}+\mathrm{HO}_{2}$ reactions. Further increase in $\mathrm{NO}_{x}$ concentration is expected to reduce the $\mathrm{HO}_{2}$ overestimation for the INTEX-B and ARCTASA profiles. Errors in the removal of $\mathrm{HO}_{2}$ by wet deposition processes might also cause biased concentrations.

Both the control and reanalysis runs overestimate the $\mathrm{OH}$ concentration in the troposphere for the INTEX-B profile, but they underestimate it for the ARCTAS and DC3 profiles. Data assimilation generally decreases the $\mathrm{OH}$ concentration in the NH extratropics for the ARCTAS and DC3 profiles, corresponding to the increased concentration of $\mathrm{CO}$. For the INTEX-B profile, the data assimilation increases $\mathrm{OH}$ and $\mathrm{O}_{3}$ in the lower part of the troposphere because of the increased $\mathrm{NO}_{x}$ emissions compensating for the decrease due to $\mathrm{CO}$. Errors in the simulated $\mathrm{H}_{2} \mathrm{O}$ could also influence the performance of the simulation of $\mathrm{OH}$ and $\mathrm{HO}_{x}$. Furthermore, large uncertainty in observed $\mathrm{OH}$ concentrations also remains an important issue (e.g. Heard and Pilling, 2003; Stone et al., 2012).

The model captures the observed $\mathrm{CH}_{2} \mathrm{O}$ profiles in the troposphere well, but it generally underestimates the concentration. The reanalysis generally increases the $\mathrm{CH}_{2} \mathrm{O}$ concentration and reduces the negative bias of the model. However, its influence on the concentrations is small because of the lack of any direct measurement and the neglect of any interspecies correlation with $\mathrm{CH}_{2} \mathrm{O}$ in the reanalysis framework. Therefore, additional constraints from satellite measurements are required. Optimising isoprene emissions from $\mathrm{CH}_{2} \mathrm{O}$ measurements will be an important development (cf. Sect. 7.7).

Generally, these results reveal the positive benefit of the assimilation of multiple-species data with different sensitivities on the analysis of unobserved species profiles in the troposphere and lower stratosphere. In particular, constraints obtained for the $\mathrm{OH}$ profiles have a large potential to influence the chemistry of the entire troposphere (cf. Sect. 7.4.2). However, many factors determine the overall analysis performance, such as chemical reaction rates, deposition rates, 

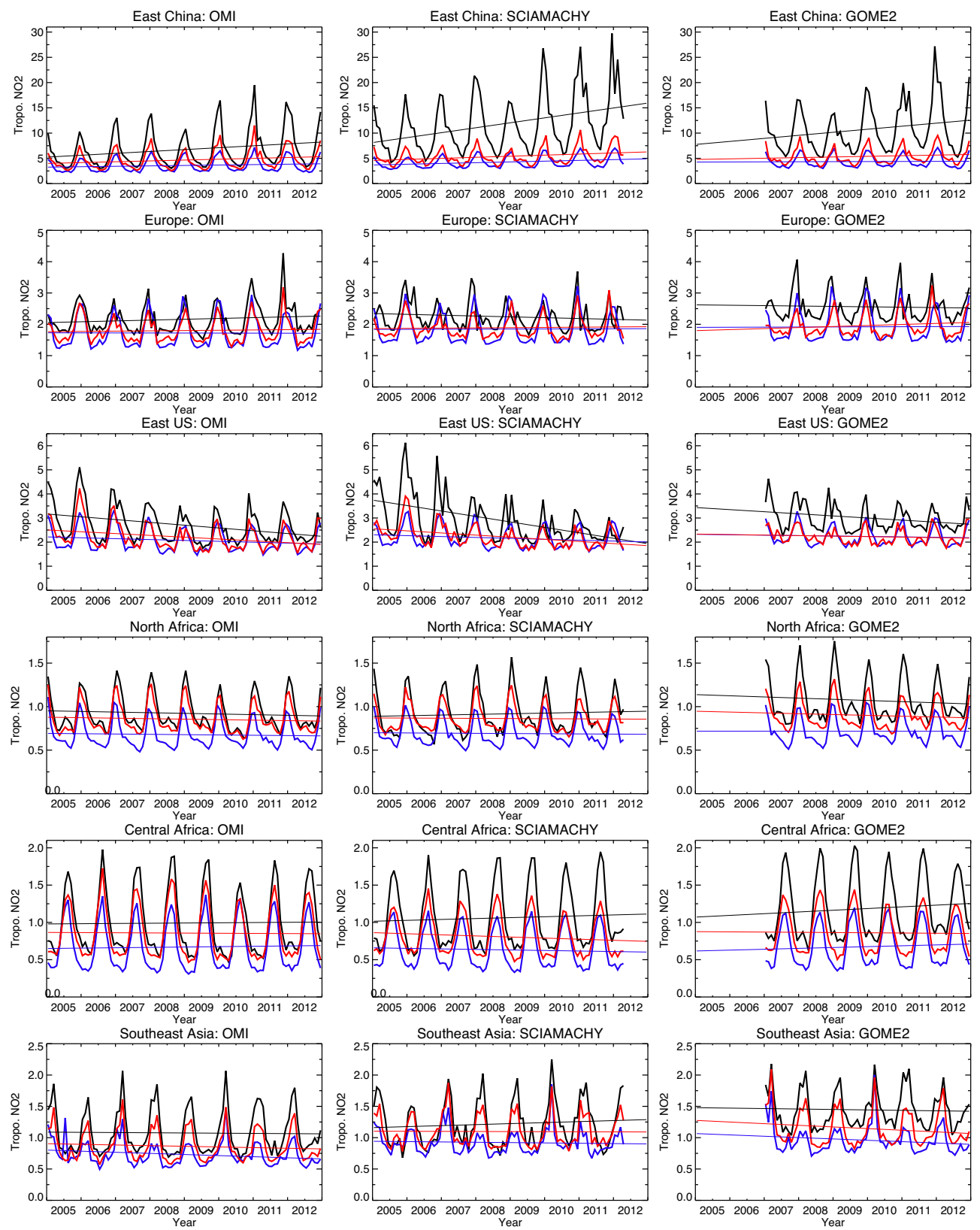

Figure 14. Time series of regional monthly mean tropospheric $\mathrm{NO}_{2}$ columns $\left(\right.$ in $10^{15}$ molec $\mathrm{cm}^{-2}$ ) averaged over eastern China $\left(110-123^{\circ} \mathrm{E}\right.$, $\left.30-40^{\circ} \mathrm{N}\right)$, Europe $\left(10^{\circ} \mathrm{W}-30^{\circ} \mathrm{E}, 35-60^{\circ} \mathrm{N}\right)$, the eastern United States $\left(71-95^{\circ} \mathrm{W}, 32-43^{\circ} \mathrm{N}\right)$, North Africa $\left(20^{\circ} \mathrm{W}-40^{\circ} \mathrm{E}\right.$, Equator $\left.-20^{\circ} \mathrm{N}\right)$, Central Africa $\left(10-40^{\circ} \mathrm{E}\right.$, Equator- $\left.20^{\circ} \mathrm{S}\right)$, Southeast Asia $\left(96-105^{\circ} \mathrm{E}, 10-20^{\circ} \mathrm{N}\right)$ obtained from the satellite retrievals (black), control run (blue), and reanalysis (red). Results are shown for the OMI retrievals (left columns), SCIAMACHY retrievals (centre columns), and GOME-2 retrievals (right columns).

and atmospheric transports, which are hardly optimised by the currently available measurements.

\section{Estimated emissions}

In previous publications (Miyazaki and Eskes, 2013; Miyazaki et al., 2014) we demonstrated that the simultane- ous analysis of chemical concentrations and emissions improves the estimate of surface $\mathrm{NO}_{x}$ emissions and $\mathrm{LNO}_{x}$ sources, with differences of up to $58 \%$ in regional surface $\mathrm{NO}_{x}$ emissions. The analysis increment produced directly via the chemical concentrations plays an important role in reducing the model-observation mismatches that arise from model errors other than those related to emissions. Here we describe the estimated emissions briefly. Further detailed 
analyses of the 8-year variations in the estimated emission sources will be discussed in a separate paper.

\subsection{Surface $\mathrm{NO}_{x}$ emissions}

The time series and global distributions of the analysed emission sources obtained during the reanalysis period are depicted in Figs. 15 and 16, respectively. The data assimilation increases the 8-year mean of global total surface $\mathrm{NO}_{x}$ emissions from 38.4 to $42.2 \mathrm{Tg} \mathrm{N}$. The approximate $10 \%$ increase in global total emissions is attributable to an approximately $7 \%$ increase in the $\mathrm{NH}\left(20-90^{\circ} \mathrm{N}\right)$ and a $14 \%$ increase in the tropics $\left(20^{\circ} \mathrm{S}-20^{\circ} \mathrm{N}\right)$. The large increase in the $\mathrm{NH}$ emissions is associated with positive corrections over industrial areas such as China and India, and with corrections in Europe and the USA. Meanwhile, the increased emissions over Central Africa indicate larger emissions from biomass burning than shown by the inventories. These needed adjustments were commonly revealed by referring to our previous estimates for 2007 (Miyazaki and Eskes, 2013). The seasonal and interannual variability is also modified considerably in many regions. The emission inventories exhibit considerable uncertainties in representing seasonal and interannual emission variabilities associated with uncertain input information, such as economic conditions, biomass-burning activity, and emission factors (e.g. Jaeglé et al., 2005; Xiao et al., 2010; Reuter et al., 2014). For instance, the anthropogenic emissions were reported on a yearly basis, and thus seasonal variability in anthropogenic emissions such as from wintertime heating of buildings (e.g. Streets et al., 2003) was not considered in the a priori emissions. Wang et al. (2007) also suggested that the emission inventories largely underestimate soil emissions by a factor of 2-3 at NH mid-latitudes during summer. The assumptions applied to the a priori emissions (cf. Sect. 2.1; for example, the anthropogenic emissions for 2008 are used in the estimations for 2009-2012) also cause an unrealistic lack of interannual variability in the a priori emissions and lead to significant differences between the a priori and a posteriori emissions.

\section{2 $\mathrm{LNO}_{x}$ sources}

The average yearly global flash rate obtained for the reanalysis period 2005-2012 was 45.3 flashes $^{-1}$, which is comparable with climatological estimates of 46 flashes s $^{-1}$ derived from Lightning Imaging Sensor (LIS) and Optical Transient Detector (OTD) measurements (Cecil et al., 2014). The $\mathrm{LNO}_{x}$ shows large discrepancies between the control and reanalysis runs. The mean annual global total $\mathrm{LNO}_{x}$ source in the reanalysis run is estimated at $6.4 \mathrm{Tg} \mathrm{N}$ for 2005-2012 and 6.0 Tg N for 2005-2009, which is about 24 and $18 \%$ higher than estimated from the parameterisation (5.1 Tg N for both 2005-2009 and 2005-2012), respectively. The analysed $\mathrm{LNO}_{x}$ sources show a positive slope during 2005-2012 (+3.8\% \pm 4.2 year $\left.^{-1}\right)$ and enhanced sources
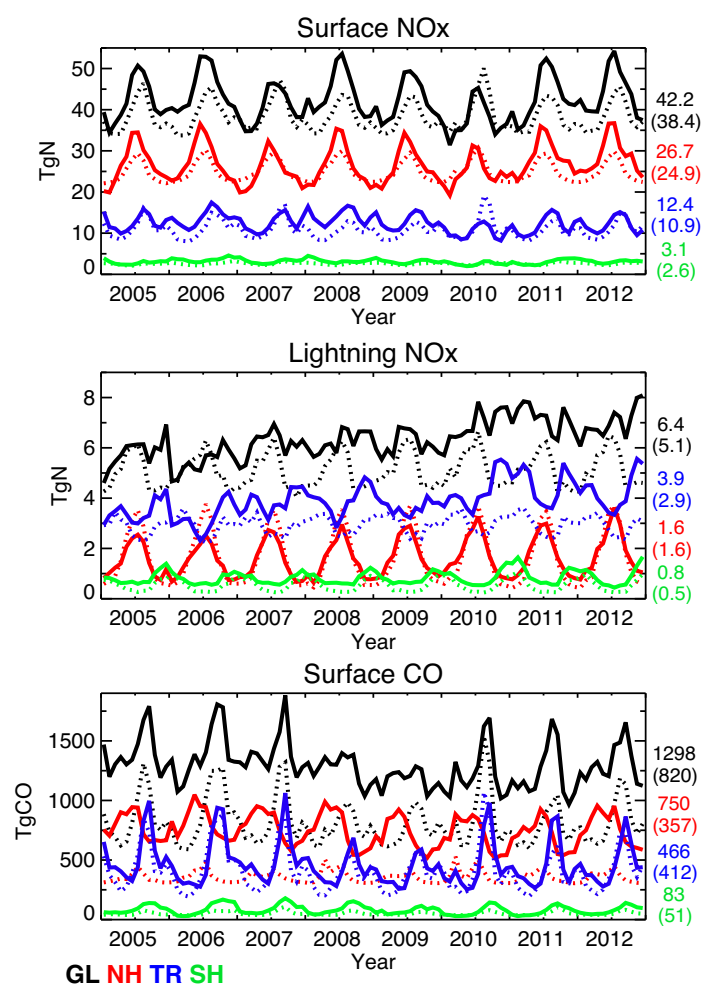

Figure 15. Time series of monthly total global and regional surface $\mathrm{NO}_{x}$ emissions (in $\mathrm{TgNyr}^{-1}$, top), $\mathrm{LNO}_{x}$ emissions (in $\mathrm{TgNyr}^{-1}$, centre), and surface $\mathrm{CO}$ emissions (in $\mathrm{TgCO}^{-1}$, bottom) obtained from the reanalysis (solid lines) and the emission inventories or the control run (dashed lines) over the globe $\left(90^{\circ} \mathrm{S}-90^{\circ} \mathrm{N}\right), \mathrm{NH}$ $\left(20-90^{\circ} \mathrm{N}\right)$, tropics $\left(\mathrm{TR}, 20^{\circ} \mathrm{S}-20^{\circ} \mathrm{N}\right)$, and SH $\left(90-20^{\circ} \mathrm{S}\right)$. The 8year mean emissions values obtained from the reanalysis run and the emission inventories (in bracket) are shown on the right-hand side.

during 2010-2012. From a sensitivity reanalysis calculation that was performed by removing the TES measurements for 2005, we conclude that the large increase in 2010-2012 is at least partly introduced artificially because of the lack of constraints from the TES measurements. The TES data assimilation generally tends to decrease the global $\mathrm{LNO}_{x}$ amount in the simultaneous assimilation framework (the global total $\mathrm{LNO}_{x}$ source in 2005 is 5.8 and $6.6 \mathrm{Tg} \mathrm{N}$ when estimated with and without the TES measurements, respectively). For the period 2005-2009, when the assimilated measurement density is nearly constant, the analysed $\mathrm{LNO}_{x}$ variability is considered to be induced by variations in convective activity, thunderstorm type, and cloud distributions. The positive slope $\left(+3.1 \% \pm 4.2\right.$ year $\left.^{-1}\right)$ obtained for the period 20052009 in the reanalysis implies that variations in such processes led to the $\mathrm{LNO}_{x}$ sources increase. The increase in the global $\mathrm{LNO}_{x}$ sources for the period 2005-2009 is attributed to large increases over North Africa $\left(+5.7 \% \pm 26.8\right.$ year $\left.^{-1}\right)$, South America $\left(+3.2 \% \pm 22.0\right.$ year $\left.^{-1}\right)$, and the Atlantic Ocean $\left(+7.4 \% \pm 11.5\right.$ year $\left.^{-1}\right)$. Further detailed analyses are 

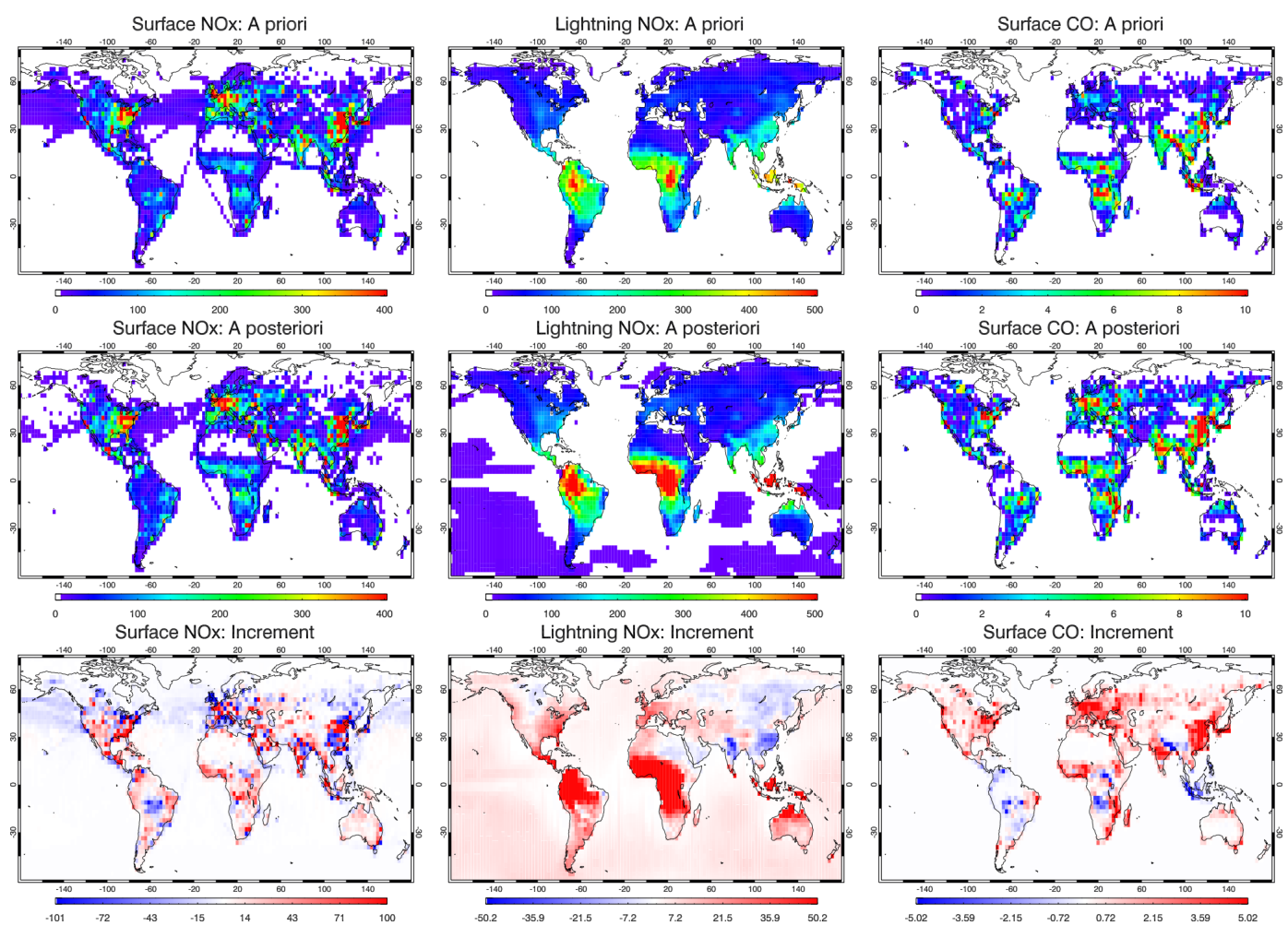

Figure 16. Global distributions of surface $\mathrm{NO}_{x}$ emissions (in $10^{-13} \mathrm{~kg} \mathrm{~m}^{-2} \mathrm{~s}^{-1}$ ) (left column), $\mathrm{LNO}_{x}$ sources (in $10^{-14} \mathrm{~kg} \mathrm{~m}^{-2} \mathrm{~s}^{-1}$ ) (centre column), and surface CO emissions (in $10^{-10} \mathrm{~kg} \mathrm{~m}^{-2} \mathrm{~s}^{-1}$ ) (right column) averaged over 2005-2012. The a priori emissions (upper row), a posteriori emissions (middle row), and analysis increment (lower row), i.e. the difference between the a posteriori and the a priori emissions, are shown for each panel.

required in order to understand the possible causal mechanisms.

The global $\mathrm{LNO}_{x}$ amount in the reanalysis $(6.15 \mathrm{Tg} \mathrm{N})$ for 2007 is in agreement with our previous estimate $(6.31 \mathrm{Tg} \mathrm{N})$ for the same year (Miyazaki et al., 2014). However, because the tuning factor applied for the global total flash frequency is about $10 \%$ larger than in the previous estimate based on the recent climatological estimates (Cecil et al., 2014), the analysis increment can be different between the two estimates. For instance, the positive increment for 2007 is smaller or becomes negative over Siberia, Southeast Asia, and South America in the reanalysis. Note that the global structure of the analysis increment is generally similar between 2007 (figure not shown) and the 8-year reanalysis mean. Meanwhile, the seasonal variation in the tropical $\mathrm{LNO}_{x}$ sources is modified more significantly in the reanalysis than in the previous estimate. In the reanalysis, the observational information is accumulated during the consequent 1-year calculation after a 2-month spin-up, while continuously correcting the $\mathrm{LNO}_{x}$ source factors. In the previous estimate (Miyazaki et al., 2014), the $\mathrm{LNO}_{x}$ sources were estimated from shorter data assimilation calculations (i.e. twelve 1-month calculations were conducted after a 15-day spin-up).

\subsection{Surface CO emissions}

The 8-year mean of global total emissions of $\mathrm{CO}$ is increased by $36 \%$ by data assimilation ( $1298 \mathrm{Tg} \mathrm{CO}$ vs. $820 \mathrm{Tg} \mathrm{CO})$, attributable mainly to an approximately $110 \%$ increase in the $\mathrm{NH}$. The increase in the total $\mathrm{CO}$ emission in the $\mathrm{NH}$ is large in the boreal late winter-spring period, especially over China and Europe. Stein et al. (2014) commonly found it necessary to adjust emissions seasonally, using regionally varying scaling factors with large corrections during winter-spring for industrialised countries. A similar seasonality in the adjustments is found in Fig. 15, whereas the seasonality in the NH is mostly absent in the a priori emissions. The positive increments for surface $\mathrm{CO}$ emissions are introduced by assimilation of MOPITT CO observations, whereas the assimilation of non- $\mathrm{CO}$ observations also affects the $\mathrm{CO}$ emission estimation via changes in $\mathrm{OH}$ concentrations. For instance, changes in surface $\mathrm{NO}_{x}$ emissions decreased tropospheric $\mathrm{OH}$ concentrations at $\mathrm{NH}$ mid-latitudes, and this in turn acted to increase the tropospheric $\mathrm{CO}$ concentrations; this is discussed further in Sect. 7.4.2. 
Table 6. Model-minus-observation comparison of mean $\mathrm{O}_{3}$ concentrations (in ppb) between the control/reanalysis calculations and the ozonesonde observations for 2005 in the $\mathrm{SH}\left(90-30^{\circ} \mathrm{S}\right)$, TR $\left(30^{\circ} \mathrm{S}-30^{\circ} \mathrm{N}\right)$, and $\mathrm{NH}\left(30-90^{\circ} \mathrm{N}\right)$. Sensitivity reanalysis calculations were conducted by excluding the emission factors from the state vector (w/o emission), with TES $\mathrm{O}_{3}$ bias correction (TES-bias), without assimilation of TES measurements (w/o TES), and with HTAP-v2 emission inventories for 2008 as the a priori surface emissions (HTAP).

\begin{tabular}{|c|c|c|c|c|c|c|c|c|c|}
\hline & \multicolumn{3}{|c|}{$850-500$} & \multicolumn{3}{|c|}{$500-200$} & \multicolumn{3}{|c|}{ 200-90 } \\
\hline & $\mathrm{SH}$ & TR & $\mathrm{NH}$ & $\mathrm{SH}$ & TR & $\mathrm{NH}$ & SH & $\mathrm{TR}$ & $\mathrm{NH}$ \\
\hline Control & -0.8 & -0.6 & -3.5 & 27.9 & -2.3 & -1.4 & 195.9 & 18.0 & 72.1 \\
\hline Reanalysis & -2.3 & 1.0 & -2.3 & 3.0 & 0.4 & 0.9 & 27.3 & 4.6 & 13.2 \\
\hline w/o emission & -3.2 & -0.5 & -3.2 & 2.3 & -1.7 & -0.7 & 28.5 & 3.6 & 14.3 \\
\hline TES-bias & -4.4 & -0.1 & -4.9 & 0.7 & -0.4 & -2.7 & 25.4 & 4.8 & 13.2 \\
\hline w/o TES & -1.1 & 1.7 & -1.0 & 9.3 & 1.6 & 5.6 & 27.5 & 5.7 & 14.6 \\
\hline HTAP & -1.9 & 1.9 & 0.1 & 3.1 & 0.7 & 2.1 & 28.4 & 8.3 & 16.3 \\
\hline
\end{tabular}

\section{Discussion}

\subsection{Impact of emission analysis}

The impact of the emission optimisation on the tropospheric $\mathrm{O}_{3}$ analysis is evaluated based on comparison between the reanalysis run and a sensitivity calculation that excludes the emission factors for the surface emissions and $\mathrm{LNO}_{x}$ sources from the state vector. The emission optimisation influences the $\mathrm{O}_{3}$ concentrations with mean changes of about $15 \%$ in the tropics and $10 \%$ in the $\mathrm{NH}$ mid-latitudes in the lower troposphere. These changes improve the agreement with ozonesonde observations in the lower troposphere in both the $\mathrm{NH}$ and $\mathrm{SH}$ (reanalysis vs. w/o emission in Table 6), but not in the tropics. At the NH mid-latitudes the changes introduced by optimising the emission factors improve the agreement with the ozonesonde observation from April to August below about $500 \mathrm{hPa}$ (Fig. 17) associated with the pronounced $\mathrm{O}_{3}$ production caused by $\mathrm{NO}_{x}$ increases; the monthly mean positive bias below about $900 \mathrm{hPa}$ is reduced by $10-15 \%$ in the summer and the negative bias between 900 and $500 \mathrm{hPa}$ is reduced by $30-50 \%$ in spring and summer. Vertical transport of $\mathrm{O}_{3}$ and its precursors propagate the variations in surface emissions into the free troposphere, whereas the $\mathrm{LNO}_{x}$ source optimisation improves the performance of the upper-tropospheric $\mathrm{O}_{3}$ simulation directly. The impact of the emission optimisation on the free troposphere is large throughout the year in the tropics.

The observed $\mathrm{O}_{3}$ concentration in the $\mathrm{NH}$ mid-latitude between 850 and $500 \mathrm{hPa}$ increased from 2005 to 2010 $\left(+2.3 \mathrm{ppb}(5 \text { years })^{-1}\right)$; the positive slope is represented in the reanalysis run $\left(+1.0 \mathrm{ppb}(5 \text { years })^{-1}\right)$, whereas a case without emission source optimisation (w/o emission) shows a negative slope $\left(-1.1 \mathrm{ppb}(5 \text { years })^{-1}\right)$. These results imply that the simultaneous optimisation approach improves the concentrations and emissions in the model and produces high-quality multiple-year reanalysis data for tropospheric $\mathrm{O}_{3}$ profiles.
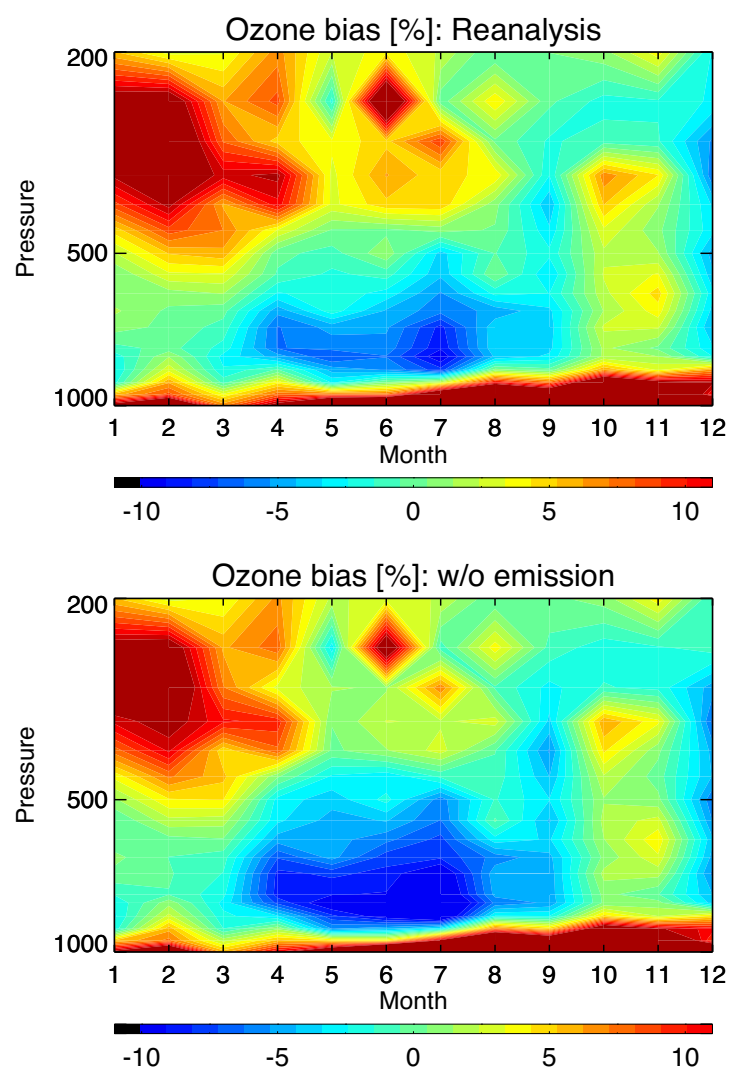

Figure 17. Month-pressure cross section of the zonal mean bias of $\mathrm{O}_{3}$ concentration (in \%) compared with the ozonesonde observations averaged over $30-60^{\circ}$ for the reanalysis run (top) and the sensitivity experiment that excludes the emission factors from the state vector (w/o emission, bottom).

\subsection{Biases in the observations}

TES $\mathrm{O}_{3}$ retrievals are known to have positive bias compared with ozonesonde observations in the troposphere (e.g. Herman and Osterman, 2012; Verstraeten et al., 2013). Based on systematic comparisons with ozonesonde observations, Ver- 
straeten et al. (2013) determined that the upper and lower troposphere mean biases range from -0.4 to +13.3 and +3.9 to $+6.0 \mathrm{ppb}$, respectively. In the reanalysis described in this paper we did not apply a bias correction to TES because of the difficulty in estimating the bias structure that possibly varies temporally and spatially in the reanalysis period. We tested a bias correction scheme with a linear concentration-bias relationship, in which the slope and intercept estimated by Verstraeten et al. (2013) for five latitudinal bands of the upper troposphere (above $464 \mathrm{hPa}$ ), at $464 \mathrm{hPa}$, and for the lower troposphere (below $464 \mathrm{hPa}$ ) were interpolated in log pressure to the model's vertical layers. For the Arctic lower troposphere, a constant bias of $1.1 \mathrm{ppb}$ was assumed because of the very small correlation found by Verstraeten et al. (2013). A sensitivity calculation for the year 2005 with the TES bias correction (TES-bias in Table 6) shows reductions in the positive $\mathrm{O}_{3}$ bias in the tropical lower and middle troposphere against the ozonesonde observations. Conversely, in the $\mathrm{NH}$ mid- and high latitudes, the mean negative $\mathrm{O}_{3}$ bias in the lower and middle troposphere increases. Because the bias was assumed constant with time, the representation of the interannual $\mathrm{O}_{3}$ variation between 2005 and 2010 was not improved by applying the TES bias correction.

In the CHASER-DAS data assimilation approach, the $\mathrm{O}_{3}$ analysis bias is not solely determined by bias in the assimilated $\mathrm{O}_{3}$ measurements. A sensitivity experiment without the assimilation of TES measurements (w/o TES in Table 6) shows improvements in the lower and middle-tropospheric $\mathrm{O}_{3}$ in the $\mathrm{NH}$ extratropics compared with the control run, demonstrating that the use of measurements other than TES measurements led to corrections in the lower- and middletropospheric $\mathrm{O}_{3}$. The additional use of the TES $\mathrm{O}_{3}$ measurements further improved the $\mathrm{O}_{3}$ analysis in most cases (see Table 6).

\subsection{Satellite data availability}

Any discontinuities in the availability and coverage of the assimilated measurement will affect the quality of the reanalysis and estimated interannual variability. In particular, the number of assimilated TES $\mathrm{O}_{3}$ retrievals decreases after 2010 through 2012, while approximately half of the OMI retrieval pixels per orbit are compromised since December 2009. Correspondingly, the data assimilation performance, as measured from the data assimilation statistics (Sect. 4) and comparisons against the independent observations (Sect. 5), became worse after 2010 in the $\mathrm{NH}$. The lack of direct $\mathrm{O}_{3}$ measurements and the reduced constraints from the precursor (i.e. $\mathrm{NO}_{2}$ ) measurements will degrade the $\mathrm{O}_{3}$ analysis in the $\mathrm{NH}$ after 2010, and will also limit the evaluation of the analysis uncertainties (cf. Sect. 7.6) and may cause spurious interannual changes and trends. Changes in the observing system thus limit the usability of the reanalysis for long-term variability studies.

\subsection{Model bias}

\subsubsection{A priori emissions}

The choice of the a priori emissions will influence the reanalysis result. To study the sensitivity of the reanalysis to the a priori settings, emissions obtained from EDGARHTAP v2 (http://edgar.jrc.ec.europa.eu/htap_v2/index.php? SECURE $=123$ ) for the years 2008 and 2010 were alternatively used as a priori anthropogenic $\mathrm{NO}_{x}$ and $\mathrm{CO}$ emissions in the calculation for 2005 and 2010, respectively (the inventory was not provided for 2005 at the time of this study). EDGAR-HTAP v2 was produced using nationally reported emissions combined with regional scientific inventories from the European Monitoring and Evaluation Programme (EMEP), Environmental Protection Agency (EPA), Greenhouse gas-Air Pollution Interactions and Synergies (GAINS), and Regional Emission Inventory in Asia (REAS). The model simulation using the a priori emissions, constructed based on the EDGAR v4 and GFED v3 emissions, shows significant underestimations in tropospheric $\mathrm{CO}$ concentrations, as in most of the CTMs (e.g. Stein et al., 2014), and this underestimation is large over urban sites in the $\mathrm{NH}$ (Sect. 5.2). The global CO emissions of EDGAR-HTAP v2 inventory are about $20 \%$ higher than the a priori emissions. Using the EDGAR-HTAP v2 emissions instead of the a priori emissions means that the negative bias in the simulated surface $\mathrm{CO}$ concentration could be reduced by about $20-40 \%$ in the tropics and the $\mathrm{NH}$ extratropics as is shown by the green lines in Fig. 11. The error reduction is large in winter-spring and small in summer in the $\mathrm{NH}$, whereas it is mostly negligible in the SH.

Despite the large differences in the simulated concentration, the choice of a priori emissions has only slight influence on the a posteriori $\mathrm{CO}$ concentrations and emissions. The annual global total emission is $1398 \mathrm{Tg}$ CO in the case with the EDGAR v4 and GFED v3 emissions and $1360 \mathrm{Tg} C \mathrm{CO}$ with the HTAP v2 emissions in 2005.

The $\mathrm{O}_{3}$ analysis is only slightly influenced by the choice of a priori emissions (reanalysis vs. HTAP in Table 6), except that the agreement against the ozonesonde observation is improved in the $\mathrm{NH}$ extratropics between 850 and $500 \mathrm{hPa}$ through use of the EDGAR HTAP v2 emissions. The changes are attributable to the slightly different a posteriori surface $\mathrm{CO}$ and $\mathrm{NO}_{x}$ emission (annual $\mathrm{NH}\left(20-90^{\circ} \mathrm{N}\right.$ ) total emission of $26.5 \mathrm{Tg} \mathrm{N}$ in the case of the EDGAR v4 and GFED v3 emissions, and $29.4 \mathrm{Tg} \mathrm{N}$ with the HTAP v2 emissions in 2005). The spatial distribution of the estimated $\mathrm{LNO}_{x}$ sources is also somewhat influenced by the choice of a priori surface emissions in the $\mathrm{NH}$ mid-latitudes (not shown), which led to differences in the agreement with the ozonesonde observation in the upper troposphere at $200 \mathrm{hPa}$. 

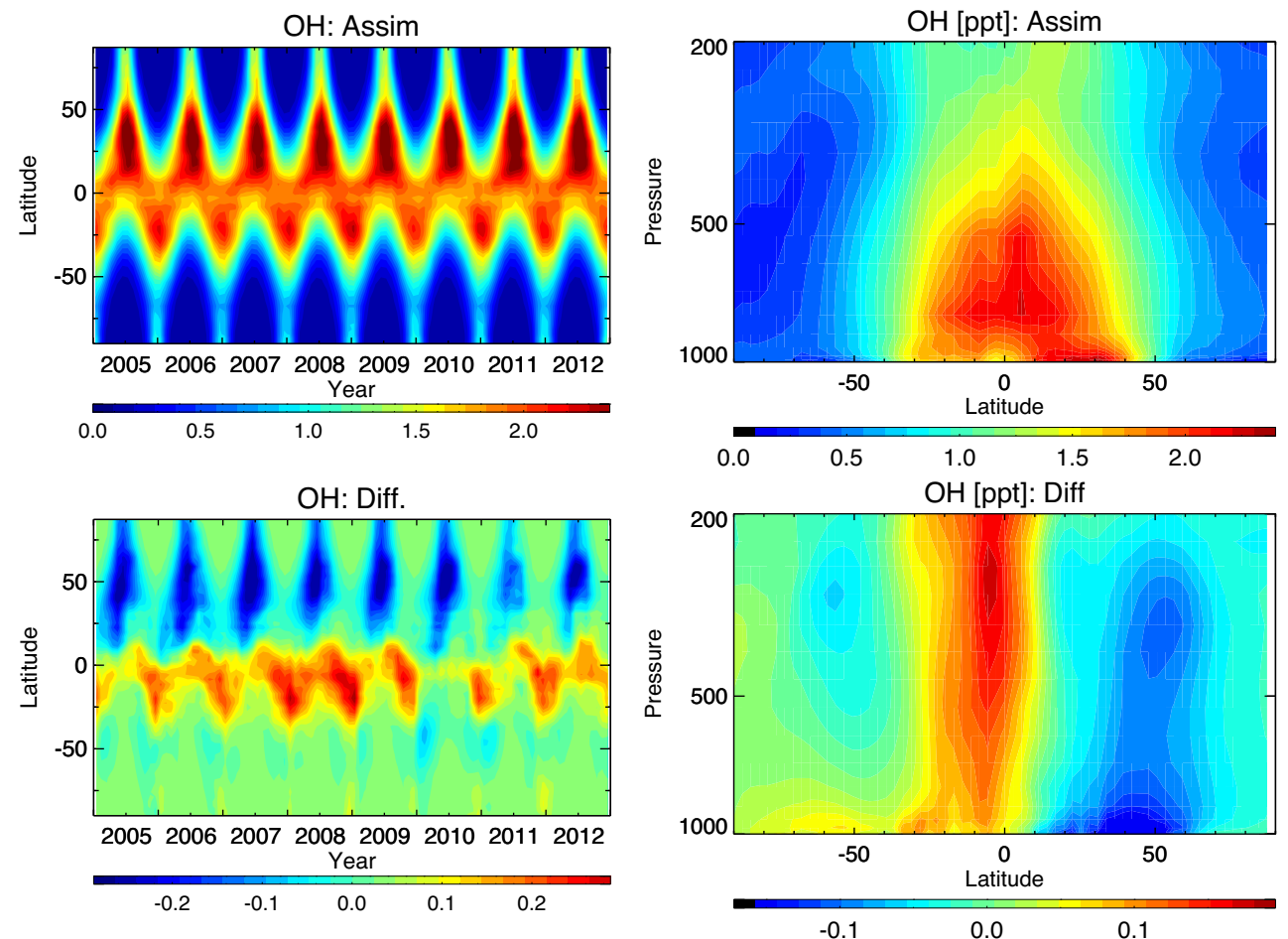

Figure 18. Latitude-pressure cross section of the 8-year mean $\mathrm{OH}$ concentration (right panels) and time-latitude cross section of the monthly mean $\mathrm{OH}$ concentration averaged between 1000 and $300 \mathrm{hPa}$ (left panels). The $\mathrm{OH}$ concentration obtained from the reanalysis (top panels) and the difference between the reanalysis and the control run (bottom panels) are also shown. Units are ppt.

\subsubsection{OH distribution}

$\mathrm{OH}$ is a key driver of the tropospheric chemical system as the processes leading to the removal of hydrocarbons from the atmosphere start with the reaction with $\mathrm{OH}$. However, its distribution is represented poorly in CTMs. Patra et al. (2014) estimated an $\mathrm{NH} / \mathrm{SH} \mathrm{OH}$ ratio of $0.97 \pm 0.12$ with the help of methyl chloroform observations (a proxy for $\mathrm{OH}$ concentrations), whereas the ratio was estimated at 1.26 in the CHASER control run. The simulated ratio from this study falls within the range $1.28 \pm 0.10$ in the ACCMIP (the Atmospheric Chemistry and Climate Model Intercomparison Project) (Naik et al., 2013). The concentration of OH is directly linked to the concentrations of species determining the primary production $\left(\mathrm{O}_{3}\right.$ and $\left.\mathrm{H}_{2} \mathrm{O}\right)$, removal $\left(\mathrm{CO}, \mathrm{CH}_{4}\right)$, and regeneration of $\mathrm{OH}\left(\mathrm{NO}_{x}\right)$. Because the CHASER-DAS system constrains $\mathrm{O}_{3}, \mathrm{CO}$, and $\mathrm{NO}_{x}$, this holds the promise of a positive impact on the modelled $\mathrm{OH}$ concentration, given that the reactions are reasonably well described by the model. The impact of the assimilation on $\mathrm{OH}$ is shown in Fig. 18.

The tropospheric $\mathrm{OH}$ concentration is decreased by the assimilation in the $\mathrm{NH}$ and increased in the SH tropics; these changes are primarily attributable to the increased concentration of $\mathrm{CO}$ and $\mathrm{O}_{3}$, respectively. From a sensitivity experiment in which the state vector was modified (either the emission factors or the concentrations were excluded from the state vector), we confirmed that the emission optimisation solely decreases the $\mathrm{OH}$ concentration in the $\mathrm{NH}$ troposphere, whereas both the concentration assimilation (mainly TES $\mathrm{O}_{3}$ ) and the emission optimisation (mainly $\mathrm{NO}_{x}$ emissions) increase the $\mathrm{OH}$ concentration in the tropics. The decrease in the tropospheric $\mathrm{OH}$ concentration in the $\mathrm{NH}$ is found throughout the reanalysis period, with the largest reductions of about $10 \%$ during boreal spring-summer, leading to about $2 \%$ decrease in the global annual mean $\mathrm{OH}$ concentration linked to $\mathrm{CO}$ increases in the $\mathrm{NH}$. Changes in surface $\mathrm{NO}_{x}$ emissions tend to decrease the annual mean tropospheric $\mathrm{OH}$ concentration in the $\mathrm{NH}$ mid-latitudes by about $3 \%$ and increase it in the tropics by about $5 \%$. The 8 -year mean $\mathrm{NH} / \mathrm{SH} \mathrm{OH}$ ratio is 1.18 in the reanalysis, which is smaller than the values of 1.26 in the control run and 1.28 in the ACCMIP; the value of 1.18 is closer to the observational estimate (0.97) of Patra et al. (2014). Because the chemical lifetimes of $\mathrm{NO}_{x}$ and $\mathrm{CO}$ are affected by the amount of $\mathrm{OH}$, these changes once more suggest the importance of the simultaneous optimisation of the concentration and emissions on the entire tropospheric chemical system and the emission estimates.

Although the methyl chloroform analysis in Patra et al. (2014) has considerable uncertainties, the large discrepancy between the analysis of Patra et al. (2014) and our estimate suggests that possible errors in the modelled $\mathrm{OH}$ could 
have had a negative influence on the reanalysis quality. If it is assumed that $\mathrm{OH}$ is overestimated in the $\mathrm{NH}$, then top-down emission estimates of reactive species such as $\mathrm{CO}$ in the $\mathrm{NH}$ could also be overestimated. Sensitivity calculations were conducted to investigate the influence of the remaining possible $\mathrm{OH}$ positive bias on the reanalysis results. In the sensitivity reanalysis calculations, a factor of 0.8 was applied to the chemical reaction rate in the calculation of the chemical reaction $\mathrm{CO}+\mathrm{OH} \rightarrow \mathrm{CO}_{2}+\mathrm{HO}_{2}$ for the $\mathrm{NH}$, in consideration of the obtained difference (1.18 vs. 0.97). Other chemical reaction rates were not adjusted so as to simplify interpretation of the calculations. In the sensitivity model calculation with reduced $\mathrm{OH}$, the model's $\mathrm{CO}$ negative bias is reduced by about $30-50 \%$ in the $\mathrm{NH}$. After assimilation with reduced $\mathrm{OH}$, the a posteriori annual total $\mathrm{CO}$ emissions become smaller by $15 \%$ in the $\mathrm{NH}$, whereas the a posteriori $\mathrm{CO}$ concentration at the surface does not change so obviously. Conversely, in the free troposphere, the a posteriori $\mathrm{CO}$ concentration becomes higher by about $5-10 \%$ with the reduced $\mathrm{OH}$, which shows better agreement with the MOZAIC/IAGOS aircraft measurements. Thus, a possible overestimation of the simulated $\mathrm{OH}$ might lead to overestimations in the estimated $\mathrm{CO}$ emissions and underestimations in the analysed $\mathrm{CO}$ concentration in the free troposphere. The large positive adjustment needed for the $\mathrm{CO}$ concentrations in the $\mathrm{NH}$ may therefore be related to deficiencies in the modelling of $\mathrm{OH}$, instead of too low emissions.

Note that $\mathrm{CO}$ is produced by the oxidation of methane and biogenic NMHCs, a process that contributes about half of the background CO (Duncan et al., 2007). This component can also account for part of the missing $\mathrm{CO}$ concentrations. Stein et al. (2014) considered that anthropogenic CO and VOC emissions in their inventory are too low for industrialised countries during winter and spring.

\subsubsection{Other error sources}

The emissions of $\mathrm{O}_{3}$ precursors other than $\mathrm{NO}_{x}$ and $\mathrm{CO}$, such as VOCs, have a pronounced influence on tropospheric chemistry. Further constraints are required to improve the $\mathrm{O}_{3}$ analysis. Optimising isoprene emissions from satellite $\mathrm{CH}_{2} \mathrm{O}$ measurements in the reanalysis framework have the potential to improve the $\mathrm{O}_{3}$ analysis; this will be investigated in a future study.

Incorrect model processes in atmospheric transport and chemistry lead to model forecast errors and degrade the reanalysis performance. Improving the forecast model is important for properly propagating observational information in space and among different species.

Meteorological fields used as inputs to the chemical reanalysis calculation were produced using an AGCM simulation nudged toward the meteorological reanalysis in order to reproduce past meteorological variations while simulating the influence of sub-grid transport processes. Simultaneous assimilation of meteorological and chemical observations us- ing an advanced data assimilation technique with consideration of radiative feedbacks and the covariances between the meteorological and chemical fields is expected to reduce systematic model errors and improve the chemical reanalysis performance.

\subsection{Data assimilation setting}

To improve the data assimilation analysis with the limited ensemble size, covariance localisation was applied to neglect the error correlation among non- or weakly related variables in the background error covariance matrix. The inclusion of correlations between a larger number of variables allows the propagation of observational information among various fields, but it requires a large ensemble size to represent the multivariate relationships properly. For instance, Zoogman et al. (2014) demonstrated the possibility of substantial benefit from joint $\mathrm{O}_{3}-\mathrm{CO}$ data assimilation in analysing nearsurface $\mathrm{O}_{3}$, if the instrument sensitivity for $\mathrm{CO}$ in the boundary layer is larger than that for $\mathrm{O}_{3}$. Such covariances were not considered in our reanalysis calculation.

\subsection{Uncertainty estimation}

Important information regarding the reanalysis product is provided by the error covariance. The analysis ensemble spread, which is estimated as the standard deviation of the simulated concentrations across the ensemble, in combination with the $\chi^{2}$ test can be used as a measure of the uncertainty of the reanalysis product within the EnKF assimilation framework (Miyazaki et al., 2012b). The analysis spread is caused by errors in the model input data, model processes, and errors in the assimilated measurements, and it is reduced if the analysis converges to a true state.

The analysis spread for $\mathrm{O}_{3}$ is about $8-12 \%$ relative to the analysed concentration in the tropical upper troposphere at $200 \mathrm{hPa}$ (lower panels in Fig. 3), which is mostly determined by the assimilation of TES and MLS $\mathrm{O}_{3}$ retrievals. The analysis spread is relatively small in the extratropical lower stratosphere (4-7\%) except at the polar regions, because of the high accuracy of the MLS measurements. At 700 and $400 \mathrm{hPa}$, the $\mathrm{O}_{3}$ analysis spread is generally smaller in the tropics than the extratropics because of the higher sensitivities in the TES $\mathrm{O}_{3}$ retrievals. The simultaneous emission and concentration optimisation is important in producing proper ensemble perturbations, especially in the lower troposphere.

The global analysis spread for $\mathrm{O}_{3}$ at 700 and $400 \mathrm{hPa}$ is small in 2010-2012 (lower panels in Fig. 3). Considering the smaller level of agreement with the ozonesonde observations in 2010-2012 than in 2005-2009 (Table 3), the small analysis spread cannot be regarded as an error reduction caused by the analysis converging to a true state. The small analysis spread is likely associated with the lack of effective observations for measuring the analysis uncertainties and with the 
stiff chemical system. The obtained results indicate the requirements for additional observational information and/or stronger covariance inflation to the forecast error covariance for measuring the long-term analysis spread corresponding to actual analysis uncertainty. The too large $\chi^{2}$ for $\mathrm{OMI} \mathrm{NO}_{2}$ and $\mathrm{TES}_{3}$ (Fig. 1) also suggested underestimations in the forecast error covariance in comparison with the actual $\mathrm{OmF}$ in 2010-2012 (cf. Sect. 4.1).

\subsection{Applications and future developments}

The chemical reanalysis data set has great potential to contribute in a number of ways to studies of the atmospheric environment and climate:

1. The concentration and emission data, which are produced consistently from a single analysis system, provide comprehensive information on atmospheric composition variability in order to improve the understanding of the processes controlling the atmospheric environment, including $\mathrm{OH}$, and their roles in changing climate.

2. The reanalysis data provide initial and boundary conditions for climate and chemical simulations. They can also be used as an input to meteorological reanalyses for radiation calculations (Dragani and McNally, 2013).

3. The obtained emission data can be used to study emission variabilities and to evaluate bottom-up emission inventories.

4. The statistical information obtained during the reanalysis calculation can be used to suggest developments of models and observations. The large spread can be regarded as an indicator for the requirement for further constraints, whereas the analysis increment identifies sources of model error.

Several further developments have been identified as necessary to improve the quality and value of the reanalysis data set:

1. Discontinuities in the assimilated measurements lead to changes in the reanalysis quality. The $\mathrm{O}_{3}$ analysis performance was degraded in 2010-2012, corresponding to the decreased number of assimilated measurements. The influence of data discontinuities must be considered or removed when studying interannual variability and trends using products from reanalyses. Including more data sets such as from IASI and GOME-2 measurements could improve the reanalysis quality.

2. Application of a bias correction procedure for multiple measurements could improve the reanalysis quality but should be carefully checked (Inness et al., 2013). Observations taken from aircraft and ozonesonde measurements or independent satellite data sets can be used as anchors in the bias correction. Alternatively, these data could be assimilated to provide additional unbiased constraints, as has been demonstrated by Baier et al. (2013).

3. Additional constraints are required to improve the lower troposphere and boundary layer concentrations and emissions. Recently developed retrievals with high sensitivity to the lower troposphere would be helpful (e.g. Deeter et al., 2013; Cuesta et al., 2013). Moreover, the optimisation of additional precursors emissions could be important for improving the lower tropospheric analysis, including the representation of long-term variability.

4. Extension of the forecast model to the entire stratosphere with detailed stratospheric chemistry is expected to reduce forecast errors in both the stratosphere and the troposphere. We plan to replace the forecast model with one that has an updated chemical scheme and a model top extended to the stratosphere (Watanabe et al., 2011). This would also allow the assimilation of total column measurements, in which the combined assimilation of limb profiles with nadir column measurements could benefit the reanalysis performance, especially in the UTLS (Barré et al., 2013; Inness et al., 2013; Emili et al., 2014).

\section{Conclusions}

We conducted a chemical reanalysis calculation for the 8 years from 2005 to 2012 based on an assimilation of multiple satellite data sets obtained from OMI, MLS, TES, and MOPITT. The simultaneous optimisation of the chemical concentrations and the precursors emissions provides a comprehensive data set that can be used for various applications in air-quality and climate research. By analysing simultaneously concentrations and emissions, the improved atmospheric concentrations of chemically related species have the potential to improve the emission inversion, whereas the improved representations of the seasonal, interannual, and geographical variability of the emissions benefit the atmospheric concentration reanalysis through a reduction in model forecast error.

Data assimilation statistics were analysed to evaluate the long-term stability of the chemical reanalysis. The analysis confirmed that the forecast error covariance was specified reasonably well. The OmFs without assimilation varied with year, which suggested an unrealistic lack of interannual variations in the precursor's emissions. The OmFs after assimilation became almost constant and decreased in the reanalysis, implying persistent reduction of model error and improved representation of emission variability. The information on the analysis uncertainty obtained during the assimilation adds value to the chemical reanalysis data set, in which the observed large analysis spreads indicated a requirement for fur- 
ther constraints from additional observations. However, the discontinuity in the assimilated measurements limited the usability of the reanalysis product. The number of available TES measurements decreased significantly after 2010, which produced unrealistically small analysis spreads and degraded the quality of the tropospheric $\mathrm{O}_{3}$ analysis.

The analysed $\mathrm{O}_{3}, \mathrm{CO}$, and $\mathrm{NO}_{2}$ concentrations in the troposphere showed good agreement with independent observations on both regional and global scales, for seasonal and interannual variations from the lower troposphere to the lower stratosphere. The linear ozone slopes observed during the reanalysis period were positive at $\mathrm{NH}$ mid-latitudes in the lower troposphere and negative in the NH UTLS; these interannual variations were captured well in the reanalysis. The model simulation without any assimilation mostly failed to reproduce the observed variations. The simultaneous assimilation of multiple-species data with optimisation of both the concentrations and emission fields was shown to be effective in correcting the profiles for the entire troposphere, including the long-term variations in $\mathrm{O}_{3}, \mathrm{CO}, \mathrm{NO}_{2}$. The global distribution of $\mathrm{OH}$ was modified considerably, decreasing the difference between $\mathrm{NH}$ and $\mathrm{SH}$ because of the simultaneous assimilation throughout the reanalysis period, which played an important role in propagating observational information among various species and in modifying the chemical lifetimes of reactive gases. To conclude, the combined analysis of concentrations and emissions is considered an important development in tropospheric chemistry reanalysis.

To produce better chemical reanalysis data, it will be necessary to have additional constraints, a better forecast model, and bias correction. Although the assimilation of multispecies data influences the representation of the entire chemical system, the influence of persistent model errors remains a concern. For instance, the reanalysis still has large negative biases in $\mathrm{NO}_{2}$ concentrations over the polluted regions, which may be associated with errors in, for instance, the model chemical equilibrium states, planetary boundary layer mixing, and diurnal variations in chemical processes and emissions. Adjusting additional model parameters such as VOC emissions, deposition, and/or chemical reactions rates by adding observational constraints will help to reduce model errors. An extension of the forecast model to the entire stratosphere and incorporating detailed stratospheric chemistry is expected to reduce forecast errors in both the stratosphere and troposphere and allow the assimilation of total column measurements (Inness et al., 2013). Techniques to reduce the influence of discontinuities in the assimilated measurements and to use sparse observations efficiently (van der A et al., 2010) on the quality of the reanalysis are also required.

Acknowledgements. We acknowledge the free use of tropospheric $\mathrm{NO}_{2}$ column data from the SCIAMACHY, GOME-2, and OMI sensors from www.temis.nl. We also acknowledge the use of data products from the NASA aircraft, the MOZAIC/IAGOS programmes, and the AURA and EOS Terra satellite missions.
We would also like to thank the two anonymous reviewers for their valuable comments. This work was supported through JSPS KAKENHI grant numbers 24740327 and 25241006.

Edited by: R. Cohen

\section{References}

Baier, F., Erbertseder, T., Elbern, H., and Schwinger, J.: Impact of different ozone sounding networks on a 4D-Var stratospheric data assimilation system, Q. J. Roy. Meteorol. Soc., 139, 20552067, doi:10.1002/qj.2086, 2013.

Barré, J., Peuch, V.-H., Lahoz, W., Attie, J.-L., Josse, B., Piacentini, A., Eremenko, M., Dufour, G., Nedelec, P., von Clarmann, T., and El Amraoui, L.: Combined data assimilation of ozone tropospheric columns and stratospheric profiles in a highresolution CTM, Q. J. Roy. Meteorol. Soc., 140, 966-981, doi:10.1002/qj.2176, 2013.

Barth, M. C., Cantrell, C. A., Brune, W. H., Rutledge, S. A., Crawford, J. H., Huntrieser, H., Carey, L. D., MacGorman, D., Weisman, M., Pickering, K. E., Bruning, E., Anderson, B., Apel, E., Biggerstaff, M., Campos, T., Campuzano-Jost, P., Cohen, R., Crounse, J., Day, D. A., Diskin, G., Flocke, F., Fried, A., Garland, C., Heikes, B., Honomichl, S., Hornbrook, R., Huey, L. G., Jimenez, J. L., Lang, T., Lichtenstern, M., Mikoviny, T., Nault, B., O’Sullivan, D., Pan, L. L., Peischl, J., Pollack, I., Richter, D., Riemer, D., Ryerson, T., Schlager, H., St. Clair, J., Walega, J., Weibring, P., Weinheimer, A., Wennberg, P., Wisthaler, A., Wooldridge, P. J., and Ziegler, C.: The Deep Convective Clouds and Chemistry (DC3) field campaign, B. Am. Meteorol. Soc., online first, doi:10.1175/BAMS-D-13-00290.1, 2015.

Beer, R.: TES on the Aura mission: scientific objectives, measurements, and analysis overview, IEEE T. Geosci. Remote, 44, 1102-1105, 2006.

Bian, H., Colarco, P. R., Chin, M., Chen, G., Rodriguez, J. M., Liang, Q., Blake, D., Chu, D. A., da Silva, A., Darmenov, A. S., Diskin, G., Fuelberg, H. E., Huey, G., Kondo, Y., Nielsen, J. E., Pan, X., and Wisthaler, A.: Source attributions of pollution to the Western Arctic during the NASA ARCTAS field campaign, Atmos. Chem. Phys., 13, 4707-4721, doi:10.5194/acp-13-47072013, 2013.

Boersma, K. F., Eskes, H. J., Dirksen, R. J., van der A, R. J., Veefkind, J. P., Stammes, P., Huijnen, V., Kleipool, Q. L., Sneep, M., Claas, J., Leitão, J., Richter, A., Zhou, Y., and Brunner, D.: An improved tropospheric $\mathrm{NO}_{2}$ column retrieval algorithm for the Ozone Monitoring Instrument, Atmos. Meas. Tech., 4, 19051928, doi:10.5194/amt-4-1905-2011, 2011.

Bovensmann, H., Burrows, J. P., Buchwitz, M., Frerick, J., Noël, S., Rozanov, V. V., Chance, K. V., and Goede, A. P. H.: SCIAMACHY: mission objectives and measurement modes, J. Atmos. Sci., 56, 127-150, 1999.

Bowman, K. P. and Carrie, G. R.: The mean-meridional transport circulation of the troposphere in an idealized GCM, J. Atmos. Sci., 59, 1502-1514, 2002.

Callies, J., Corpaccioli, E., Eisinger, M., Hahne, A., and Lefebvre, A.: GOME-2 - MetOp's second generation sensor for operational ozone monitoring, ESA Bull.-Eur. Space, 102, 28-36, 2000 . 
Castellanos, P. and Boersma, K. F.: Reductions in nitrogen oxides over Europe driven by environmental policy and economic recession, Sci. Rep., 2, 265, doi:10.1038/srep00265, 2012.

Cecil, D. J., Buechler, D. E., and Blakeslee, R. J.: Gridded lightning climatology from TRMM-LIS and OTD: dataset description, Atmos. Res., 135-136, 404-414, 2014.

Coman, A., Foret, G., Beekmann, M., Eremenko, M., Dufour, G., Gaubert, B., Ung, A., Schmechtig, C., Flaud, J.-M., and Bergametti, G.: Assimilation of IASI partial tropospheric columns with an Ensemble Kalman Filter over Europe, Atmos. Chem. Phys., 12, 2513-2532, doi:10.5194/acp-12-2513-2012, 2012.

Crumeyrolle, S., Chen, G., Ziemba, L., Beyersdorf, A., Thornhill, L., Winstead, E., Moore, R. H., Shook, M. A., Hudgins, C., and Anderson, B. E.: Factors that influence surface $\mathrm{PM}_{2.5}$ values inferred from satellite observations: perspective gained for the US Baltimore-Washington metropolitan area during DISCOVERAQ, Atmos. Chem. Phys., 14, 2139-2153, doi:10.5194/acp-142139-2014, 2014.

Cuesta, J., Eremenko, M., Liu, X., Dufour, G., Cai, Z., Höpfner, M., von Clarmann, T., Sellitto, P., Foret, G., Gaubert, B., Beekmann, M., Orphal, J., Chance, K., Spurr, R., and Flaud, J.-M.: Satellite observation of lowermost tropospheric ozone by multispectral synergism of IASI thermal infrared and GOME-2 ultraviolet measurements over Europe, Atmos. Chem. Phys., 13, 9675-9693, doi:10.5194/acp-13-9675-2013, 2013.

Deeter, M. N., Martinez-Alonso, S., Edwards, D. P., Emmons, L. K., Gille, J. C., Worden, H. M., Pittman, J. V., Daube, B. C., and Wofsy, S. C.: Validation of MOPITT Version 5 thermal-infrared, near-infrared, and multispectral carbon monoxide profile retrievals for 2000-2011, J. Geophys. Res.-Atmos., 118, 67106725, doi:10.1002/jgrd.50272, 2013.

Dragani, R. and McNally, A. P.: Operational assimilation of ozonesensitive infrared radiances at ECMWF, Q. J. Roy. Meteorol. Soc., 139, 2068-2080, doi:10.1002/qj.2106, 2013.

Duncan, B. N., Logan, J. A., Bey, I., Megretskaia, I. A., Yantosca, R. M., Novelli, P. C., Jones, N. B., and Rinsland, C. P.: The global budget of CO, 1988-1997: source estimates and validation with a global model, J. Geophys. Res., 112, D22301, doi:10.1029/2007JD008459, 2007.

Emili, E., Barret, B., Massart, S., Le Flochmoen, E., Piacentini, A., El Amraoui, L., Pannekoucke, O., and Cariolle, D.: Combined assimilation of IASI and MLS observations to constrain tropospheric and stratospheric ozone in a global chemical transport model, Atmos. Chem. Phys., 14, 177-198, doi:10.5194/acp-14177-2014, 2014.

Eskes, H. J. and Boersma, K. F.: Averaging kernels for DOAS totalcolumn satellite retrievals, Atmos. Chem. Phys., 3, 1285-1291, doi:10.5194/acp-3-1285-2003, 2003.

Flemming, J., Inness, A., Jones, L., Eskes, H. J., Huijnen, V., Schultz, M. G., Stein, O., Cariolle, D., Kinnison, D., and Brasseur, G.: Forecasts and assimilation experiments of the Antarctic ozone hole 2008, Atmos. Chem. Phys., 11, 1961-1977, doi:10.5194/acp-11-1961-2011, 2011

Fortems-Cheiney, A., Chevallier, F., Pison, I., Bousquet, P., Szopa, S., Deeter, M. N., and Clerbaux, C.: Ten years of $\mathrm{CO}$ emissions as seen from Measurements of Pollution in the Troposphere (MOPITT), J. Geophys. Res., 116, D05304, doi:10.1029/2010JD014416, 2011.
Graedel, T. E., Bates, T. S., Bouwman, A. F., Cunnold, D., Dignon, J., Fung, I., Jacob, D. J., Lamb, B. K., Logan, J. A., Marland, G., Middleton, P., Pacyna, J. M., Placet, M., and Veldt, C.: A compilation of inventories of emissions to the atmosphere, Global Biogeochem. Cy., 7, 1-26, 1993.

Gu, D., Wang, Y., Smeltzer, C., and Liu, Z.: Reduction in $\mathrm{NO}_{x}$ emission trends over China: regional and seasonal variations, Environ. Sci. Technol., 47, 12912-12919, doi:10.1021/es401727e, 2013.

Hains, J. C., Boersma, K. F., Kroon, M., Dirksen, R. J., Cohen, R. C., Perring, A. E., Bucsela, E., Volten, H., Swart, D. P. J., Richter, A., Wittrock, F., Schoenhardt, A., Wagner, T., Ibrahim, O. W., van Roozendael, M., Pinardi, G., Gleason, J. F., Veefkind, J. P., and Levelt, P.: Testing and improving OMI DOMINO tropospheric $\mathrm{NO}_{2}$ using observations from the DANDELIONS and NTEX-B validation campaigns, J. Geophys. Res.-Atmos., 115, D05301, doi:10.1029/2009JD012399, 2010.

Heald, C. L., Jacob, D. J., Jones, D. B. A., Palmer, P. I., Logan, J. A., and Streets, D. G.: Comparative inverse analysis of satellite (MOPITT) and aircraft (TRACE-P) observations to estimate Asian sources of carbon monoxide, J. Geophys. Res., 109, D23306, doi:10.1029/2004JD005185, 2004.

Heard, D. E. and Pilling, M. J.: Measurement of $\mathrm{OH}$ and $\mathrm{HO}_{2}$ in the troposphere, Chem. Rev., 103, 5163-5198, 2003.

Herman, R. L. and Kulawik, S. S. (Eds.): Tropospheric Emission Spectrometer TES Level 2 (L2) Data User's Guide, D-38042, version 5.0, Jet Propulsion Laboratory, California Institute of Technology, Pasadena, CA, available at: http://tes.jpl.nasa.gov/ documents (last access: 10 January 2015), 2013.

Herman, R. L. and Osterman, G. B. (Eds.): Tropospheric Emission Spectrometer Data Validation Report (Version F06_08, F06_09 data), D-33192, Version 5.0, Jet Propulsion Laboratory, California Institute of Technology, Pasadena, CA, available at: https: //eosweb.larc.nasa.gov/project/tes/validation (last access: 10 January 2015), 2012.

Hooghiemstra, P. B., Krol, M. C., Meirink, J. F., Bergamaschi, P., van der Werf, G. R., Novelli, P. C., Aben, I., and Röckmann, T.: Optimizing global $\mathrm{CO}$ emission estimates using a four-dimensional variational data assimilation system and surface network observations, Atmos. Chem. Phys., 11, 4705-4723, doi:10.5194/acp-11-4705-2011, 2011.

HTAP: Part A: Ozone and Particulate Matter, edited by: Dentener, F., Keating, T., and Akimoto, H., prepared by the Task Force on Hemispheric Transport of Air Pollution acting within the framework of the Convention on Long-range Transboundary Air Pollution, United Nations, New York and Geneva, 2010.

Hunt, B. R., Kostelich, E. J., and Szunyogh, I.: Efficient data assimilation for spatiotemporal chaos: a local ensemble transform Kalman filter, Physica D, 230, 112-126, 2007.

Inness, A., Baier, F., Benedetti, A., Bouarar, I., Chabrillat, S., Clark, H., Clerbaux, C., Coheur, P., Engelen, R. J., Errera, Q., Flemming, J., George, M., Granier, C., Hadji-Lazaro, J., Huijnen, V., Hurtmans, D., Jones, L., Kaiser, J. W., Kapsomenakis, J., Lefever, K., Leitão, J., Razinger, M., Richter, A., Schultz, M. G., Simmons, A. J., Suttie, M., Stein, O., Thépaut, J.-N., Thouret, V., Vrekoussis, M., Zerefos, C., and the MACC team: The MACC reanalysis: an $8 \mathrm{yr}$ data set of atmospheric composition, Atmos. Chem. Phys., 13, 4073-4109, doi:10.5194/acp-13-4073-2013, 2013. 
IPCC: Climate Change 2013: the Physical Science Basis, contribution of Working Group I to the Fifth Assessment Report of the Intergovernmental Panel on Climate Change, edited by: Stocker, T. F., Qin, D., Plattner, G.-K., Tignor, M., Allen, S. K., Boschung, J., Nauels, A., Xia, Y., Bex, V., and Midgley, P. M., Cambridge University Press, Cambridge, UK and New York, NY, USA, 1535 p., doi:10.1017/CBO9781107415324, 2013.

Jackson, D. R.: Assimilation of EOS MLS ozone observations in the Met Office data-assimilation system, Q. J. Roy. Meteorol. Soc., 133, 1771-1788, doi:10.1002/qj.140, 2007.

Jacob, D. J., Crawford, J. H., Maring, H., Clarke, A. D., Dibb, J. E., Emmons, L. K., Ferrare, R. A., Hostetler, C. A., Russell, P. B., Singh, H. B., Thompson, A. M., Shaw, G. E., McCauley, E., Pederson, J. R., and Fisher, J. A.: The Arctic Research of the Composition of the Troposphere from Aircraft and Satellites (ARCTAS) mission: design, execution, and first results, Atmos. Chem. Phys., 10, 5191-5212, doi:10.5194/acp-10-5191-2010, 2010.

Jaeglé, L., Steinberger, L., Martin, R. V., and Chance, K.: Global partitioning of $\mathrm{NO}_{x}$ sources using satellite observations: relative roles of fossil fuel combustion, biomass burning and soil emissions, Faraday Discuss., 130, 407-423, 2005.

Jourdain, L., Worden, H. M., Bowman, K., Li, Q. B., Eldering, A., Kulawik, S. S., Osterman, G., Boersma, K. F., Fisher, B., Rinsland, C. P., Beer, R., and Gunson, M.: Tropospheric vertical distribution of tropical Atlantic ozone observed by TES during the northern African biomass burning season, Geophys. Res. Lett., 34, L04810, doi:10.1029/2006GL028284, 2007.

Kalnay, E.: Atmospheric Modeling, Data Assimilation and Predictability, Cambridge University Press, 341 p., 2003.

Kanamitsu, M., Ebisuzaki, W., Woollen, J., Yang, S. K., Hnilo, J. J., Fiorino, M., and Potter, G. L.: NCEP-DOE AMIP-II reanalysis (R-2), B. Am. Meteorol. Soc., 83, 1631-1643, doi:10.1175/BAMS-83-11-1631, 2002.

Kiesewetter, G., Sinnhuber, B. M., Vountas, M., Weber, M., and Burrows, J. P.: A long-term stratospheric ozone data set from assimilation of satellite observations: highlatitude ozone anomalies, J. Geophys. Res., 115, D10307, doi:10.1029/2009JD013362, 2010.

Klonecki, A., Pommier, M., Clerbaux, C., Ancellet, G., Cammas, J.-P., Coheur, P.-F., Cozic, A., Diskin, G. S., Hadji-Lazaro, J., Hauglustaine, D. A., Hurtmans, D., Khattatov, B., Lamarque, J.F., Law, K. S., Nedelec, P., Paris, J.-D., Podolske, J. R., Prunet, P., Schlager, H., Szopa, S., and Turquety, S.: Assimilation of IASI satellite CO fields into a global chemistry transport model for validation against aircraft measurements, Atmos. Chem. Phys., 12, 4493-4512, doi:10.5194/acp-12-4493-2012, 2012.

Kopacz, M., Jacob, D. J., Fisher, J. A., Logan, J. A., Zhang, L., Megretskaia, I. A., Yantosca, R. M., Singh, K., Henze, D. K., Burrows, J. P., Buchwitz, M., Khlystova, I., McMillan, W. W., Gille, J. C., Edwards, D. P., Eldering, A., Thouret, V., and Nedelec, P.: Global estimates of $\mathrm{CO}$ sources with high resolution by adjoint inversion of multiple satellite datasets (MOPITT, AIRS, SCIAMACHY, TES), Atmos. Chem. Phys., 10, 855-876, doi:10.5194/acp-10-855-2010, 2010.

Lahoz, W. A. and Schneider, P.: Data assimilation: making sense of Earth Observation, Front. Environ. Sci., 2, 16, doi:10.3389/fenvs.2014.00016, 2014.

Lamsal, L. N., Martin, R. V., van Donkelaar, A., Celarier, E. a., Bucsela, E. J., Boersma, K. F., Dirksen, C. L., and Wang, Y.: Indirect validation of tropospheric nitrogen dioxide retrieved from the OMI satellite instrument: insight into the seasonal variation of nitrogen oxides at northern midlatitudes, J. Geophys. Res., 115, $1-15,2010$.

Levelt, P. F., Hilsenrath, E., Leppelmeier, G. W., van den Oord, G. H. J., Bhartia, P. K., Tamminen, J., de Haan, J. F., and Veefkind, J. P.: Science objectives of the Ozone Monitoring Instrument, Geosci. Remote Sens., 44, 1199-1208, 2006.

Levy, H.: Normal atmosphere: large radical and formaldehyde concentrations predicted, Science, 173, 141-143, 1971.

Liang, Q., Rodriguez, J. M., Douglass, A. R., Crawford, J. H., Olson, J. R., Apel, E., Bian, H., Blake, D. R., Brune, W., Chin, M., Colarco, P. R., da Silva, A., Diskin, G. S., Duncan, B. N., Huey, L. G., Knapp, D. J., Montzka, D. D., Nielsen, J. E., Pawson, S., Riemer, D. D., Weinheimer, A. J., and Wisthaler, A.: Reactive nitrogen, ozone and ozone production in the Arctic troposphere and the impact of stratosphere-troposphere exchange, Atmos. Chem. Phys., 11, 13181-13199, doi:10.5194/acp-11-13181-2011, 2011.

Livesey, N. J., Read, W. G., Froidevaux, L., Lambert, A., Manney, G. L., Pumphrey, H. C., Santee, M. L., Schwartz, M. J., Wang, S., Cofield, R. E., Cuddy, D. T., Fuller, R. A., Jarnot, R. F., Jiang, J. H., Knosp, B. W., Stek, P. C., Wagner, P. A., and Wu, D. L.: Aura Microwave Limb Sounder (MLS), Version 3.3 Level 2 data quality and description document, Tech. Rep. JPL D-33509, Jet Propul. Lab., Pasadena, CA, 2011.

Logan, J. A., Prather, M. J., Wofsy, S. C., and McElroy, M. B.: Tropospheric chemistry: a global perspective, J. Geophys. Res., 86, 7210-7354, 1981.

Martin, R. V., Sauvage, B., Folkins, I., Sioris, C. E., Boone, C., Bernath, P., and Ziemke, J. R.: Space-based constraints on the production of nitric oxide by lightning, J. Geophys. Res., 112, D09309, doi:10.1029/2006JD007831, 2007.

Ménard, R. and Chang, L.-P.: Assimilation of stratospheric chemical tracer observations using a Kalman filter, Part 2: 2-validated results and analysis of variance and correlation dynamics, Mon. Weather Rev., 128, 2672-2686, 2000.

Migliorini, S.: On the Equivalence between Radiance and Retrieval Assimilation. Mon. Weather Rev., 140, 258-265, doi:10.1175/MWR-D-10-05047.1, 2012.

Mijling, B., van der A, R. J., and Zhang, Q.: Regional nitrogen oxides emission trends in East Asia observed from space, Atmos. Chem. Phys., 13, 12003-12012, doi:10.5194/acp-1312003-2013, 2013.

Miyazaki, K. and Eskes, $\mathrm{H}$.: Constraints on surface $\mathrm{NO}_{x}$ emissions by assimilating satellite observations of multiple species, Geophys. Res. Lett., 40, 4745-4750, doi:10.1002/grl.50894, 2013.

Miyazaki, K., Patra, P. K., Takigawa, M., Iwasaki, T., and Nakazawa, T.: Global-scale transport of carbon dioxide in the troposphere, J. Geophys. Res., 113, D15301, doi:10.1029/2007JD009557, 2008.

Miyazaki, K., Eskes, H. J., and Sudo, K.: Global $\mathrm{NO}_{x}$ emission estimates derived from an assimilation of OMI tropospheric $\mathrm{NO}_{2}$ columns, Atmos. Chem. Phys., 12, 2263-2288, doi:10.5194/acp12-2263-2012, 2012a.

Miyazaki, K., Eskes, H. J., Sudo, K., Takigawa, M., van Weele, M., and Boersma, K. F.: Simultaneous assimilation of satellite $\mathrm{NO}_{2}$, $\mathrm{O}_{3}, \mathrm{CO}$, and $\mathrm{HNO}_{3}$ data for the analysis of tropospheric chemical composition and emissions, Atmos. Chem. Phys., 12, 95459579, doi:10.5194/acp-12-9545-2012, 2012b. 
Miyazaki, K., Eskes, H. J., Sudo, K., and Zhang, C.: Global lightning $\mathrm{NO}_{x}$ production estimated by an assimilation of multiple satellite data sets, Atmos. Chem. Phys., 14, 3277-3305, doi:10.5194/acp-14-3277-2014, 2014

Naik, V., Voulgarakis, A., Fiore, A. M., Horowitz, L. W., Lamarque, J.-F., Lin, M., Prather, M. J., Young, P. J., Bergmann, D., Cameron-Smith, P. J., Cionni, I., Collins, W. J., Dalsøren, S. B., Doherty, R., Eyring, V., Faluvegi, G., Folberth, G. A., Josse, B., Lee, Y. H., MacKenzie, I. A., Nagashima, T., van Noije, T. P. C., Plummer, D. A., Righi, M., Rumbold, S. T., Skeie, R., Shindell, D. T., Stevenson, D. S., Strode, S., Sudo, K., Szopa, S., and Zeng, G.: Preindustrial to present-day changes in tropospheric hydroxyl radical and methane lifetime from the Atmospheric Chemistry and Climate Model Intercomparison Project (ACCMIP), Atmos. Chem. Phys., 13, 5277-5298, doi:10.5194/acp-13-5277-2013, 2013.

Parrington, M., Jones, D. B. A., Bowman, K. W., Thompson, A. M., Tarasick, D. W., Merrill, J., Oltmans, S. J., Leblanc, T., Witte, J. C., and Millet, D. B.: Impact of the assimilation of ozone from the Tropospheric Emission Spectrometer on surface ozone across North America, Geophys. Res. Lett., 36, L04802, doi:10.1029/2008GL036935, 2009.

Patra, P. K., Krol, M. C., Montzka, S. A., Arnold, T., Atlas, E. L., Lintner, B. R., Stephens, B. B., Xiang, B., Elkins, J. W., Fraser, P. J., Ghosh, A., Hintsa, E. J., Hurst, D. F., Ishijima, K., Krummel, P. B., Miller, B. R., Miyazaki, K., Moore, F. L., Mhle, J., O'Doherty, S., Prinn, R. G., Steele, L. P., Takigawa, M., Wang, H. J., Weiss, R. F., Wofsy, S. C., and Young, D.: Observational evidence for interhemispheric hydroxyl parity, Nature, 513, 219-223, 2014.

Petzold, A., Volz-Thomas, A., Thouret, V., Cammas, J.-P., and Brenninkmeijer, C. A. M.: IAGOS - In-Service Aircraft for a Global Observing System, in: 3rd International Conferene on Transport, Atmosphere and Climate, Prien am Chiemsee, Germany, 25-28 June 2012, 69-76, 2013.

Price, C. and Rind, D.: A simple lightning parameterization for calculating global lightning distributions, J. Geophys. Res., 97, 9919-9933, doi:10.1029/92JD00719, 1992.

Reuter, M., Buchwitz, M., Hilboll, A., Richter, A., Schneising, O., Hilker, M., Heymann, J., Bovensmann, H., and Burrows, J. P.: Decreasing emissions of $\mathrm{NO}_{x}$ relative to $\mathrm{CO}_{2}$ in East Asia inferred from satellite observations, Nat. Geosci., 7, 792-795, doi:10.1038/ngeo2257, 2014

Schumann, U. and Huntrieser, H.: The global lightning-induced nitrogen oxides source, Atmos. Chem. Phys., 7, 3823-3907, doi:10.5194/acp-7-3823-2007, 2007.

Shindell, D. T., Faluvegi, G., Stevenson, D. S., Krol, M. C., Emmons, L. K., Lamarque, J.-F., Petron, G., Dentener, F. J., Ellingsen, K., Schultz, M. G., Wild, O., Amann, M., Atherton, C. S., Bergmann, D. J., Bey, I., Butler, T., Cofala, J., Collins, W. J., Derwent, R. G., Doherty, R. M., Drevet, J., Eskes, H. J., Fiore, A. M., Gauss, M., Hauglustaine, D. A., Horowitz, L. W., Isaksen, I. S. A., Lawrence, M. G., Montanaro, V., Mueller, J.-F., Pitari, G., Prather, M. J., Pyle, J. A., Rast, S., Rodriguez, J. M., Sanderson, M. G., Savage, N. H., Strahan, S. E., Sudo, K., Szopa, S., Unger, N., van Noije, T. P. C., and Zeng, G.: Multimodel simulations of carbon monoxide: comparison with observations and projected near-future changes, J. Geophys. Res., 111, D19306, doi:10.1029/2006JD007100, 2006.
Singh, H. B., Brune, W. H., Crawford, J. H., Flocke, F., and Jacob, D. J.: Chemistry and transport of pollution over the Gulf of Mexico and the Pacific: spring 2006 INTEX-B campaign overview and first results, Atmos. Chem. Phys., 9, 2301-2318, doi:10.5194/acp-9-2301-2009, 2009.

Smit, H. G. J., Straeter, W., Johnson, B. J., Oltmans, S. J., Davies, J., Tarasick, D. W., Hoegger, B., Stubi, R., Schmidlin, F. J., Northam, T., Thompson, A. M., Witte, J. C., Boyd, I., and Posny, F.: Assessment of the performance of ECC ozonesondes under quasi flight conditions in the environmental simulation chamber: insights from the Juelich Ozone Sonde Intercomparison Experiment (JOSIE), J. Geophys. Res., 112, D19306, doi:10.1029/2006JD007308, 2007.

Stajner, I. and Wargan, K.: Antarctic stratospheric ozone from the assimilation of occultation data, Geophys. Res. Lett., 31, L18108, doi:10.1029/2004GL020846, 2004.

Stajner, I., Wargan, K., Pawson, S., Hayashi, H., Chang, L. P., Hudman, R. C., Froidevaux, L., Livesey, N., Levelt, P. F., Thompson, A. M., Tarasick, D. W., Stübi, R., Andersen, S. B., Yela, M., König-Langlo, G., Schmidlin, F. J., and Witte, J. C.: Assimilated ozone from EOS-Aura: evaluation of the tropopause region and tropospheric columns, J. Geophys. Res., 113, D16S32, doi:10.1029/2007JD008863, 2008.

Stein, O., Schultz, M. G., Bouarar, I., Clark, H., Huijnen, V., Gaudel, A., George, M., and Clerbaux, C.: On the wintertime low bias of Northern Hemisphere carbon monoxide found in global model simulations, Atmos. Chem. Phys., 14, 9295-9316, doi:10.5194/acp-14-9295-2014, 2014.

Stone, D., Whalley, L. K., and Heard, D. E.: Tropospheric $\mathrm{OH}$ and $\mathrm{HO}_{2}$ radicals: field measurements and model comparisons, Chem. Soc. Rev., 41, 6348-6404, 2012.

Streets, D. G., Bond, T. C., Carmichael, G. R., Fernandes, S. D., Fu, Q., He, D., Klimont, Z., Nelson, S. M., Tsai, N. Y., Wang, M. Q., Woo, J. H., and Yarber, K. F.: An inventory of gaseous and primary aerosol emissions in Asia in the year 2000, J. Geophys. Res., 108, 8809, doi:10.1029/2002JD003093, 2003.

Streets, D. G., Canty, T., Carmichael, G. R., de Foy, B., Dickerson, R. R., Duncan, B. N., Edwards, D. P., Haynes, J. A., Henze, D. K., Houyoux, M. R., Jacob, D. J., Krotkov, N. A., Lamsal, L. N., Liu, Y., Lu, Z., Martin, R. V., Pfister, G., Pinder, R. W., Salawitch, R. J., and Wecht, K. J.: Emissions estimation from satellite retrievals: a review of current capability, Atmos. Environ., 77, 1011-1042, doi:10.1016/j.atmosenv.2013.05.051, 2013.

Sudo, K. and Akimoto, H.: Global source attribution of tropospheric ozone: long-range transport from various source regions, J. Geophys. Res., 112, D12302, doi:10.1029/2006JD007992, 2007.

Sudo, K., Takahashi, M., and Akimoto, H.: CHASER: a global chemical model of the troposphere, 2. Model results and evaluation, J. Geophys. Res., 107, 4586, doi:10.1029/2001JD001114, 2002.

Thompson, A. M.: The oxidizing capacity of the Earth's atmossphere: probable past and future changes, Science, 256, 11571165, 1992.

Thompson, A. M., Balashov, N. V., Witte, J. C., Coetzee, J. G. R., Thouret, V., and Posny, F.: Tropospheric ozone increases over the southern Africa region: bellwether for rapid growth in South- 
ern Hemisphere pollution?, Atmos. Chem. Phys., 14, 9855-9869, doi:10.5194/acp-14-9855-2014, 2014.

van der A, R. J., Allaart, M. A. F., and Eskes, H. J.: Multi sensor reanalysis of total ozone, Atmos. Chem. Phys., 10, 11277-11294, doi:10.5194/acp-10-11277-2010, 2010.

van der Werf, G. R., Randerson, J. T., Giglio, L., Collatz, G. J., Mu, M., Kasibhatla, P. S., Morton, D. C., DeFries, R. S., Jin, Y., and van Leeuwen, T. T.: Global fire emissions and the contribution of deforestation, savanna, forest, agricultural, and peat fires (19972009), Atmos. Chem. Phys., 10, 11707-11735, doi:10.5194/acp10-11707-2010, 2010.

Verstraeten, W. W., Boersma, K. F., Zörner, J., Allaart, M. A. F., Bowman, K. W., and Worden, J. R.: Validation of six years of TES tropospheric ozone retrievals with ozonesonde measurements: implications for spatial patterns and temporal stability in the bias, Atmos. Meas. Tech., 6, 1413-1423, doi:10.5194/amt-61413-2013, 2013.

Wang, Y., McElroy, M. B., Martin, R. V., Streets, D. G., Zhang, Q., and $\mathrm{Fu}, \mathrm{T} . \mathrm{M}$.: Seasonal variability of $\mathrm{NO}_{x}$ emissions over east China constrained by satellite observations: Implications for combustion and microbial sources, J. Geophys. Res., 112, 1-19, doi:10.1029/2006JD007538, 2007.

Wargan, K., Pawson, S., Stajner, I., and Thouret, V.: Spatial structure of assimilated ozone in the upper troposphere and lower stratosphere, J. Geophys. Res., 115, D24316, doi:10.1029/2010JD013941, 2010.

Watanabe, S., Hajima, T., Sudo, K., Nagashima, T., Takemura, T., Okajima, H., Nozawa, T., Kawase, H., Abe, M., Yokohata, T., Ise, T., Sato, H., Kato, E., Takata, K., Emori, S., and Kawamiya, M.: MIROC-ESM 2010: model description and basic results of CMIP5-20c3m experiments, Geosci. Model Dev., 4, 845-872, doi:10.5194/gmd-4-845-2011, 2011.

Wespes, C., Emmons, L., Edwards, D. P., Hannigan, J., Hurtmans, D., Saunois, M., Coheur, P.-F., Clerbaux, C., Coffey, M. T., Batchelor, R. L., Lindenmaier, R., Strong, K., Weinheimer, A. J., Nowak, J. B., Ryerson, T. B., Crounse, J. D., and Wennberg, P. O.: Analysis of ozone and nitric acid in spring and summer Arctic pollution using aircraft, ground-based, satellite observations and MOZART-4 model: source attribution and partitioning, Atmos. Chem. Phys., 12, 237-259, doi:10.5194/acp-12-237-2012, 2012.
Wofsy, S. C., Daube, B. C., Jimenez, R., Kort, E., Pittman, J. V., Park, S., Commane, R., Xiang, B., Santoni, G., Jacob, D., Fisher, J., Pickett-Heaps, C., Wang, H., Wecht, K., Wang, Q.Q., Stephens, B. B., Shertz, S., Watt, A. S., Romashkin, P., Campos, T., Haggerty, J., Cooper, W. A., Rogers, D., Beaton, S., Hendershot, R., Elkins, J. W., Fahey, D. W., Gao, R. S., Moore, F., Montzka, S. A., Schwarz, J. P., Perring, A. E., Hurst, D., Miller, B. R., Sweeney, C., Oltmans, S., Nance, D., Hintsa, E., Dutton, G., Watts, L. A., Spackman, J. R., Rosenlof, K. H., Ray, E. A., Hall, B., Zondlo, M. A., Diao, M., Keeling, R., Bent, J., Atlas, E. L., Lueb, R., and Mahoney, M. J.: HIPPO Merged 10-second Meteorology, Atmospheric Chemistry, Aerosol Data (R_20121129), Carbon Dioxide Information Analysis Center, Oak Ridge National Laboratory, Oak Ridge, TN, USA, Release 20121129, doi:10.3334/CDIAC/hippo_010, 2012.

Worden, H. M., Deeter, M. N., Frankenberg, C., George, M., Nichitiu, F., Worden, J., Aben, I., Bowman, K. W., Clerbaux, C., Coheur, P. F., de Laat, A. T. J., Detweiler, R., Drummond, J. R., Edwards, D. P., Gille, J. C., Hurtmans, D., Luo, M., MartínezAlonso, S., Massie, S., Pfister, G., and Warner, J. X.: Decadal record of satellite carbon monoxide observations, Atmos. Chem. Phys., 13, 837-850, doi:10.5194/acp-13-837-2013, 2013.

Worden, J., Kulawik, S. S., Shephard, M. W., Clough, S. A., Worden, H., Bowman, K., and Goldman, A.: Predicted errors of tropospheric emission spectrometer nadir retrievals from spectral window selection, J. Geophys. Res., 109, D09308, doi:10.1029/2004JD004522, 2004.

Xiao, X., Cohan, D. S., Byun, D. W., and Ngan, F.: Highly nonlinear ozone formation in the Houston region and implications for emission controls, J. Geophys. Res., 115, D23309, doi:10.1029/2010JD014435, 2010.

Zbinden, R. M., Thouret, V., Ricaud, P., Carminati, F., Cammas, J.P., and Nédélec, P.: Climatology of pure tropospheric profiles and column contents of ozone and carbon monoxide using MOZAIC in the mid-northern latitudes $\left(24^{\circ} \mathrm{N}\right.$ to $\left.50^{\circ} \mathrm{N}\right)$ from 1994 to 2009, Atmos. Chem. Phys., 13, 12363-12388, doi:10.5194/acp13-12363-2013, 2013.

Zoogman, P., Jacob, D. J., Chance, K., Worden, H. M., Edwards, D. P., and Zhang, L.: Improved monitoring of surface ozone air quality by joint assimilation of geostationary satellite observations of ozone and CO, Atmos. Environ., 84, 254-261, 2014. 